\title{
Involvement of CytochromeP4504a in Adenosine A1 receptor mediated regulation of vascular tone
}

\author{
Swati S Kunduri \\ West Virginia University
}

Follow this and additional works at: https://researchrepository.wvu.edu/etd

\section{Recommended Citation}

Kunduri, Swati S, "Involvement of CytochromeP4504a in Adenosine A1 receptor mediated regulation of vascular tone" (2013). Graduate Theses, Dissertations, and Problem Reports. 3655.

https://researchrepository.wvu.edu/etd/3655

This Dissertation is protected by copyright and/or related rights. It has been brought to you by the The Research Repository @ WVU with permission from the rights-holder(s). You are free to use this Dissertation in any way that is permitted by the copyright and related rights legislation that applies to your use. For other uses you must obtain permission from the rights-holder(s) directly, unless additional rights are indicated by a Creative Commons license in the record and/ or on the work itself. This Dissertation has been accepted for inclusion in WVU Graduate Theses, Dissertations, and Problem Reports collection by an authorized administrator of The Research Repository @ WVU.

For more information, please contact researchrepository@mail.wvu.edu. 
Involvement of CytochromeP4504a in Adenosine $A_{1}$ receptor mediated regulation of vascular tone

Swati S Kunduri

Dissertation submitted to the School of Pharmacy at West Virginia University in partial fulfillment of the requirements for the degree of

\section{Doctor of Philosophy}

in

Pharmaceutical and Pharmacological Sciences

S. Jamal Mustafa, Ph. D., Chair

Matthew Boegehold, Ph. D.

Robert Brock, Ph. D.

Gregory Dick, Ph. D.

Jason Huber, Ph. D.

Mohammed Nayeem, Ph.D.

Department of Pharmaceutical and Pharmacological Sciences

Morgantown, West Virginia

2013

Keywords: Vascular tone; Adenosine; $A_{1}$ adenosine receptors; Cyp4a;

BK channels; PKC- $\alpha$; ERK

Copyright 2013 Swati S Kunduri 


\section{ABSTRACT \\ Involvement of CypP4504a in Adenosine $A_{1}$ receptor mediated regulation of vascular tone}

\section{Swati S Kunduri}

Cardiovascular diseases are one of the leading causes of morbidity and mortality worldwide. The regulation of vascular tone plays an important role in normal cardiovascular function. Adenosine, an autacoid has several physiological and pathophysiological roles, apart from the regulation of vascular tone. Adenosine receptor (AR) contracts and relaxes blood vessels through all four subtypes $\left(\mathrm{A}_{1}, \mathrm{~A}_{2 \mathrm{~A}}, \mathrm{~A}_{2 \mathrm{~B}}\right.$, and $\left.\mathrm{A}_{3}\right)$ linked to different signaling mechanisms. Deciphering complex tissue responses remains difficult because relationships of individual receptor subtypes and various end-effectors (e.g., ion channels) are yet to be identified. Apart from adenosine, 20-HETE, a cytochrome P4504a (Cyp4a) metabolite of arachidonic acid (AA) is a potent vasoconstrictor.

We hypothesized that $A_{1} A R$ induced contraction of the smooth muscle involves Cyp4a, with Protein Kinase C (PKC)- $\alpha$, extracellular regulated kinase (ERK) 1/2 contributing to the downstream signaling events. Another key question we addressed were the ion channel(s) contributing to smooth muscle contraction. Experiments included isometric tension recordings of aortic contraction and western blots. In addition, patch clamp experiments were done with freshly isolated smooth muscle cells from wild type (WT) and $A_{1}$ knockout $\left(A_{1} K O\right)$ mice aortae. We found that inhibition of Cyp4a led to lesser contraction in the adenosine agonists' mediated responses. 20-HETE induced contraction in both WT and $\mathrm{A}_{1} \mathrm{KO}$, but this response was lower in $\mathrm{A}_{1} \mathrm{KO}$. Inhibition of PKC- $\alpha$ and ERK1/2 attenuated the 20-HETE-induced contraction in both WT and $\mathrm{A}_{1} \mathrm{KO}$. These findings suggest that $\mathrm{A}_{1} \mathrm{AR}$ couples with 20 -HETE and negatively modulates vascular tone through PKC- $\alpha$ and ERK1/2. Furthermore, electrophysiological experiments revealed that non-selective adenosine agonist increased the $\mathrm{BK}$ current in $\mathrm{A}_{1} \mathrm{KO}$ as compared to the WT. This suggests $\mathrm{A}_{1}$ receptors have a negative regulatory effect on $\mathrm{BK}$ current. On the other hand, $\mathrm{A}_{1}$ selective agonist decreased the BK current in WT, with no effect on $\mathrm{A}_{1} \mathrm{KO}$. PKC- $\alpha$ inhibitor abolished the effect of the $\mathrm{A}_{1}$ selective agonist on $\mathrm{BK}$ current. These findings suggest that $\mathrm{A}_{1} \mathrm{AR}$ regulates contraction of the aortic smooth muscle through inhibition of BK channels in a PKC- $\alpha$ dependent manner. From these data, we conclude that $A_{1}$ AR negatively couples with 20-HETE and by inhibiting BK channels mediates smooth muscle contraction via PKC- $\alpha$. 
Dedicated to my mother and father, Sailaja and Iswara Dutt and sister Shruti and

husband, Kamalesh 


\section{Acknowledgement}

First and foremost, I thank GOD for giving me the strength and grace to come 13000 miles away from my family to pursue my studies.

This dissertation would not have been completed had it not been for the many people who contributed to it. I would like to thank my mentor, Dr. S. Jamal Mustafa for giving me an opportunity in his lab and for his continuous guidance, patience and mentorship during these four and half years. I am very grateful to him for encouraging me to stretch beyond my comfort zone and help me discover my abilities more. A special thanks to Dr. Nayeem, co-investigator on the grant for his valuable input and support. I am thankful to my committee members: Drs. Matt Boegehold, Rob Brock, Jason Huber for their guidance during the course of my dissertation. My deepest gratitude to our collaborator and committee member, Dr. Gregory Dick for graciously mentoring me in patch clamp technique. His kindness and ever willingness to help and answer questions has shaped my project a lot. I would also like to thank our collaborator Dr. Samuel Poloyac at University of Pittsburgh and Dr. Stephen Tilley at University of North Carolina.

I have had the opportunity to work with some wonderful people during these years in Dr. Mustafa's lab. Each one of them has taught me something and helped me out at various points. Thank you: Drs. Teng, Nadeem and; especially Dr. Ponnoth, a very dear friend, always willing to help and give her best suggestions; Dr. Sharifi and fellow student Isha, who have been very supportive friends; our lab technicians, past and present, Brandy Wilmoth and Sherry Xie. A special thanks to the new members in our lab in the past one year Dr. Zhou and fellow student Ahmad Hanif for their support and 
encouragement. I am also thankful to Claire Noel, Debbie Beery, Teresa Lewis, Vickie White, Brenda Moran and Brad Rager. I would like to acknowledge the staff and students of Departments of Basic Pharmaceutical Sciences, Physiology and Pharmacology and Center for Cardiovascular and Respiratory Sciences. Thanks to Drew Fancher and Dr. Asano in the Dr. Dick's lab for all their tips during the patch clamp experiments.

I am very grateful to Dr. Nidhi Malhotra who has been there with me right from the time I applied for graduate programs. I also express my gratitude to Kimberly Miede Arnold, Praveena Jayaraman, Dr. Brandi Snyder and senior graduate students: Drs. Sanjeev Kumar, Neelam Azad and Anand Iyer.

Last but certainly not the least, I thank my family: my mother whose has been the driving force and without whom I would have never completed this; my father for being constant source of encouragement and support; my husband for his unconditional support, love, patience and sacrifice during these years of long distance marriage and encouragement during the tough times and helping me realize my strengths and my sister who has been my biggest fan and critic has helped me immensely. I thank my extended family in this country and back in India who have always been my strength and support system. 


\section{Table of Contents}

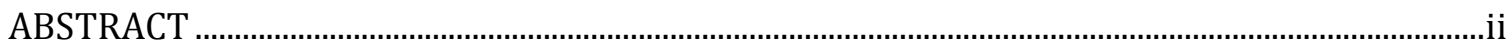

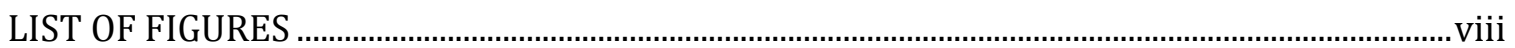

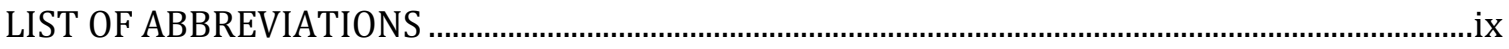

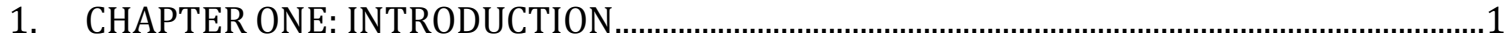

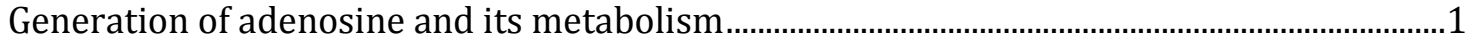

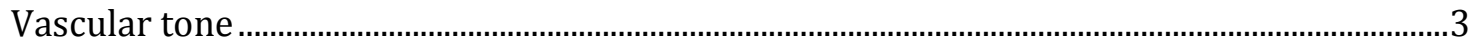

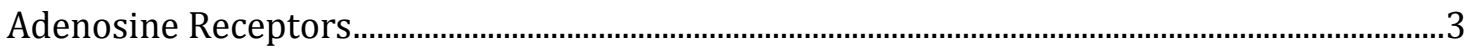

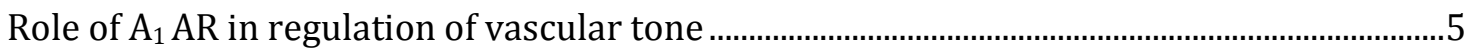

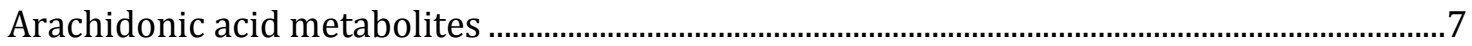

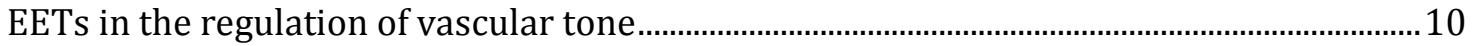

20-HETE in the regulation of vascular tone..................................................................................11

Adenosine and Cyp450 metabolites in the regulation of vascular tone ...................................12

Potassium $\left(\mathrm{K}^{+}\right)$channels in the regulation of vascular tone ....................................................12

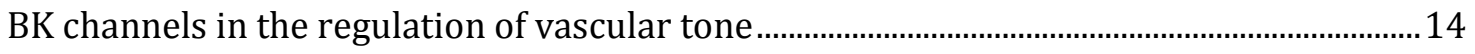

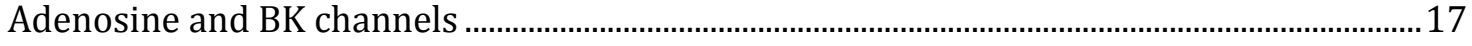

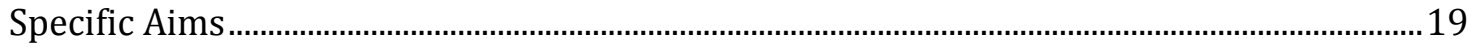

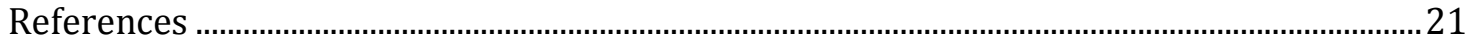

2. CHAPTER TWO: ADENOSINE A1 RECEPTORS LINK TO SMOOTH MUSCLE

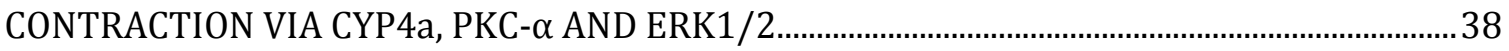

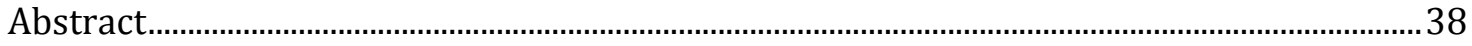

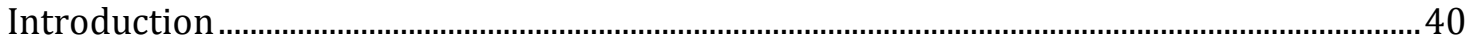

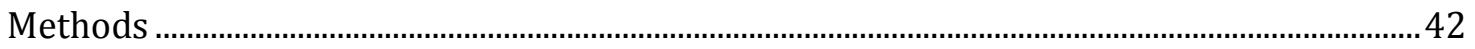

Real Time PCR

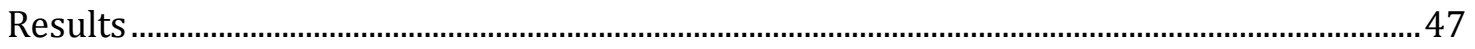

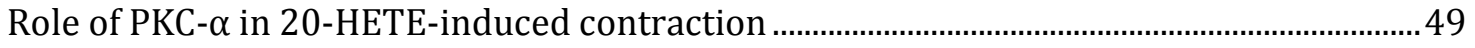

Role of ERK1/2 kinase in 20-HETE-induced contraction .............................................................. 49

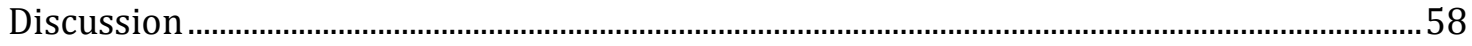

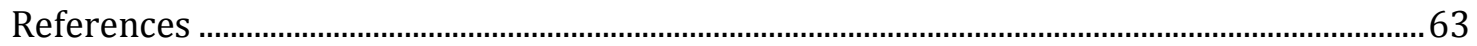

3. CHAPTER THREE: ADENOSINE A 1 RECEPTORS INHIBIT BK CHANNELS THROUGH PKC$\alpha$ DEPENDENT MECHANISM IN MOUSE AORTIC SMOOTH MUSCLE CONTRACTION..............69

Abstract

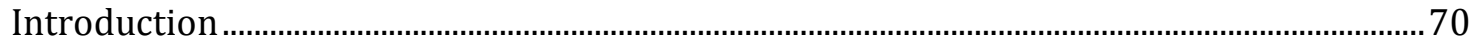




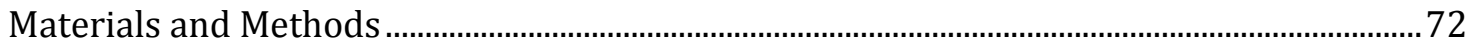

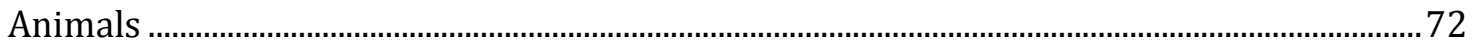

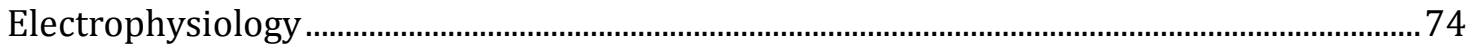

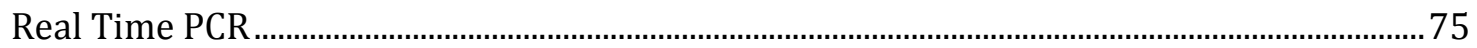

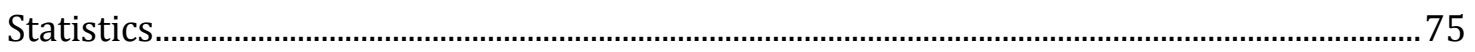

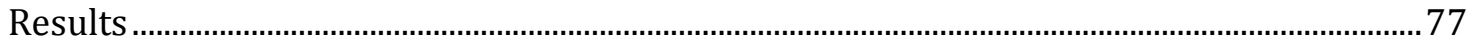

Total BK current and BK subunit expression in WT and $\mathrm{A}_{1} \mathrm{KO}$ mice aortic myocytes .........77

Effect of 20-HETE on BK current in WT and $\mathrm{A}_{1} \mathrm{KO}$ mice aortic myocytes................................77

Effect of NECA on BK current in WT and $\mathrm{A}_{1} \mathrm{KO}$ mice aortic myocytes......................................78

Effect of CCPA on BK current in WT and $\mathrm{A}_{1} \mathrm{KO}$ mice aortic myocytes ...................................... 78

Effect of PKC $\alpha$ inhibition on BK current in WT and $\mathrm{A}_{1} \mathrm{KO}$ mice aortic myocytes..................79

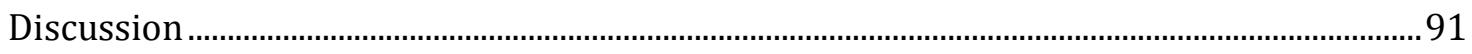

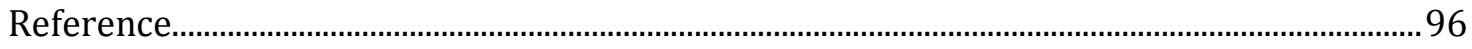

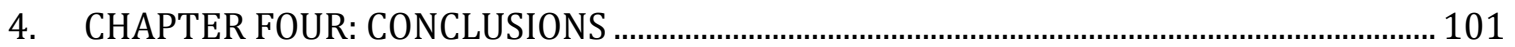

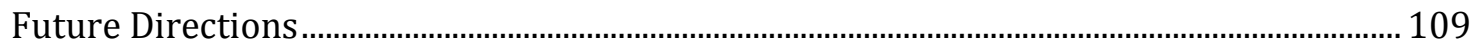

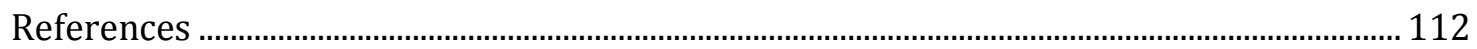

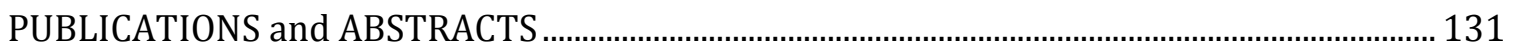

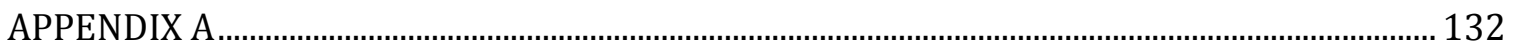

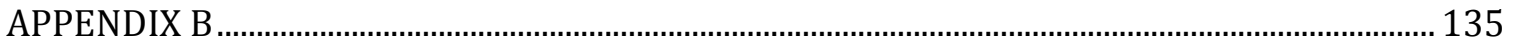

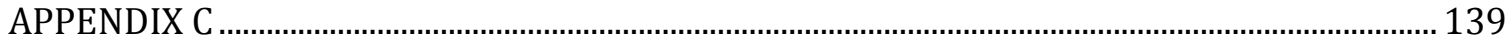

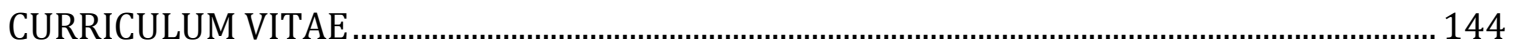




\section{LIST OF FIGURES}

Figure 1.1: Structure of Adenosine 2

Figure 1.2: Metabolism of Adenosine (Vallon et al., 2006)..................................................2

Figure 1.3: Structure of adenosine A1 receptor (Nell and Albrecht-Kupper, 2009).............6

Figure 1.4: The enzymatic pathway of AA producing EETs and HETEs .............................

Figure 1.5: Structure of BK channel (Ledoux et al., 2006) ................................................... 16

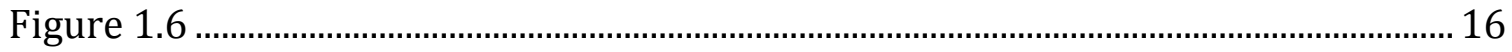

Figure 2.1: Cyp4a protein and mRNA levels in WT and $\mathrm{A}_{1} \mathrm{KO}$.......................................5 50

Figure 2.2: Effect of Adenosine Receptor agonists' and acetylcholine -induced responses in WT and $\mathrm{A}_{1} \mathrm{KO}$ aortae and mesenteric arteries............................................................. 51

Figure 2.3: Effect of the CYP4a product, 20-HETE on smooth muscle contraction from

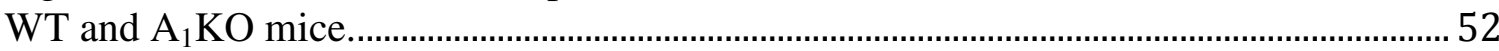

Figure 2.4: 20-HETE formation rate in microsomes from $\mathrm{WT}$ and $\mathrm{A}_{1} \mathrm{KO}$ mice aortae

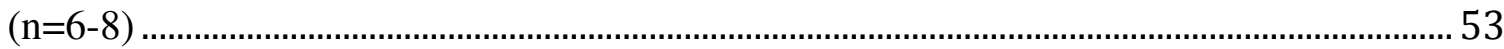

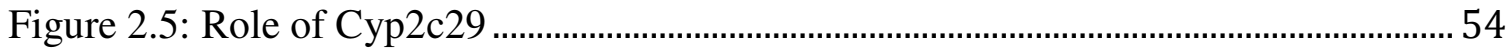

Figure 2.6: Effect of on PKC- $\alpha$ on WT and $\mathrm{A}_{1} \mathrm{KO}$ contractile responses to 20-HETE.... 55

Figure 2.7 Effect of ERK $1 / 2$ on WT and A1KO mice aortae contractile responses (A) ... 56

Figure 2.8 Adenosine $\mathrm{A}_{1}$ receptors link to smooth muscle contraction via CYP4a, PKC- $\alpha$,

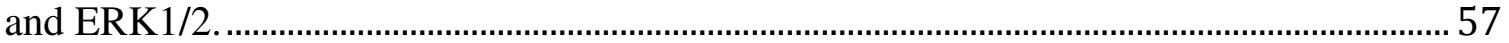

Figure 3.1: Whole-cell $\mathrm{K}^{+}$current and $\mathrm{BK}$ channel subunit expression is similar in smooth muscle from WT and $\mathrm{A}_{1} \mathrm{KO}$ mice. ................................................................... 81

Figure 3.2: Effect of 20-HETE on BK current in WT and $\mathrm{A}_{1} \mathrm{KO}$ aortic myocytes: .......... 82

Figure 3.3: Effect of NECA on BK current in WT and $\mathrm{A}_{1} \mathrm{KO}$ aortic myocytes ................ 83

Figure 3.4: Effect of CCPA on BK current in WT and $\mathrm{A}_{1} \mathrm{KO}$ aortic myocytes.................. 84

Figure 3.5: Effect of PKC $\alpha$ inhibitor, Gö6976 on BK current in WT and $\mathrm{A}_{1} \mathrm{KO}$ aortic

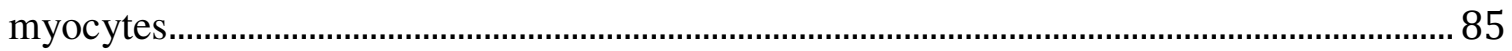

Figure 3.6 Effect of NS1619 on NECA induced relaxation.............................................. 86 Figure 3.7 Effect of Penitrem A (Pen A) on adenosine agonists' induced responses: (A)Effect of Penitrem A on NECA induced vascular response 87 Figure 3.8 Effect of Penitrem A (BK channel inhbitor; Pen A) and NS1619 (BK channel opener;NS) on CCPA induced contraction. ...................................................................... 88

Figure 3.9 Adenosine receptor expression in WT and A1KO mice aortae $(\mathrm{n}=10) \ldots \ldots \ldots \ldots . . . .89$ Figure 3.10: Adenosine $A_{1}$ receptors regulate aortic smooth muscle contraction by inhibiting BK channels via PKC- $\alpha$ dependent mechanism. ................................................... 90 Figure 4.1: Schematic showing the events leading from activation of $A_{1} A R$ coupled to Cyp4a product, 20-HETE and mediating contraction through PKC- $\alpha$ and p-ERK1/2 and BK channels Figure 4.2: Schematic showing the events in the absence of $A_{1} A R$. NECA possibly activates $A_{2 A} R$, leading to activation of Cyp-epoxygenases , which produce EETs and actiavte $\mathrm{K}_{\text {ATP }}$ channels.................................................................................106

Figure 4.3: Effect of Glibenclamide $(\mathrm{Glib} ; 10 \mu \mathrm{M})$ on CCPA induced contraction. .........108 


\section{LIST OF ABBREVIATIONS}

$\mu g$

$\mu \mathrm{l}$

AA

$\mathrm{A}_{1} \mathrm{AR}$

$\mathrm{A}_{2 \mathrm{~B}} \mathrm{AR}$

$\mathrm{A}_{3} \mathrm{AR}$

AC

$\mathrm{ACh}$

ADA

ADO

ADP

AK

AMP

ANOVA

AR

ATP

BK

BSA

$\mathrm{Ca}^{2+}$

cAMP micro gram

micro liter

Arachidonic acid

$\mathrm{A}_{1}$ adenosine receptor $\mathrm{A}_{2 \mathrm{~A}} \mathrm{AR}$

$\mathrm{A}_{2 \mathrm{~A}}$ adenosine receptor

$A_{2 B}$ adenosine receptor

$A_{3}$ adenosine receptor

Adenylyl cyclase

Acetylcholine

Adenosine deaminase

Adenosine

Adenosine diphosphate

Adenosine kinase

Adenosine monophosphate

Analysis of variance

Adenosine receptor

Adenosine triphosphate

Large conductance Potassium channels

Bovine serum albumin

Calcium

Cyclic adenosine monophosphate 
cGMP

CGS 21860

$\operatorname{COX}$

$\mathrm{COOH}$

CRC

Cyp-epoxygenases

DAG

diHETEs

DMSO

DPCPX

EDHF

EETs

EGTA

ERK1/2

Glib

GPCR

GTP

HEPES

HETE
Cyclic guanosine monophosphate

2-p-(2-carboxyethyl)phenethylamino-

5' N- ethylcarboxy amidoadenosine

hydrochloride

Cyclooxygenase

Carboxyl

Concentration response curve

CytochromeP450 epoxygenase

Diacylglycerol

Di hydroxy eicosatrienoic acids

Dimethyl sulfoxide

1,3-Dipropyl-8-cyclopentylxanthine

Endothelium-Derived Hyperpolarizing

Factor

Epoxyeicosatrienoic acids

Ethylene glycol tetraacetic acid

Extracellular signal-regulated kinase 1/2

Glibenclamide

G Protein Coupled Receptor

Guanosine triphosphate

4-(2-hydroxyethyl)-1-

piperazineethanesulfonic acid

Hydroxy eicosa-trienoic acids 
HET0016

$\mathrm{IP}_{3}$

$\mathrm{K}_{\mathrm{ATP}}$

$\mathrm{KCl}$

$\mathrm{kg}$

Kir

KO

$\mathrm{K}_{\mathrm{V}}$

LOX

LT

L-VDCC

MAPK

mg

MLCK

$\mathrm{ml}$

$\mathrm{mm}$

$\mathrm{mM}$

NADPH

Nox-2

NE

NECA
N-hydroxy-N'-(4-n-butyl-2-

methylphenyl)Formamidine

Inositol triphosphate

ATP-dependent $\mathrm{K}^{+}$channels

Potassium Chloride

Kilogram

inward rectifier $\mathrm{K}^{+}$channels

Knock out

voltage-dependent $\mathrm{K}^{+}$channels

Lipoxygenase

Leukotrienes

L-type voltage dependent $\mathrm{Ca}^{2+}$ channel

mitogen-activated protein kinase

milligram

Myosin light chain kinase

milliliter

millimeter

millimole

Nicotinamide adenosine dinucleotide

phosphate

NADPH oxidase-2

Norepinephrine

N-ethylcarboxamide-adenosine 


\begin{tabular}{|c|c|}
\hline $\mathrm{NH}_{2}$ & Amino terminus \\
\hline NO & Nitric oxide \\
\hline PCR & Polymerase chain reaction \\
\hline PE & Phenylephrine \\
\hline PG & Prostaglandin \\
\hline Pin & Pinacidil \\
\hline PKA & Protein kinase $\mathrm{A}$ \\
\hline PKC & Protein kinase $\mathrm{C}$ \\
\hline PLC & Phospholipase C \\
\hline PPAR- $\alpha$ & $\begin{array}{l}\text { Peroxisome proliferator activated } \\
\text { receptor }\end{array}$ \\
\hline RyR & Ryanodine receptors \\
\hline RCK & Regulator for conductance of $\mathrm{K}^{+}$ \\
\hline RIPA & Radio-immuno precipitation assay \\
\hline ROS & reactive oxygen species \\
\hline SAH & S-Adenosyl-L-homocysteine \\
\hline SAH-hydrolase & S-Adenosyl-L-homocysteine-hydrolase \\
\hline SAM & S-Adenosyl-L methionine \\
\hline SCH58261 & $\begin{array}{l}\text { 2-(2-Furanyl)-7-(2-phenylethyl)-7H- } \\
\text { pyrazolo[4,3-e][1,2,4]triazolo[1,5- } \\
\text { c]pyrimidin-5-amine }\end{array}$ \\
\hline SEH & soluble Epoxide Hydrolase \\
\hline SEM & Standard error of the mean \\
\hline
\end{tabular}


$\mathrm{TP}$

TRP

TRPV4

UPLC

VSMC

WT
Thromboxane

Transient receptor potential

Vanilloid type 4 TRP

Ultra performance liquid

chromatography

Vascular smooth muscle cell

Wild type 


\section{CHAPTER ONE: INTRODUCTION}

Adenosine, the breakdown product of the energy molecule adenosine triphosphate (ATP), is a ubiquitous nucleoside. In mammalian cells it plays a key role in a number of physiological and pathophysiological conditions. Figure 1.1 shows the chemical structure of Adenosine. Under physiological conditions, some of its regulatory activities include decreasing the glomerular filtration, neuro-modulation during the sleep-wake cycle, antiinflammatory action, effects on the heart including chronotropy, ionotropy and the regulation of the vascular tone (Fredholm, 2007).

\section{Generation of adenosine and its metabolism}

Adenosine is released when the cells are metabolically stressed either through an equilibrative transporter on the cell or as a result of cell damage (Abbracchio et al., 2003). At intracellular and extracellular sites, adenosine can be formed by enzymatic hydrolysis from two different substrates. The first pathway, 5' nucleotidase hydrolyzes adenosine monophosphate (AMP) to adenosine (Frick and Lowenstein, 1976; Newby et al., 1985). Adenosine can also be synthesized by the action of S-adenosylhomocysteine hydrolase (SAH) on S-adenosylhomocysteine (Schutz et al., 1981). SAH is tightly bound to adenosine and prevents its breakdown by adenosine deaminase (ADA) to inosine and the latter is finally broken down to uric acid and excreted in the urine (Lloyd and Fredholm, 1995). In another pathway, adenosine is re-converted to AMP by adenosine kinase (AK). In addition to being metabolized, adenosine uptake into cells occurs by either a carrier system or a sodium-ribonucleside co-transport system. Once adenosine enters the cell, it binds to its receptors and exerts various physiological effects. 


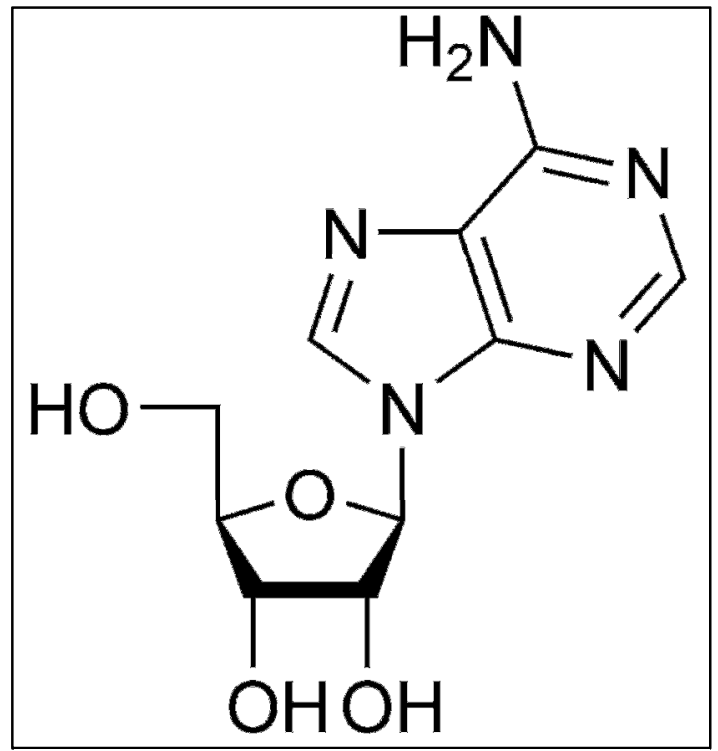

Figure 1.1: Structure of Adenosine

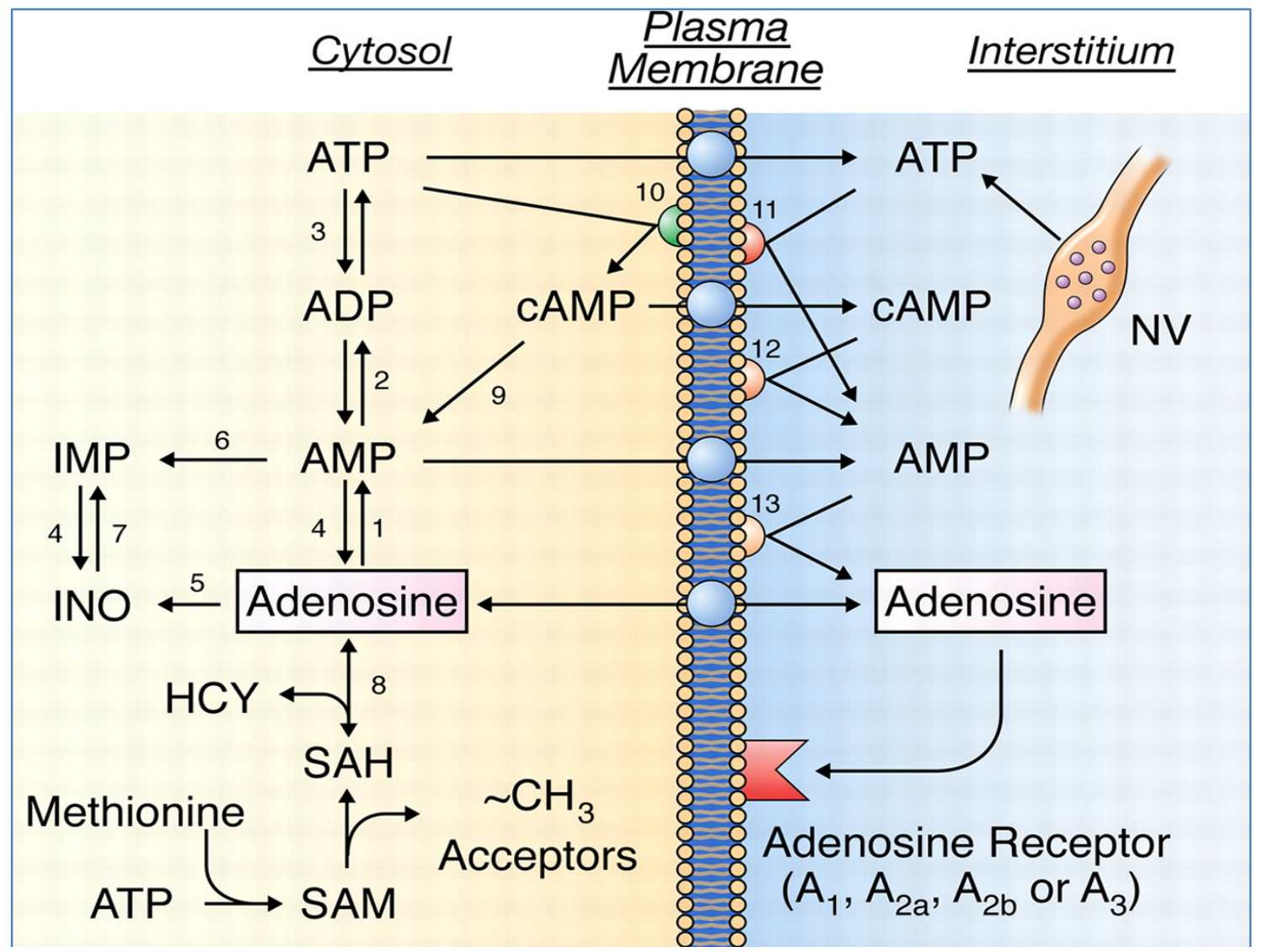

Figure 1.2: Metabolism of Adenosine (Vallon et al., 2006) 


\section{Vascular tone}

The contractile state of the smooth muscle cell is defined as the vascular tone. The smooth muscle of the blood vessel exists in a partial contracted state; this tone increases as the diameter of the vessel decreases. This tone is independent of any hormonal or neural influences as there are sufficient calcium $\left(\mathrm{Ca}^{2+}\right)$ channels on the membrane to maintain the partial contracted state. In addition, the norepinephrine (NE) released from sympathetic fibers further augments the vascular tone (Sherwood Lauralee, Human Physiology Cells to Systems, 7e;(Jackson, 2000).

However, the vascular tone can be regulated by a complex interplay of contracting and relaxing factors, hormones, neurotransmitters, and endothelium -derived hyperpolarizing factors (EDHF). The contraction and relaxation of the smooth muscle is determined by the movement of ions through the ion channels on the plasma membrane.

The role of various contracting and dilating factors and ion channels with focus on adenosine and large conductance potassium (BK) channels in the regulation of vascular tone has been discussed in subsequent sections.

\section{Adenosine Receptors}

Adenosine exerts its physiological effects by binding to one of its four G-protein coupled receptors: $A_{1}, A_{2 A}, A_{2 B}$ and $A_{3}$. These glycoproteins have in common a central core of seven transmembrane spanning domains, and each transmembrane is composed of 20-27 amino acids and with 3 extracellular and intracellular loops (Fredholm, 2007). The intracellular loops, extracellular amino $\left(\mathrm{NH}_{2}\right)$ and the intracellular carboxy $(\mathrm{COOH})$ termini differ in their length, function and sequence variation and are responsible for the specific properties of these receptor proteins. Apart from $\mathrm{A}_{2 \mathrm{~A}} \mathrm{R}$, all other receptors have cysteine residue in the $\mathrm{COOH}$ terminus for receptor palmitoylation. All the ARs are 
glycosylated on their second extracellular loop (Moro et al., 2006). Each of these receptors has their own pharmacological profile, affinity to adenosine, tissue distribution and effector coupling. The receptors derive their name due to their affinity to adenosine, which acts as a full agonist at all the four receptors (Fredholm et al., 2001). Adenosine receptors are classified based on their ability to activate or inhibit adenylyl cyclase (AC) and regulation of the cyclic adenosine monophosphate (cAMP) levels.

$A_{1}$ adenosine receptor $\left(A_{1} A R\right)$ : It inhibits $\mathrm{AC}$ through inhibition of pertussis toxin sensitive $\mathrm{G}_{\mathrm{i}}$ proteins and decreases the cAMP levels and results in an increased activity of phospholipase C (PLC) activity (Rogel et al., 2005; Tawfik et al., 2005). In cardiac muscle and neurons, $\mathrm{A}_{1}$ receptor can activate potassium channels $\left(\mathrm{K}^{+}\right)$and inhibits $\mathrm{Q}-\mathrm{P}$ and N-type $\mathrm{Ca}^{2+}$ channels (Fredholm et al., 2001). $\mathrm{A}_{1}$ couples with $\mathrm{K}^{+}$channels and is responsible for the bradycardiac effect of adenosine on heart function.

$A_{2}$ adenosine receptor $\left(A_{2 A} R\right.$ and $\left.A_{2 B} R\right)$ : It stimulates the AC and increases the cAMP levels through the cholera toxin sensitive $G_{S}$ protein in the peripheral system and in the striatal system $A_{2 A} R$ mediates effects through $G_{\text {olf }}$ It has anti-inflammatory and vasodilatory role through the activation of PLC. The $A_{2 B}$ receptor signals through $G_{s / q}$ and its activation can either result in increased cAMP or inositol,1,4,5- triphosphate $\left(\mathrm{IP}_{3}\right) /$ diacylglycerol (DAG) and $\mathrm{Ca}^{2+}$ levels. Our lab has shown previously that $\mathrm{A}_{2 \mathrm{~B}}$ mediates relaxation in mouse aorta through nitric oxide (NO) in the endothelium (Ansari et al., 2007a)

$A_{3}$ adenosine receptor: $\mathrm{A}_{3}$ receptors are negatively coupled to $\mathrm{AC}$ and decrease cAMP levels. They also stimulate PLC pathway and aid in mobilizing $\mathrm{Ca}^{2+}(\mathrm{Jacobson}$ and Gao, 2006). In cardiac cells, they provide protection through ATP sensitive $\mathrm{K}^{+}\left(\mathrm{K}_{\mathrm{ATP}}\right)$ channel activation (Tracey et al., 1998). $\mathrm{A}_{3}$ mediates vasoconstriction through the endothelial 
dependent cyclooxygenase (COX) pathway and involves nicotinamide adenosine dinucleotide phosphate (NADPH) oxidase (Nox-2) (Ansari et al., 2007b; El-Awady et al., 2011).

The current thesis focuses on the role of $\mathrm{A}_{1} \mathrm{AR}$ in vascular tone regulation.

\section{Role of $A_{1} A R$ in regulation of vascular tone}

$\mathrm{A}_{1} \mathrm{AR}$ is a $36 \mathrm{kDa}$ protein found in highest density in the kidney, atria and in lower density in ventricles, lung, pancreas, liver and gastrointestinal tract (GI). The third intracellular loop and the $\mathrm{COOH}$ terminus of the receptor influence the coupling of $\mathrm{A}_{1} \mathrm{AR}$ to $G_{i}$ (Tucker et al., 2000). Furthermore, the coupling of the $A_{1} A R$ is affected by the composition, prenylation state and phosphorylation state of $G$ protein $\gamma$ subunits (Yasuda et al., 1996; Yasuda et al., 1998). The cytoplasmic domain of the receptor has several serine and threonine residues, which are potential sites for protein kinase A (PKA), protein kinase $\mathrm{C}(\mathrm{PKC})$ and $\beta$-adrenoreceptor kinase-mediated phosphorylation and may play a role in receptor desensitization (Nell and Albrecht-Kupper, 2009). It is well accepted that adenosine mediates contraction of the smooth muscle in several vascular beds. Activation of adenosine $\mathrm{A}_{1}$ receptors induces contraction through a COX dependent pathway in pulmonary artery (Biaggioni et al., 1989). Similar results were seen in guinea pig and feline pulmonary vasculature (Szentmiklosi et al., 1995; Cheng et al., 1996). $\mathrm{A}_{1} \mathrm{AR}$ activation leads to $\mathrm{IP}_{3}$ in rabbit airway smooth muscle and negatively modulates the vascular tone (Abebe and Mustafa, 1998). Adenosine at low concentrations contracts the afferent arterioles through $\mathrm{A}_{1} \mathrm{AR}$ activation. However at higher concentrations, adenosine has been shown to mediate vasodilation of the afferent arterioles through $\mathrm{A}_{2 \mathrm{~A}}$, which is coupled to $\mathrm{K}_{\mathrm{ATP}}$ channel (Tabrizchi and Bedi, 2001). 


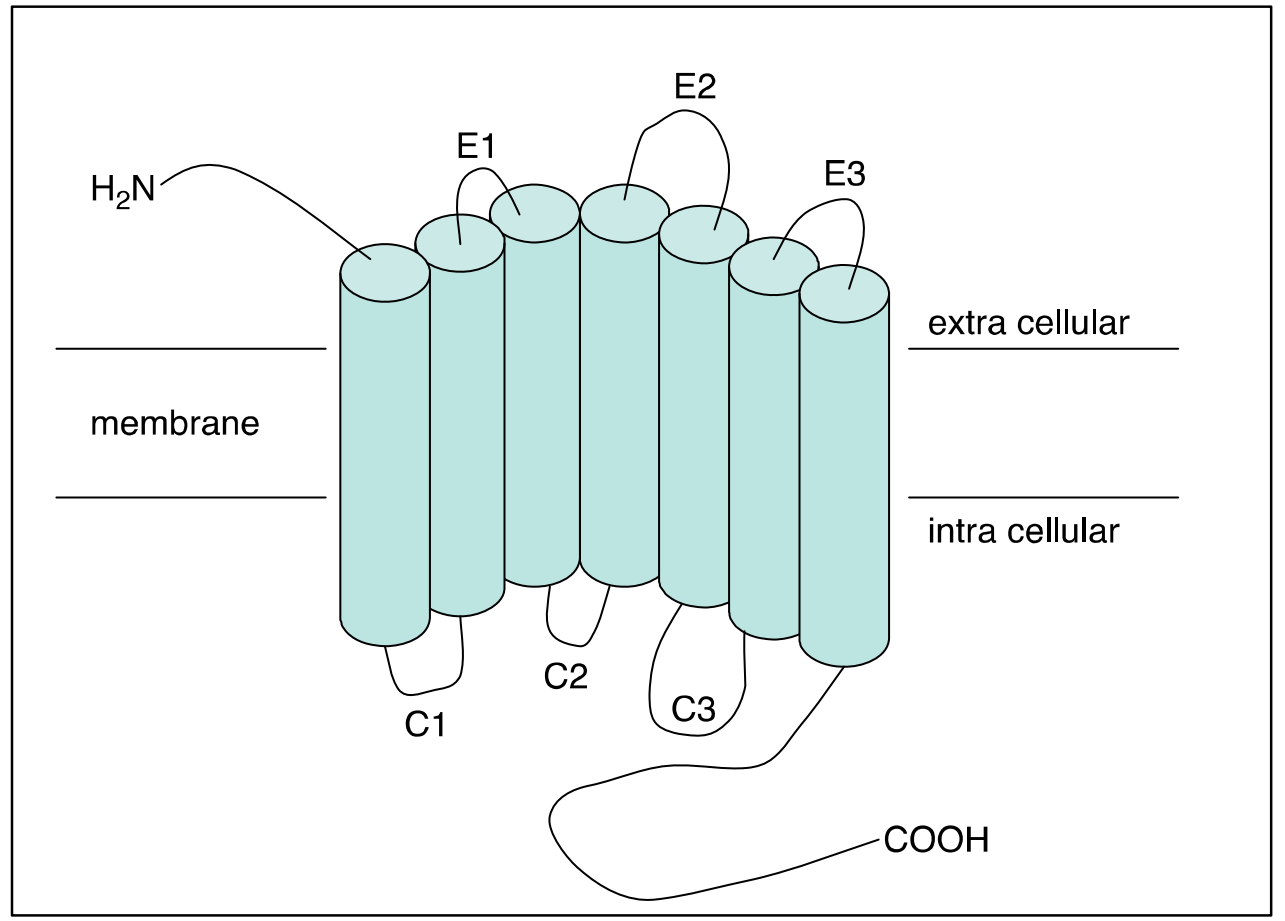

Figure 1.1: Structure of adenosine A1 receptor (Nell and Albrecht-Kupper, 2009) 
Our lab provided the first evidence that $\mathrm{A}_{1} \mathrm{AR}$ negatively modulates the effect of adenosine on vascular tone in mouse aorta and coronary flow regulations (Tawfik et al., 2005) resulting from activation of PLC pathway and $\mathrm{Ca}^{2+}$ mobilization (Tawfik et al., 2005). Others have showed similar results in different vascular beds like human cultured prostatic stromal cells (Preston et al., 2004), cat esophageal smooth muscle cells (Shim et al., 2002), guinea pig aorta (Ford and Broadley, 1999) and mouse coronary artery cells, heart, aorta and carotid artery (Prentice et al., 2002; Talukder et al., 2002; Ansari et al., 2009). Though $A_{1}$ is primarily known to mediate contraction, there are a few reports suggesting that $A_{1}$ mediates vasodilation through $K_{\text {ATP }}$ channel in the rat aortic endothelium (Ray and Marshall, 2006), in rat diaphragmatic arterioles (Danialou et al., 1997), in the rat skeletal muscle (Bryan and Marshall, 1999), in pig coronary artery smooth muscle cells (Dart and Standen, 1993).

\section{Arachidonic acid metabolites}

A major component of the cell membrane phospholipid pool is the arachidonic acid (AA). This 20-carbon fatty acid when released from the membrane is catalyzed by several enzymes to numerous biological metabolites called eicosanoids. Apart from adenosine, AA metabolites can also regulate the vascular tone. It has long been known that AA can be metabolized by COX and lipoxygenases (LOX) to prostaglandins (PG), thromoboxane (TP), leukotrienes (LT), 5-, 12- and 15- hydroxyeicosatetraenoic acid (HETE). These metabolites play a significant role in pulmonary and renal function, vascular tone, and inflammation (Roman, 2002; Miyata and Roman, 2005). Cytochrome P450 enzymes metabolize AA, it was discovered thirty years ago (Chacos et al., 1982) and consists of two families: a) Cytochrome P-450-epoxygenases (Cyp epoxygenases) and b) $\omega$-hydroxylases. Cyp epoxygenases catalyzes AA to epoxyeicosatrienoic acids 
(EETs) and dihydroxyeicosatrienoic acids (diHETEs), while $\omega$-hydroxylases metabolizes them to 19- and 20- HETEs and 7-, 10-, 12-, 13-, 15-, 16-, 17- and 18-HETEs from AA. These metabolites play a pivotal role as second messengers and paracrine factors in liver, kidney, blood vessels, lung, intestines, heart, pancreas and white blood cells and regulate pulmonary, renal, cardiac and vascular function and modulate inflammatory and growth responses (Capdevila et al., 1982; Randriamboavonjy et al., 2005). 


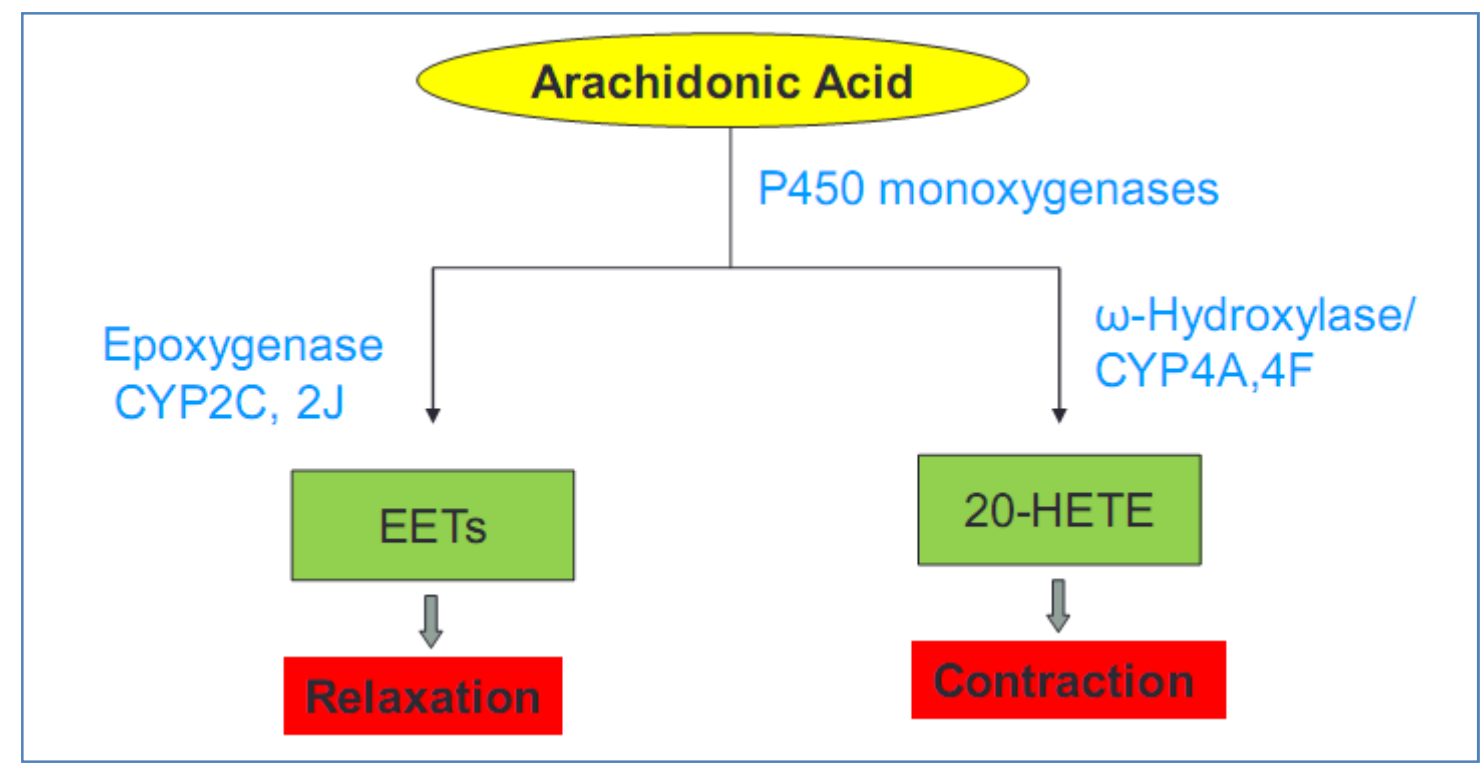

Figure 1.2: The enzymatic pathway of AA producing EETs and HETEs 


\section{EETs in the regulation of vascular tone}

Cyp epoxygenases produce EETs and belong to a conserved super-family of genes with a common evolutionary origin. Epoxygenase enzymes are present in the endothelial and vascular smooth muscle cells. Cyp2C and Cyp2J belonging to the Cyp epoxygenases family convert AA to 5,6-EET; 8,9-EET; 11,12- EET and 14,15-EET. The major CYP epoxygenases in humans are Cyp2C8, Сyp2C9 and Cyp2J2; in rats are Сyp2C11, Сyp2C23 and Сyp2J3; in mice are Сyp2C40, Сyp2C44, Сyp2C29, Сyp2J5 (Fleming, 2001; Michaelis and Fleming, 2006).

Studies in coronary, renal and cerebral vascular beds have shown that EETs increase the organ blood flow or cause vasodilation. Rodents, rabbits, canine and bovine blood vessels have also shown EET vasodilation (Imig et al., 2000; Fleming, 2001; Sudhahar et al., 2010). However, there are also studies showing where 5,6 EET and 8,9EET mediate vasoconstriction as these metabolites are also substrates for COX enzymes and bind to the TP receptors, activating it (Fulton et al., 1996; Imig and Navar, 1996). The main catabolic pathway for EETs is the conversion to diHETEs by soluble epoxide hyrdolase (sEH) enzyme. They can also be metabolized by $\omega$-oxidation, $\beta$-oxidation and chain elongation; the latter two being more prominent when sEH activity is low or inhibited in the tissue (Carroll et al., 2006; Fleming, 2010). EETs are known to activate the BK channels in the smooth muscle resulting in cell membrane hyperpolarization and causing vasodilation. There is accumulating evidence that EETs activation of the BK channels in the smooth muscle requires $\mathrm{G}_{\mathrm{s}}$ and cAMP/ PKA (Li and Campbell, 1997; $\mathrm{Li}$ et al., 2002; Krotz et al., 2004; Fleming, 2010). However, studies in smooth muscle cells from rat cerebral arteries and mice mesenteric arteries suggest that EETs increase endothelial $\mathrm{Ca}^{2+}$ levels through activation of vanilloid type 4 transient receptor potential 
(TRPV4) channels. There are also reports that $\mathrm{K}_{\mathrm{ATP}}$ channel contributes to EET mediated vasorelaxation (Imig, 2012; Ponnoth et al., 2012a).

\section{0-HETE in the regulation of vascular tone}

$\omega$ - hydroxylases consists of Cyp4a and Cyp4f families metabolize AA to 20HETE in the liver, kidney, heart, lung, brain and vasculature. There are several different isoforms encoded by cDNA in various species. In humans these are the Cyp4a11, Cyp4f2 and Cyp4f3; in rats there are 4 of Cyp4a: Cyp4a1, Cyp4a2, Сyp4a3, Cyp4a8 and 4 Cyp4f isoforms: Cyp4f1, Cyp4f4, Cyp4f5 and Cyp4f6, and in mice Cyp4a10, Cyp4a12, and Cyp4a14 are expressed. Fibrates are known to induce Cyp4a1 and Cyp4a3 in the liver and kidney, but not in the blood vessels as they do not express peroxisome proliferator activated receptor (PPAR)- $\alpha$ (Sundseth et al., 1992; Zhou et al., 2006). The main pathway for their breakdown is by $\beta$-oxidation to less active shorter chain length products. The other pathways are metabolism by COX enzymes to form vasoconstrictor endoperoxides and vasodilator prostanoids (Schwartzman et al., 1989; Carroll et al., 1992; Roman, 2002).

20-HETE is a potent vasoconstrictor of renal, cerebral, mesenteric and cardiac vascular beds $\left(\mathrm{EC}_{50}<10^{-8} \mathrm{M}\right)$ (Ma et al., 1993; Imig et al., 1996; Zou et al., 1996). Angiotensin II (AngII), endothelin and serotonin (5-HT) stimulate the formation of 20HETE. Vasoconstrictor responses to these agonists are attenuated on inhibiting the 20HETE formation (Carroll et al., 1996; Oyekan et al., 1997; Alonso-Galicia et al., 1998; Alonso-Galicia et al., 1999; Croft et al., 2000). The production of 20-HETE is inhibited by NO, carbon monoxide and superoxide radicals (Roman, 2002). PKC, mitogen activated protein kinase (MAPK), src-type tyrosine kinase and rho kinase pathways are activated by 20 -HETE and all play role in the regulation of vascular tone. Furthermore, 
20-HETE increases the conductance of L-type $\mathrm{Ca}^{2+}$ channel and inhibits BK channels through PKC activation. This allows for sustained depolarization of vascular smooth muscle and $\mathrm{Ca}^{2+}$ entry through L-type $\mathrm{Ca}^{2+}$ channel and causes contraction of the smooth muscle (Zou et al., 1996; Lange et al., 1997; Sun et al., 1998; Sun et al., 1999; Gebremedhin et al., 2000). Recent studies have implicated that 20-HETE augments the activation of inward non-selective cation currents through transient receptor potential canonical 6 channels involved in myogenic response (Basora et al., 2003; Brayden et al., 2008).

\section{Adenosine and Cyp450 metabolites in the regulation of vascular tone}

The interplay between adenosine and Cyp450 metabolites has come into light in past few years. Studies have shown a relationship between $\mathrm{A}_{2 \mathrm{~A}} \mathrm{AR}$ and EETs. In rat preglomerular vessels, $\mathrm{A}_{2 \mathrm{~A}} \mathrm{AR}$ have shown to mediate vasodilation through EETs via cAMP-PKA pathway activating BK channels (Carroll et al., 2006). Inhibition of the EETs pathway with 14,15-EEZE (EETs antagonist) decreased the NECA-induced relaxation and showed contraction at higher doses in the $\mathrm{A}_{2 \mathrm{~A}} \mathrm{WT}$ mice aortae as compared to the untreated control (Nayeem et al., 2008). In addition, $A_{1} A R$ and Cyp4a protein has been shown to be up-regulated in $\mathrm{A}_{2 \mathrm{~A}} \mathrm{KO}$ mice, suggesting a relationship between them (Ponnoth et al., 2012a). These findings have been discussed in the subsequent chapters.

\section{Potassium $\left(K^{+}\right)$channels in the regulation of vascular tone}

There are several ion channels on the vascular smooth muscle cell surface. There are more than 4 types of $\mathrm{K}^{+}$channels (Nelson et al., 1990; Nelson and Quayle, 1995; Jackson, 2000), 4 types of voltage gated $\mathrm{Ca}^{2+}$ channels, more than 2 types of $\mathrm{Cl}^{-}$channels, store-operated $\mathrm{Ca}^{2+}$ channels and stretch activated cation channels (Nelson et al., 1990; Jackson, 2000). 
The most dominant ion channels are $\mathrm{K}^{+}$channels and their activity plays a pivotal role in determining and regulating the membrane potential, thereby the vascular tone. There are 4 different types of $\mathrm{K}^{+}$channels: voltage gated $\mathrm{K}^{+}\left(\mathrm{K}_{\mathrm{V}}\right)$ channels, inward rectifier $\mathrm{K}^{+}\left(\mathrm{K}_{\mathrm{IR}}\right)$ channels, $\mathrm{K}_{\mathrm{ATP}}$ channels, and BK channels. This dissertation thesis focuses on role of BK channels in the regulation of vascular tone.

a) $\underline{K}_{\underline{V}}$ channels: They are also known as delayed rectifier channels and are expressed on the smooth muscle. They are activated by membrane depolarization with threshold potentials of approximately $30 \mathrm{mV}$ for substantial activation. Vasoconstrictors have a tendency to close $\mathrm{K}_{\mathrm{V}}$ channels through $\mathrm{PKC}$ and intracellular $\mathrm{Ca}^{2+}$ and vasodilators open $\mathrm{K}_{\mathrm{V}}$ via cAMP signaling cascade (Nelson and Quayle, 1995).

$\underline{b)} \underline{K_{I R}} \underline{\text { channels: }}$ These are found in both excitable and non-excitable cells. The inward $\mathrm{K}^{+}$current pass through these channels much more readily than the outward current with physiological ion gradients and with increase in extracellular $\mathrm{K}^{+}$concentration increases the channel conductance. They are known to mediate vasodilation in cerebral, coronary, skeletal muscle vascular beds through elevated extracellular $\mathrm{K}^{+}$resulting in hyperpolarization of vascular smooth muscle membrane and thereby dilation (Quayle et al., 1993).

c) BK channels: These are found in vascular smooth muscle cells. As they allow the $\mathrm{K}^{+}$channels to pass readily through them, they are also known as maxi-K channels or big $\mathrm{K}$ channels. They have a conductance of $250 \mathrm{pS}$ and are activated by elevations in intracellular $\mathrm{Ca}^{2+}$ and membrane depolarization (Nelson, 1993).

d) $\underline{K}_{\text {ATP }}$ channels: These channels derive their name due to their sensitivity to intracellular ATP concentrations. They close as the ATP concentration increases. 
Apart from smooth muscle; they are found in cardiac muscle, skeletal muscle, pancreatic $\beta$ - cells and certain types of neurons (Nelson et al., 1990; Nelson, 1993).

\section{BK channels in the regulation of vascular tone}

They are known as Slo 1 as they had been cloned from the drosophila slowpoke locus (Atkinson NS, Robertson GA and Gantetzky B; Science Wash. DC 253:551-555, 1991). BK channels are composed of $4 \alpha$ subunits and 1-4 $\beta$-subunits $(\beta 1-\beta 4)$. The pore forming $\alpha$ subunit is composed of 11 hyrdophobic domains (S0-S10), of which membrane spanning S0-S6 domains constitute the core region with an $\mathrm{NH}_{2}$ terminus and the remaining four domains (S7-S10) are located in cytoplasm and form the $\mathrm{COOH}$ terminus of the protein. The voltage sensor property of the channel is located on the S4 domain and the pore forming region on the S5-S6 linker (Toro L, Taanaka Y News Physiol Sci 13:112-117, 1998). The $\alpha$ subunit also contains the $\mathrm{Ca}^{2+}$ bowl in the tail region of the protein conferring the intrinsic sensitivity to $\mathrm{Ca}^{2+}$ to the protein. However, the regulator of conductance for $\mathrm{K}^{+}(\mathrm{RCK})$ domain present between the core and the tail region of the protein is also associated to $\mathrm{Ca}^{2+}$ sensitivity by some (Xia et al., 2002; Krishnamoorthy et al., 2005). The $\alpha$ subunit is encoded by Slo gene only, but has several subunits which confer different properties to the channels in various tissues like voltage sensitivity, phosphorylation by cAMP dependent PKA or PKG. The four- $\beta$ subunits further add on to the variability as there are 4 subunit genes and 8 subunit proteins have been discovered with different pharmacological, modulatory effects and the activation gating of the channel. The $\beta$ subunit is composed of two transmembrane domains with an extracellular domain and cytoplasmic $\mathrm{NH}_{2}$ and $\mathrm{COOH}$ terminals. It enhances the voltage and the calcium sensitivity of the channel by interacting with the S0 subunit and 
$\mathrm{NH} 2$ terminus of the $\alpha$-subunit. In vascular smooth muscle cells (VSMC) $\beta 1$ is the prominent one. 


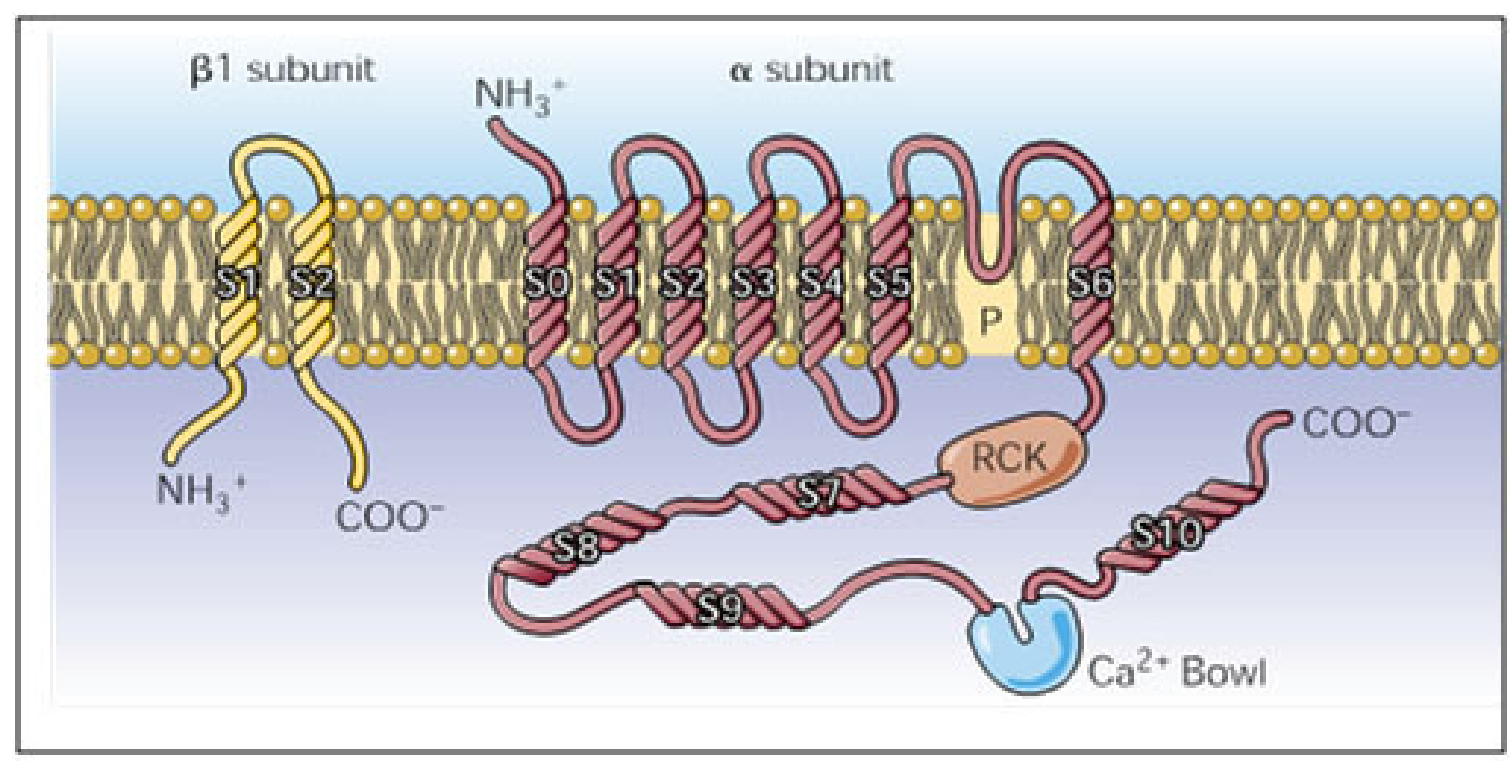

Figure 1.3: Structure of BK channel (Ledoux et al., 2006)

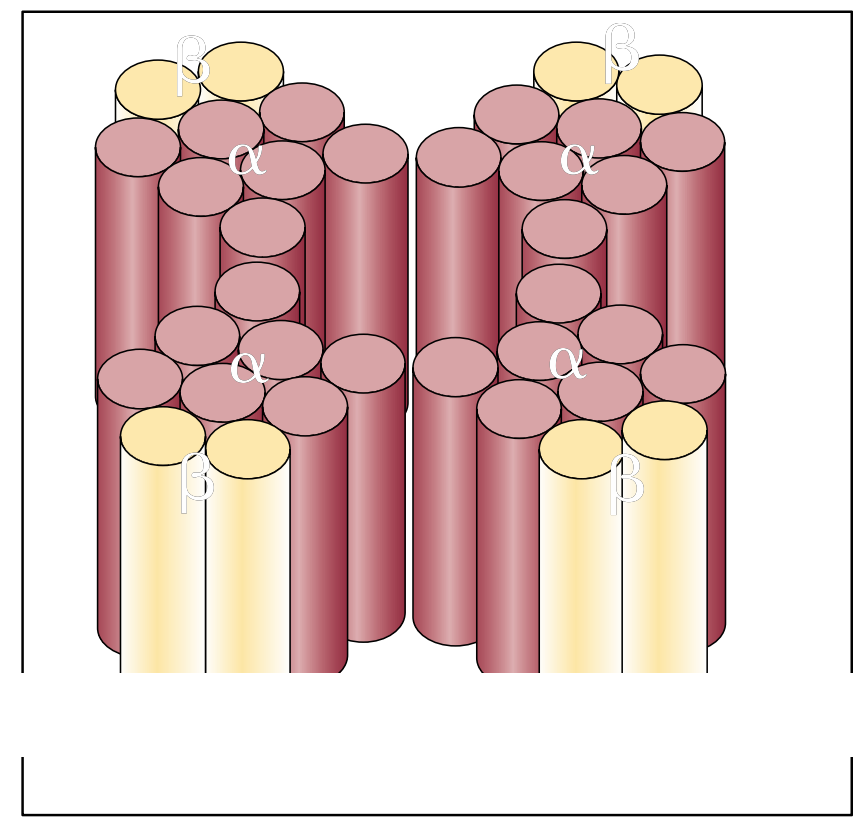

Figure 1.4: The native BK channel composed of 4- $\alpha$ and 4- $\beta$ subunits (Ledoux et al., 2006) 
Intracellular $\mathrm{Ca}^{2+}$ can cause dilation or constriction of the smooth muscle. A global increase in the cytoplasm $\mathrm{Ca}^{2+}$ concentration results in activation of the myosin light chain kinase (MLCK) and causes contraction of the smooth muscle. This global increase in calcium occurs through open state probability of the L-type voltage dependent calcium channel (L-VDCC) and regulated by the membrane potential and results in vasoconstriction. The $\mathrm{Ca}^{2+}$ increase from the ryanodine receptors $(\mathrm{RyR}) / \mathrm{IP}_{3}$ receptors, known as $\mathrm{Ca}^{2+}$ sparks, generates a highly localized elevation in the $\mathrm{Ca}^{2+}$ levels but the global $\mathrm{Ca}^{2+}$ level is raised minimally. The $\mathrm{IP}_{3} / \mathrm{RyR}$ receptors are located in close proximity to the $\mathrm{BK}$ channels and the $\mathrm{Ca}^{2+}$ sparks activates the $\mathrm{BK}$ channel (Perez et al., 1999). Opening of the BK channels hyperpolarizes the membrane and promotes the closure of the L-VDCC and thus causing dilation. Thus, the $\mathrm{Ca}^{2+}$ sparks opposes the vasoconstriction.

BK channels play an important role in myogenic tone and contribute to the peripheral resistance. Several studies in rat cerebral, coronary and saphenous arteries have shown that increase in intracellular $\mathrm{Ca}^{2+}$ caused by pressure induced membrane depolarization and results in activation of BK (Brayden et al., 1991; Berczi et al., 1992).

\section{Adenosine and BK channels}

Adenosine relaxes vascular smooth muscle through several mechanisms, including the activation of $\mathrm{K}^{+}$channels (Dart and Standen, 1993). Reports regarding the role of BK channels in adenosine-induced smooth muscle relaxation vary widely. In canine coronary arterioles, vasodilation in response to adenosine is inhibited by iberiotoxin (Cabell et al., 1994). Blocking BK channels inhibits vasodilation to 2-chloroadenosine in pig coronary arterioles (Borbouse et al., 2009); however, the role of BK channels in this response is abolished in pigs with metabolic syndrome (Borbouse et al., 
2009). Thus, it could be pathology that explains why BK channels play no role in adenosine-induced vasodilation in human coronary arterioles (Sato et al., 2005), as they are typically collected from patients with heart disease. Conversely, it may be that BK channels play little, if any role, in adenosine-induced vasodilation, as this has been reported in the majority of studies from pig coronary arterioles (Hein and Kuo, 1999; Hein et al., 2001; Heaps and Bowles, 2002). However, it cannot be ignored that BK channels are reported to contribute to adenosine-induced relaxation/vasodilation of rat cerebral arterioles (Paterno et al., 1996), rabbit renal arteries (Rump et al., 1999); rat aortas (Ray and Marshall, 2006); and rat pre-glomerular microvessels (Carroll et al., 2006). Further, adenosine increases a $\mathrm{Ca}^{2+-}$ dependent $\mathrm{K}^{+}$current in smooth muscle cells from the rat mesenteric artery that may be mediated by BK channels ( $\mathrm{Li}$ and Cheung, 2000). At present, there is little consensus regarding the role of BK channels in adenosine-induced smooth muscle relaxation and very little data directly addressing whether adenosine increases BK current in smooth muscle cells isolated from those same arteries or arterioles. 


\section{Specific Aims}

Adenosine plays an important role in the regulation of vascular tone in both physiological and patho-physiological conditions, where AR expression is altered.Apart from adenosine, the Cyp450 metabolites have also been shown to have pivotal role in the regulating the tone of the blood vessels. Although the work cited above provides evidence that $\mathrm{A}_{2 \mathrm{~A}} \mathrm{AR}$ and Cyp-epoxygenases-derived metabolites (EETs) do interact, but the precise mechanism by which $\mathrm{A}_{1} \mathrm{AR}$ interacts with Cyp4a and regulate the vascular tone is completely unknown.

Given the traits of $\mathrm{A}_{1} \mathrm{AR}$ and Cyp4a derived metabolite of AA (20-HETE), a relationship between the two is highly plausible. Both $\mathrm{A}_{1} \mathrm{AR}$ and 20-HETE are altered in several pathophysiological conditions. Thus, understanding the relationship between the two will help to better develop therapeutic targets. Thus, the purpose of this dissertation is to identify the relationship between $A_{1} A R$ and Cyp4a and elucidate the signaling pathways in the regulation of vascular tone.

With this in mind, the following aims were developed:

\section{Specific Aim 1: To determine elucidate the relationship between $A_{1} A R$} and Cyp4504a and in the $A_{1} A R$ mediated contraction of smooth muscle Working Hypothesis: Adenosine $\mathrm{A}_{1}$ receptor induced -vascular contraction is mediated through Cyp4504a metabolite, 20-HETE

Specific Aim 2: To delineate the signaling pathways through which $\mathrm{A}_{1} \mathrm{AR}$ mediates vasoconstriction via 20-HETE

Sub specific aim 2.1: To identify the signaling mechanisms of $\mathrm{A}_{1} \mathrm{AR}$ mediated smooth muscle contraction. 
Working hypothesis: $\mathrm{A}_{1} \mathrm{AR}-20 \mathrm{HETE}$ mediates vasoconstriction through activation of PKC- $\alpha$ and $\mathrm{p}-\mathrm{ERK} 1 / 2$ pathway.

Sub-specific aim 2.2: To identify the ion channels involved in $A_{1} A R$ mediated contraction through 20-HETE

Working hypothesis: In the presence of $\mathrm{A}_{1} \mathrm{AR}, 20$-HETE modulates vascular response through BK channels in the aortic smooth muscle. 


\section{References}

Abbracchio MP, Boeynaems JM, Barnard EA, Boyer JL, Kennedy C, Miras-Portugal MT, King BF, Gachet C, Jacobson KA, Weisman GA and Burnstock G (2003) Characterization of the UDP-glucose receptor (re-named here the P2Y14 receptor) adds diversity to the P2Y receptor family. Trends Pharmacol Sci 24:5255.

Abbracchio MP, Brambilla R, Ceruti S, Kim HO, von Lubitz DK, Jacobson KA and Cattabeni F (1995) G protein-dependent activation of phospholipase C by adenosine A3 receptors in rat brain. Mol Pharmacol 48:1038-1045.

Abebe W and Mustafa SJ (1998) A1 adenosine receptor-mediated Ins(1,4,5)P3 generation in allergic rabbit airway smooth muscle. Am J Physiol 275:L990-997.

Alonso-Galicia M, Hudetz AG, Shen H, Harder DR and Roman RJ (1999) Contribution of 20-HETE to vasodilator actions of nitric oxide in the cerebral microcirculation. Stroke 30:2727-2734; discussion 2734.

Alonso-Galicia M, Sun CW, Falck JR, Harder DR and Roman RJ (1998) Contribution of 20-HETE to the vasodilator actions of nitric oxide in renal arteries. Am J Physiol 275:F370-378.

Ansari HR, Husain S and Abdel-Latif AA (2001) Activation of p42/p44 mitogenactivated protein kinase and contraction by prostaglandin F2alpha, ionomycin, and thapsigargin in cat iris sphincter smooth muscle: inhibition by PD98059, KN93, and isoproterenol. J Pharmacol Exp Ther 299:178-186.

Ansari HR, Nadeem A, Talukder MA, Sakhalkar S and Mustafa SJ (2007a) Evidence for the involvement of nitric oxide in $\mathrm{A} 2 \mathrm{~B}$ receptor-mediated vasorelaxation of mouse aorta. Am J Physiol Heart Circ Physiol 292:H719-725. 
Ansari HR, Nadeem A, Tilley SL and Mustafa SJ (2007b) Involvement of COX-1 in A3 adenosine receptor-mediated contraction through endothelium in mice aorta. Am J Physiol Heart Circ Physiol 293:H3448-3455.

Ansari HR, Teng B, Nadeem A, Roush KP, Martin KH, Schnermann J and Mustafa SJ (2009) A(1) adenosine receptor-mediated PKC and p42/p44 MAPK signaling in mouse coronary artery smooth muscle cells. Am J Physiol Heart Circ Physiol 297:H1032-1039.

Asano S, Tune JD and Dick GM (2010) Bisphenol A activates Maxi-K (K(Ca)1.1) channels in coronary smooth muscle. Br J Pharmacol 160:160-170.

Basora N, Boulay G, Bilodeau L, Rousseau E and Payet MD (2003) 20hydroxyeicosatetraenoic acid (20-HETE) activates mouse TRPC6 channels expressed in HEK293 cells. J Biol Chem 278:31709-31716.

Berczi V, Stekiel WJ, Contney SJ and Rusch NJ (1992) Pressure-induced activation of membrane $\mathrm{K}+$ current in rat saphenous artery. Hypertension 19:725-729.

Biaggioni I, King LS, Enayat N, Robertson D and Newman JH (1989) Adenosine produces pulmonary vasoconstriction in sheep. Evidence for thromboxane A2/prostaglandin endoperoxide-receptor activation. Circ Res 65:1516-1525.

Bonev AD and Nelson MT (1996) Vasoconstrictors inhibit ATP-sensitive K+ channels in arterial smooth muscle through protein kinase C. J Gen Physiol 108:315-323.

Borbouse L, Dick GM, Asano S, Bender SB, Dincer UD, Payne GA, Neeb ZP, Bratz IN, Sturek M and Tune JD (2009) Impaired function of coronary BK(Ca) channels in metabolic syndrome. Am J Physiol Heart Circ Physiol 297:H1629-1637. 
Brayden JE, Earley S, Nelson MT and Reading S (2008) Transient receptor potential (TRP) channels, vascular tone and autoregulation of cerebral blood flow. Clin Exp Pharmacol Physiol 35:1116-1120.

Brayden JE, Quayle JM, Standen NB and Nelson MT (1991) Role of potassium channels in the vascular response to endogenous and pharmacological vasodilators. Blood Vessels 28:147-153.

Brenner R, Perez GJ, Bonev AD, Eckman DM, Kosek JC, Wiler SW, Patterson AJ, Nelson MT and Aldrich RW (2000) Vasoregulation by the betal subunit of the calcium-activated potassium channel. Nature 407:870-876.

Bryan PT and Marshall JM (1999) Adenosine receptor subtypes and vasodilatation in rat skeletal muscle during systemic hypoxia: a role for A1 receptors. J Physiol 514 ( Pt 1):151-162.

Cabell F, Weiss DS and Price JM (1994) Inhibition of adenosine-induced coronary vasodilation by block of large-conductance $\mathrm{Ca}(2+)$-activated $\mathrm{K}+$ channels. Am J Physiol 267:H1455-1460.

Capdevila J, Marnett LJ, Chacos N, Prough RA and Estabrook RW (1982) Cytochrome P-450-dependent oxygenation of arachidonic acid to hydroxyicosatetraenoic acids. Proc Natl Acad Sci U S A 79:767-770.

Carroll MA, Balazy M, Margiotta P, Huang DD, Falck JR and McGiff JC (1996) Cytochrome P-450-dependent HETEs: profile of biological activity and stimulation by vasoactive peptides. Am J Physiol 271:R863-869.

Carroll MA, Doumad AB, Li J, Cheng MK, Falck JR and McGiff JC (2006) Adenosine2A receptor vasodilation of rat preglomerular microvessels is mediated 
by EETs that activate the cAMP/PKA pathway. Am J Physiol Renal Physiol 291:F155-161.

Carroll MA, Garcia MP, Falck JR and McGiff JC (1992) Cyclooxygenase dependency of the renovascular actions of cytochrome P450-derived arachidonate metabolites. $J$ Pharmacol Exp Ther 260:104-109.

Chacos N, Falck JR, Wixtrom C and Capdevila J (1982) Novel epoxides formed during the liver cytochrome P-450 oxidation of arachidonic acid. Biochem Biophys Res Commun 104:916-922.

Chang K, Xiao D, Huang X, Longo LD and Zhang L (2009) Chronic hypoxia increases pressure-dependent myogenic tone of the uterine artery in pregnant sheep: role of ERK/PKC pathway. Am J Physiol Heart Circ Physiol 296:H1840-1849.

Cheng DY, DeWitt BJ, Suzuki F, Neely CF and Kadowitz PJ (1996) Adenosine A1 and A2 receptors mediate tone-dependent responses in feline pulmonary vascular bed. Am J Physiol 270:H200-207.

Cheng MK, Doumad AB, Jiang H, Falck JR, McGiff JC and Carroll MA (2004) Epoxyeicosatrienoic acids mediate adenosine-induced vasodilation in rat preglomerular microvessels (PGMV) via A2A receptors. $\mathrm{Br} J$ Pharmacol 141:441-448.

Cogolludo A, Moreno L, Bosca L, Tamargo J and Perez-Vizcaino F (2003) Thromboxane A2-induced inhibition of voltage-gated $\mathrm{K}+$ channels and pulmonary vasoconstriction: role of protein kinase Czeta. Circ Res 93:656-663.

Coulson R, Proch PS, Olsson RA, Chalfant CE and Cooper DR (1996) Upregulated renal adenosine A1 receptors augment PKC and glucose transport but inhibit proliferation. Am J Physiol 270:F263-274. 
Croft KD, McGiff JC, Sanchez-Mendoza A and Carroll MA (2000) Angiotensin II releases 20-HETE from rat renal microvessels. Am J Physiol Renal Physiol 279:F544-551.

Danialou G, Vicaut E, Sambe A, Aubier M and Boczkowski J (1997) Predominant role of A1 adenosine receptors in mediating adenosine induced vasodilatation of rat diaphragmatic arterioles: involvement of nitric oxide and the ATP-dependent $\mathrm{K}+$ channels. Br J Pharmacol 121:1355-1363.

Dart C and Standen NB (1993) Adenosine-activated potassium current in smooth muscle cells isolated from the pig coronary artery. J Physiol 471:767-786.

Ding Y, Schwartz D, Posner P and Zhong J (2004) Hypotonic swelling stimulates L-type $\mathrm{Ca} 2+$ channel activity in vascular smooth muscle cells through PKC. Am $J$ Physiol Cell Physiol 287:C413-421.

Drury AN and Szent-Gyorgyi A (1929) The physiological activity of adenine compounds with especial reference to their action upon the mammalian heart. J Physiol 68:213-237.

El-Awady MS, Ansari HR, Fil D, Tilley SL and Mustafa SJ (2011) NADPH oxidase pathway is involved in aortic contraction induced by A3 adenosine receptor in mice. J Pharmacol Exp Ther 338:711-717.

Fleming I (2001) Cytochrome p450 and vascular homeostasis. Circ Res 89:753-762.

Fleming I (2010) Molecular mechanisms underlying the activation of eNOS. Pflugers Arch 459:793-806.

Ford WR and Broadley KJ (1999) Effects of adenosine receptor agonists on induction of contractions to phenylephrine of guinea-pig aorta mediated via intra- or extracellular calcium. Gen Pharmacol 33:143-150. 
Fredholm BB (2007) Adenosine, an endogenous distress signal, modulates tissue damage and repair. Cell Death Differ 14:1315-1323.

Fredholm BB, AP IJ, Jacobson KA, Klotz KN and Linden J (2001) International Union of Pharmacology. XXV. Nomenclature and classification of adenosine receptors. Pharmacol Rev 53:527-552.

Frick GP and Lowenstein JM (1976) Studies of 5'-nucleotidase in the perfused rat heart. Including measurements of the enzyme in perfused skeletal muscle and liver. $J$ Biol Chem 251:6372-6378.

Fulton D, Balazy M, McGiff JC and Quilley J (1996) Possible contribution of platelet cyclooxygenase to the renal vascular action of 5,6-epoxyeicosatrienoic acid. $J$ Pharmacol Exp Ther 277:1195-1199.

Gebremedhin D, Lange AR, Lowry TF, Taheri MR, Birks EK, Hudetz AG, Narayanan J, Falck JR, Okamoto H, Roman RJ, Nithipatikom K, Campbell WB and Harder DR (2000) Production of 20-HETE and its role in autoregulation of cerebral blood flow. Circ Res 87:60-65.

Hansen PB, Castrop H, Briggs J and Schnermann J (2003) Adenosine induces vasoconstriction through Gi-dependent activation of phospholipase $\mathrm{C}$ in isolated perfused afferent arterioles of mice. J Am Soc Nephrol 14:2457-2465.

Harder DR, Gebremedhin D, Narayanan J, Jefcoat C, Falck JR, Campbell WB and Roman R (1994) Formation and action of a P-450 4A metabolite of arachidonic acid in cat cerebral microvessels. Am J Physiol 266:H2098-2107.

Harder DR, Lange AR, Gebremedhin D, Birks EK and Roman RJ (1997) Cytochrome P450 metabolites of arachidonic acid as intracellular signaling molecules in vascular tissue. $J$ Vasc Res 34:237-243. 
Heaps CL and Bowles DK (2002) Gender-specific K(+)-channel contribution to adenosine-induced relaxation in coronary arterioles. J Appl Physiol 92:550-558.

Hein TW and Kuo L (1999) cAMP-independent dilation of coronary arterioles to adenosine : role of nitric oxide, G proteins, and K(ATP) channels. Circ Res 85:634-642.

Hein TW, Wang W, Zoghi B, Muthuchamy M and Kuo L (2001) Functional and molecular characterization of receptor subtypes mediating coronary microvascular dilation to adenosine. J Mol Cell Cardiol 33:271-282.

Hill KJ, Webber AC and Hill SJ (2003) A role of protein kinase C mu in signalling from the human adenosine A1 receptor to the nucleus. Br J Pharmacol 139:721-732.

Hoagland KM, Maier KG, Moreno C, Yu M and Roman RJ (2001) Cytochrome P450 metabolites of arachidonic acid: novel regulators of renal function. Nephrol Dial Transplant 16:2283-2285.

Imig JD (2012) Epoxides and soluble epoxide hydrolase in cardiovascular physiology. Physiol Rev 92:101-130.

Imig JD and Navar LG (1996) Afferent arteriolar response to arachidonic acid: involvement of metabolic pathways. Am J Physiol 271:F87-93.

Imig JD, Pham BT, LeBlanc EA, Reddy KM, Falck JR and Inscho EW (2000) Cytochrome P450 and cyclooxygenase metabolites contribute to the endothelin-1 afferent arteriolar vasoconstrictor and calcium responses. Hypertension 35:307312.

Imig JD, Zou AP, Stec DE, Harder DR, Falck JR and Roman RJ (1996) Formation and actions of 20-hydroxyeicosatetraenoic acid in rat renal arterioles. Am J Physiol 270:R217-227. 
Jackson WF (2000) Ion channels and vascular tone. Hypertension 35:173-178.

Jacobson KA and Gao ZG (2006) Adenosine receptors as therapeutic targets. Nat Rev Drug Discov 5:247-264.

Kitamura K, Xiong Z, Teramoto N and Kuriyama H (1992) Roles of inositol trisphosphate and protein kinase $\mathrm{C}$ in the spontaneous outward current modulated by calcium release in rabbit portal vein. Pflugers Arch 421:539-551.

Krishnamoorthy G, Shi J, Sept D and Cui J (2005) The NH2 terminus of RCK1 domain regulates Ca2+-dependent BK(Ca) channel gating. J Gen Physiol 126:227-241.

Krotz F, Riexinger T, Buerkle MA, Nithipatikom K, Gloe T, Sohn HY, Campbell WB and Pohl U (2004) Membrane-potential-dependent inhibition of platelet adhesion to endothelial cells by epoxyeicosatrienoic acids. Arterioscler Thromb Vasc Biol 24:595-600.

Kunduri S, Mustafa S, Ponnoth D, Dick G and Nayeem M (2013) Adenosine A1 receptors link to smooth muscle contraction via CYP4a, PKC-alpha, and ERK1/2. J Cardiovasc Pharmacol.

Lange A, Gebremedhin D, Narayanan J and Harder D (1997) 20Hydroxyeicosatetraenoic acid-induced vasoconstriction and inhibition of potassium current in cerebral vascular smooth muscle is dependent on activation of protein kinase C. J Biol Chem 272:27345-27352.

Ledoux J, Werner ME, Brayden JE and Nelson MT (2006) Calcium-activated potassium channels and the regulation of vascular tone. Physiology (Bethesda) 21:69-78.

Lee HT and Emala CW (2002) Characterization of adenosine receptors in human kidney proximal tubule (HK-2) cells. Exp Nephrol 10:383-392. 
Li G and Cheung DW (2000) Modulation of $\mathrm{Ca}(2+)$-dependent $\mathrm{K}(+)$ currents in mesenteric arterial smooth muscle cells by adenosine. Eur J Pharmacol 394:3540.

Li PL and Campbell WB (1997) Epoxyeicosatrienoic acids activate K+ channels in coronary smooth muscle through a guanine nucleotide binding protein. Circ Res 80:877-884.

Li PL, Zhang DX, Ge ZD and Campbell WB (2002) Role of ADP-ribose in 11,12-EETinduced activation of $\mathrm{K}(\mathrm{Ca})$ channels in coronary arterial smooth muscle cells. Am J Physiol Heart Circ Physiol 282:H1229-1236.

Livak KJ and Schmittgen TD (2001) Analysis of relative gene expression data using realtime quantitative PCR and the 2(-Delta Delta C(T)) Method. Methods 25:402-408.

Lloyd HG and Fredholm BB (1995) Involvement of adenosine deaminase and adenosine kinase in regulating extracellular adenosine concentration in rat hippocampal slices. Neurochem Int 26:387-395.

Lo RK and Wong YH (2006) Transcriptional activation of c-Fos by constitutively active Galpha(16)QL through a STAT1-dependent pathway. Cell Signal 18:2143-2153.

Loufrani L, Lehoux S, Tedgui A, Levy BI and Henrion D (1999) Stretch induces mitogen-activated protein kinase activation and myogenic tone through 2 distinct pathways. Arterioscler Thromb Vasc Biol 19:2878-2883.

Ma YH, Gebremedhin D, Schwartzman ML, Falck JR, Clark JE, Masters BS, Harder DR and Roman RJ (1993) 20-Hydroxyeicosatetraenoic acid is an endogenous vasoconstrictor of canine renal arcuate arteries. Circ Res 72:126-136. 
Matsumoto T, Tostes RC and Webb RC (2011) Uridine adenosine tetraphosphateinduced contraction is increased in renal but not pulmonary arteries from DOCAsalt hypertensive rats. Am J Physiol Heart Circ Physiol 301:H409-417.

Michaelis UR and Fleming I (2006) From endothelium-derived hyperpolarizing factor (EDHF) to angiogenesis: Epoxyeicosatrienoic acids (EETs) and cell signaling. Pharmacol Ther 111:584-595.

Miller TM, Donnelly MK, Crago EA, Roman DM, Sherwood PR, Horowitz MB and Poloyac SM (2009) Rapid, simultaneous quantitation of mono and dioxygenated metabolites of arachidonic acid in human CSF and rat brain. $J$ Chromatogr $B$ Analyt Technol Biomed Life Sci 877:3991-4000.

Miyata N and Roman RJ (2005) Role of 20-hydroxyeicosatetraenoic acid (20-HETE) in vascular system. J Smooth Muscle Res 41:175-193.

Moro S, Gao ZG, Jacobson KA and Spalluto G (2006) Progress in the pursuit of therapeutic adenosine receptor antagonists. Med Res Rev 26:131-159.

Nayeem MA, Poloyac SM, Falck JR, Zeldin DC, Ledent C, Ponnoth DS, Ansari HR and Mustafa SJ (2008) Role of CYP epoxygenases in A2A AR-mediated relaxation using A2A AR-null and wild-type mice. Am J Physiol Heart Circ Physiol 295:H2068-2078.

Nayeem MA, Ponnoth DS, Boegehold MA, Zeldin DC, Falck JR and Mustafa SJ (2009) High-salt diet enhances mouse aortic relaxation through adenosine A2A receptor via CYP epoxygenases. Am J Physiol Regul Integr Comp Physiol 296:R567-574.

Nell PG and Albrecht-Kupper B (2009) The adenosine A1 receptor and its ligands. Prog Med Chem 47:163-201. 
Nelson MT (1993) Ca(2+)-activated potassium channels and ATP-sensitive potassium channels as modulators of vascular tone. Trends Cardiovasc Med 3:54-60.

Nelson MT, Cheng H, Rubart M, Santana LF, Bonev AD, Knot HJ and Lederer WJ (1995) Relaxation of arterial smooth muscle by calcium sparks. Science 270:633637.

Nelson MT, Patlak JB, Worley JF and Standen NB (1990) Calcium channels, potassium channels, and voltage dependence of arterial smooth muscle tone. Am J Physiol 259:C3-18.

Nelson MT and Quayle JM (1995) Physiological roles and properties of potassium channels in arterial smooth muscle. Am J Physiol 268:C799-822.

Newby AC, Worku Y and Holmquist CA (1985) Adenosine formation. Evidence for a direct biochemical link with energy metabolism. Adv Myocardiol 6:273-284.

Nowicki S, Chen SL, Aizman O, Cheng XJ, Li D, Nowicki C, Nairn A, Greengard P and Aperia A (1997) 20-Hydroxyeicosa-tetraenoic acid (20 HETE) activates protein kinase C. Role in regulation of rat renal $\mathrm{Na}+, \mathrm{K}+-\mathrm{ATPase}$ J Clin Invest 99:12241230.

Obara K, Koide M and Nakayama K (2002) 20-Hydroxyeicosatetraenoic acid potentiates stretch-induced contraction of canine basilar artery via PKC alpha-mediated inhibition of KCa channel. Br J Pharmacol 137:1362-1370.

Oyekan A, Balazy M and McGiff JC (1997) Renal oxygenases: differential contribution to vasoconstriction induced by ET-1 and ANG II. Am J Physiol 273:R293-300.

Paterno R, Faraci FM and Heistad DD (1996) Role of Ca(2+)-dependent K+ channels in cerebral vasodilatation induced by increases in cyclic GMP and cyclic AMP in the rat. Stroke 27:1603-1607; discussion 1607-1608. 
Perez GJ, Bonev AD, Patlak JB and Nelson MT (1999) Functional coupling of ryanodine receptors to $\mathrm{KCa}$ channels in smooth muscle cells from rat cerebral arteries. J Gen Physiol 113:229-238.

Poloyac SM, Zhang Y, Bies RR, Kochanek PM and Graham SH (2006) Protective effect of the 20-HETE inhibitor HET0016 on brain damage after temporary focal ischemia. J Cereb Blood Flow Metab 26:1551-1561.

Ponnoth DS, Nadeem A and Mustafa SJ (2008) Adenosine-mediated alteration of vascular reactivity and inflammation in a murine model of asthma. Am J Physiol Heart Circ Physiol 294:H2158-2165.

Ponnoth DS, Nayeem MA, Kunduri SS, Tilley SL, Zeldin DC, Ledent C and Mustafa SJ (2012) Role of omega-hydroxylase in adenosine-mediated aortic response through MAP kinase using A2A-receptor knockout mice. Am J Physiol Regul Integr Comp Physiol 302:R400-408.

Ponnoth DS, Sanjani MS, Ledent C, Roush K, Krahn T and Mustafa SJ (2009) Absence of adenosine-mediated aortic relaxation in $\mathrm{A}(2 \mathrm{~A})$ adenosine receptor knockout mice. Am J Physiol Heart Circ Physiol 297:H1655-1660.

Prentice DJ, Kelly MD, Ledent C and Hourani SM (2002) Relaxation of the mouse isolated aorta and carotid artery in response to adenosine analogues in geneticallymodified mice lacking the adenosine $\mathrm{A}(2 \mathrm{~A})$ receptor. Naunyn Schmiedebergs Arch Pharmacol 366:127-133.

Preston A, Frydenberg M and Haynes JM (2004) A1 and A2A adenosine receptor modulation of alpha 1-adrenoceptor-mediated contractility in human cultured prostatic stromal cells. Br J Pharmacol 141:302-310. 
Quayle JM, McCarron JG, Brayden JE and Nelson MT (1993) Inward rectifier K+ currents in smooth muscle cells from rat resistance-sized cerebral arteries. Am J Physiol 265:C1363-1370.

Randriamboavonjy V, Kiss L, Falck JR, Busse R and Fleming I (2005) The synthesis of 20-HETE in small porcine coronary arteries antagonizes EDHF-mediated relaxation. Cardiovasc Res 65:487-494.

Ray CJ and Marshall JM (2006) The cellular mechanisms by which adenosine evokes release of nitric oxide from rat aortic endothelium. J Physiol 570:85-96.

Rogel A, Bromberg Y, Sperling O and Zoref-Shani E (2005) Phospholipase C is involved in the adenosine-activated signal transduction pathway conferring protection against iodoacetic acid-induced injury in primary rat neuronal cultures. Neurosci Lett 373:218-221.

Roman RJ (2002) P-450 metabolites of arachidonic acid in the control of cardiovascular function. Physiol Rev 82:131-185.

Roman RJ, Maier KG, Sun CW, Harder DR and Alonso-Galicia M (2000) Renal and cardiovascular actions of 20-hydroxyeicosatetraenoic acid and epoxyeicosatrienoic acids. Clin Exp Pharmacol Physiol 27:855-865.

Rump LC, Jabbari TJ, von Kugelgen I and Oberhauser V (1999) Adenosine mediates nitric-oxide-independent renal vasodilation by activation of A2A receptors. $J$ Hypertens 17:1987-1993.

Sakwe AM, Rask L and Gylfe E (2005) Protein kinase C modulates agonist-sensitive release of $\mathrm{Ca} 2+$ from internal stores in HEK293 cells overexpressing the calcium sensing receptor. J Biol Chem 280:4436-4441. 
Sato A, Terata K, Miura H, Toyama K, Loberiza FR, Jr., Hatoum OA, Saito T, Sakuma I and Gutterman DD (2005) Mechanism of vasodilation to adenosine in coronary arterioles from patients with heart disease. Am J Physiol Heart Circ Physiol 288:H1633-1640.

Schubert R, Noack T and Serebryakov VN (1999) Protein kinase C reduces the KCa current of rat tail artery smooth muscle cells. Am J Physiol 276:C648-658.

Schutz W, Schrader J and Gerlach E (1981) Different sites of adenosine formation in the heart. Am J Physiol 240:H963-970.

Schwartzman ML, Falck JR, Yadagiri P and Escalante B (1989) Metabolism of 20hydroxyeicosatetraenoic acid by cyclooxygenase. Formation and identification of novel endothelium-dependent vasoconstrictor metabolites. $J$ Biol Chem 264:11658-11662.

Sharifi Sanjani M, Zhou X, Asano S, Tilley SL, Ledent C, Teng B, Dick GM and Mustafa SJ (2013) Interactions between A2A adenosine receptors, hydrogen peroxide, and KATP channels in coronary reactive hyperemia. Am J Physiol Heart Circ Physiol.

Shim JO, Shin CY, Lee TS, Yang SJ, An JY, Song HJ, Kim TH, Huh IH and Sohn UD (2002) Signal transduction mechanism via adenosine A1 receptor in the cat esophageal smooth muscle cells. Cell Signal 14:365-372.

Singh TU, Choudhury S, Parida S, Maruti BS and Mishra SK (2012) Arachidonic acid inhibits Na-K-ATPase via cytochrome P-450, lipoxygenase and protein kinase Cdependent pathways in sheep pulmonary artery. Vascul Pharmacol 56:84-90.

Sodhi K, Wu CC, Cheng J, Gotlinger K, Inoue K, Goli M, Falck JR, Abraham NG and Schwartzman ML (2010) CYP4A2-induced hypertension is 20- 
hydroxyeicosatetraenoic acid- and angiotensin II-dependent. Hypertension 56:871-878.

Sudhahar V, Shaw S and Imig JD (2010) Epoxyeicosatrienoic acid analogs and vascular function. Curr Med Chem 17:1181-1190.

Sun CW, Alonso-Galicia M, Taheri MR, Falck JR, Harder DR and Roman RJ (1998) Nitric oxide-20-hydroxyeicosatetraenoic acid interaction in the regulation of $\mathrm{K}+$ channel activity and vascular tone in renal arterioles. Circ Res 83:1069-1079.

Sun CW, Falck JR, Harder DR and Roman RJ (1999) Role of tyrosine kinase and PKC in the vasoconstrictor response to 20-HETE in renal arterioles. Hypertension 33:414418.

Sundseth SS, Alberta JA and Waxman DJ (1992) Sex-specific, growth hormoneregulated transcription of the cytochrome $\mathrm{P} 4502 \mathrm{C} 11$ and $2 \mathrm{C} 12$ genes. J Biol Chem 267:3907-3914.

Szentmiklosi AJ, Ujfalusi A, Cseppento A, Nosztray K, Kovacs P and Szabo JZ (1995) Adenosine receptors mediate both contractile and relaxant effects of adenosine in main pulmonary artery of guinea pigs. Naunyn Schmiedebergs Arch Pharmacol 351:417-425.

Tabrizchi R and Bedi S (2001) Pharmacology of adenosine receptors in the vasculature. Pharmacol Ther 91:133-147.

Talukder MA, Morrison RR and Mustafa SJ (2002) Comparison of the vascular effects of adenosine in isolated mouse heart and aorta. Am J Physiol Heart Circ Physiol 282:H49-57. 
Tawfik HE, Schnermann J, Oldenburg PJ and Mustafa SJ (2005) Role of A1 adenosine receptors in regulation of vascular tone. Am J Physiol Heart Circ Physiol 288:H1411-1416.

Toth P, Rozsa B, Springo Z, Doczi T and Koller A (2011) Isolated human and rat cerebral arteries constrict to increases in flow: role of 20-HETE and TP receptors. J Cereb Blood Flow Metab.

Tracey WR, Magee W, Masamune H, Oleynek JJ and Hill RJ (1998) Selective activation of adenosine A3 receptors with N6-(3-chlorobenzyl)-5'-Nmethylcarboxamidoadenosine (CB-MECA) provides cardioprotection via KATP channel activation. Cardiovasc Res 40:138-145.

Tucker AL, Jia LG, Holeton D, Taylor AJ and Linden J (2000) Dominance of G(s) in doubly G(s)/G(i)-coupled chimaeric A(1)/A(2A) adenosine receptors in HEK-293 cells. Biochem J 352 Pt 1:203-210.

Vallon V, Muhlbauer B and Osswald H (2006) Adenosine and kidney function. Physiol Rev 86:901-940.

Wang Y, Yang JN, Arner A, Boels PJ and Fredholm BB (2010) Adenosine A(1) receptors and vascular reactivity. Acta Physiol (Oxf) 199:211-220.

Williams JM, Murphy S, Burke M and Roman RJ (2010) 20-hydroxyeicosatetraeonic acid: a new target for the treatment of hypertension. J Cardiovasc Pharmacol 56:336-344.

Wu CC and Schwartzman ML (2011) The role of 20-HETE in androgen-mediated hypertension. Prostaglandins Other Lipid Mediat 96:45-53.

Xia XM, Zeng X and Lingle CJ (2002) Multiple regulatory sites in large-conductance calcium-activated potassium channels. Nature 418:880-884. 
Yasuda H, Lindorfer MA, Myung CS and Garrison JC (1998) Phosphorylation of the G protein gamma12 subunit regulates effector specificity. J Biol Chem 273:2195821965.

Yasuda H, Lindorfer MA, Woodfork KA, Fletcher JE and Garrison JC (1996) Role of the prenyl group on the $\mathrm{G}$ protein gamma subunit in coupling trimeric $\mathrm{G}$ proteins to A1 adenosine receptors. J Biol Chem 271:18588-18595.

Zhou XB, Wulfsen I, Utku E, Sausbier U, Sausbier M, Wieland T, Ruth P and Korth M (2009) Dual role of protein kinase C on BK channel regulation. Proc Natl Acad Sci U S A 107:8005-8010.

Zhou Y, Huang H, Chang HH, Du J, Wu JF, Wang CY and Wang MH (2006) Induction of renal 20-hydroxyeicosatetraenoic acid by clofibrate attenuates high-fat dietinduced hypertension in rats. J Pharmacol Exp Ther 317:11-18.

Zou AP, Fleming JT, Falck JR, Jacobs ER, Gebremedhin D, Harder DR and Roman RJ (1996) 20-HETE is an endogenous inhibitor of the large-conductance $\mathrm{Ca}(2+)$ activated K+ channel in renal arterioles. Am J Physiol 270:R228-237. 


\section{CHAPTER TWO: ADENOSINE A1 RECEPTORS LINK TO SMOOTH MUSCLE CONTRACTION VIA CYP4a, PKC- $\alpha$ AND ERK1/2}

\section{Abstract}

Adenosine induces contraction of smooth muscle through $A_{1}$ adenosine receptor $\left(\mathrm{A}_{1} \mathrm{AR}\right)$, possibly via generation of arachidonic acid-derived metabolite (20-HETE) by Сур4a. 20-HETE is important in regulation of vascular tone. We tested the hypothesis that $\mathrm{A}_{1} \mathrm{AR}$ contraction of smooth muscle depends on Cyp4a through PKC- $\alpha-$ ERK 1/2 pathway. Experiments included isometric tension recordings of aortic contraction and Western blots of signaling molecules in wild type (WT) and $\mathrm{A}_{1} \mathrm{AR}$ knockout $\left(\mathrm{A}_{1} \mathrm{KO}\right)$ mice. Vascular responses for adenosine agonists and 20-HETE were obtained in both WT and $\mathrm{A}_{1} \mathrm{KO}$ mice aortae and mesenteric arteries. 20-HETE formation was evaluated in-vitro from WT and $\mathrm{A}_{1} \mathrm{KO}$ mice aortae. In addition, vascular responses to adenosine agonists with Cyp4a inhibitor and to 20-HETE with PKC- $\alpha$ and ERK1/2 inhibitors were studied in mice aortae. Immunoblots revealed higher Cyp4a levels in WT than $\mathrm{A}_{1}$ KO. HET0016 (Cyp4a inhibitor, $10^{-5} \mathrm{M}$ ) dramatically reduced 5'-N-ethylcarboxamide adenosine (NECA, adenosine analog)induced contraction in WT $\left(-4.02 \pm 1.2 \%\right.$ to $3.9 \pm 0.7 \%$ at $\left.10^{-6} \mathrm{M}, \mathrm{p}<0.05\right)$, and enhanced relaxation in $\mathrm{A}_{1} \mathrm{KO}\left(16.1 \pm 3.5 \%\right.$ to $28.9 \pm 6.6 \%$ at $\left.10^{-6} \mathrm{M}, \mathrm{p}<0.05\right)$. Also, 2chloro- $\mathrm{N}^{6}$-cyclopentyladenosine (CCPA, an $\mathrm{A}_{1} \mathrm{AR}$ agonist)-elicited contraction was significantly blunted with HET0016 in WT $\left(-36.1 \pm 1.9 \%\right.$ to $-9.4 \pm 2.9 \%$ at $10^{-6} \mathrm{M}$, $\mathrm{p}<0.05)$ with no effect in $\mathrm{A}_{1}$ KO. 20 -HETE $\left(10^{-7} \mathrm{M}\right)$ induced contraction was higher in WT than $\mathrm{A}_{1} \mathrm{KO}$ in aortae $(33.4 \pm 2.9 \%$ vs. $23.9 \pm 2.4 \%)$ as well as mesenteric arteries $(10.5 \pm 1.52 \%$ vs. $0.3 \pm 1.6 \%)$. This contraction was abated in WT and $\mathrm{A}_{1} \mathrm{KO}$ by 
Gö6976 (PKC- $\alpha$ inhibitor) and PD98059 (ERK1/2 inhibitor). PKC- $\alpha$, p-ERK1/2 and total ERK1/2 protein levels were higher in WT than $\mathrm{A}_{1} \mathrm{KO}(\mathrm{p}<0.05)$, and Cyp2c29 was upregulated in $A_{1} K O$. Our data indicate that $A_{1} A R$ mediates smooth muscle contraction via CYP4a and a PKC- $\alpha-E R K 1 / 2$ pathway. These data suggest a relationship between $\mathrm{A}_{1} \mathrm{AR}$ and Cyp4a, and may have important implications in cardiovascular disorders. 


\section{Introduction}

Adenosine is an extracellular signaling molecule that affects heart rate, coronary blood flow, and blood pressure (Drury and Szent-Gyorgyi, 1929). Adenosine alters vascular tone by binding to one of the four G-protein coupled receptors: $A_{1}, A_{2 A}, A_{2 B}$ and $A_{3}$. Activation of $A_{1}$ and $A_{3}$ receptors contracts vascular smooth muscle, in part, by inhibiting adenylyl cyclase through pertussis toxin-sensitive $\mathrm{G}_{\mathrm{i}}$ protein (Abbracchio et al., 1995; Tawfik et al., 2005; Jacobson and Gao, 2006). In contrast, activation of $A_{2 A}$ and $\mathrm{A}_{2 \mathrm{~B}}$ receptors relaxes smooth muscle, in part, by stimulating adenylyl cyclase (Abbracchio et al., 1995). In the case of $A_{2 A}$, receptors, this process occurs through $G_{s}$ and $\mathrm{G}_{\text {olf }}$ proteins, whereas $A_{2 B}$ receptors utilize $G_{s}$ and $G_{q}$ proteins (Abbracchio et al., 1995). In addition to $G$ protein signaling, activation of adenosine receptors also leads to the metabolism of arachidonic acid and the production of myriad signaling molecules (Cheng et al., 2004).

Metabolites of arachidonic acid regulate smooth muscle tone, including prostaglandins, thromoboxanes, leukotrienes, and hydroxyeicosatetraenoic acids (HETEs) (Hoagland et al., 2001; Roman, 2002; Miyata and Roman, 2005). Two subfamilies of cytochrome P450 (CYP) enzymes metabolize arachidonic acid: CYPepoxygenases and $\omega$-hydroxylases (Miyata and Roman, 2005). The CYP-epoxygenases produce epoxyeicosatrienoic acids (EETs), which relax smooth muscle. In contrast, the w-hydroxylases such as CYP4a and CYP4f produce 20-HETE, which contracts smooth muscle (Harder et al., 1994; Zou et al., 1996; Lange et al., 1997; Nayeem et al., 2008; Ponnoth et al., 2012a). The mechanisms linking CYP4a to smooth muscle contraction, however, are not entirely clear, especially in regard to adenosine $\mathrm{A}_{1}$ receptor activation. 
20-HETE-induced contraction of smooth muscle appears to involve protein kinase C (PKC), Src-type tyrosine kinase, rho kinase and mitogen activated protein kinase (MAPK) pathways (Lange et al., 1997; Sun et al., 1999; Obara et al., 2002; Williams et al., 2010). We have demonstrated previously that $A_{1}$ receptor stimulation is linked to PKC- $\alpha$ and ERK1/2 activation in coronary artery smooth muscle (Ansari et al., 2009). Gaps in our knowledge remain to be addressed, the most important of which pertain to whether $\mathrm{A}_{1}$-dependent activation of PKC- $\alpha$ and ERK1/2 results in smooth muscle contraction. Thus, the aim of the present study was to delineate mechanisms downstream of $\mathrm{A}_{1}$ receptor activation that lead to smooth muscle contraction. We tested the hypothesis that adenosine $\mathrm{A}_{1}$ receptors contract smooth muscle through a pathway involving CYP4a, PKC- $\alpha$, and ERK1/2. 


\section{Methods}

Animals: Some of the $\mathrm{A}_{1} \mathrm{KO}$ mice were obtained from Dr. Jurgen Schnermann (NIDDK, NIH) on C57BL/6 background. C57BL/6 (WT) mice were purchased from The Jackson Laboratory (Bar Harbor, ME). Equal number of males and females of 14-18 weeks of age were used in our studies, as no gender differences were observed in the responses to the pharmacological agents used. The Institutional Animal Care and Use Committee of West Virginia University approved this study.

Isometric tension: Following anesthesia with pentobarbital sodium $(100 \mathrm{mg} / \mathrm{kg}$, i.p.), the aorta was removed and cut into 3-4 mm rings. Rings were mounted on stainless steel wires and suspended in $10 \mathrm{ml}$ organ baths filled with Krebs-Henseleit buffer containing (in mM): $118 \mathrm{NaCl}, 4.8 \mathrm{KCl}, 1.2 \mathrm{MgSO}_{4}, 1.2 \mathrm{KH}_{2} \mathrm{PO}_{4}, 25 \mathrm{NaHCO}_{3}, 11$ glucose and $2.5 \mathrm{CaCl}_{2}$. Baths were maintained at $37^{\circ} \mathrm{C}$ and bubbled with $95 \% \mathrm{O}_{2}$ and $5 \%$ $\mathrm{CO}_{2}$ (pH 7.4). Rings were equilibrated for 90 min under a resting tension of $1 \mathrm{~g}$. Rings were contracted with $50 \mathrm{mM} \mathrm{KCl}$ twice to check viability. Rings were then treated with submaximal phenylephrine $(\mathrm{PE} ; 1 \mu \mathrm{M})$ to obtain a stable contraction and integrity of the vascular endothelium was confirmed by relaxation to acetylcholine $(1 \mu \mathrm{M})$. Tension was monitored continuously with a digital acquisition system and analyzed using Acknowledge 3.5.7 software (BIOPAC). Our laboratory previously validated all methods (Tawfik et al., 2005; Ansari et al., 2007a; Ponnoth et al., 2008; Ansari et al., 2009).

Concentration-response curves for 5'-N-ethylcarboxamido adenosine (NECA; 10-

$\left.{ }^{11}-10^{-5} \mathrm{M}\right), 2$-chloro-N (6) cyclo-pentyl-adenosine (CCPA; $10 \mathrm{pM}$ to $\left.10 \mu \mathrm{M}\right)$ were run in parallel in aortic rings from $\mathrm{WT}$ and $\mathrm{A}_{1} \mathrm{KO}$ mice. In all experiments, drugs were administered to yield the next higher concentration only when the previous response reached steady state. 20-HETE (Cayman Chemical; Ann Arbor, MI) concentration- 
response curves were constructed, but in some experiments a single concentration (100 nM) was used as described previously (Alonso-Galicia et al., 1998; Obara et al., 2002; Wu and Schwartzman, 2011; Singh et al., 2012). Inhibitors of CYP4a (HET0016; Cayman Chemical), PKC- $\alpha$, (Gö6976; Calbiochem; La Jolla, CA), and ERK1/2 (PD98059; Calbiochem) were added 30 min prior to contraction with PE $\left(10^{-6} \mathrm{M}\right)$ and present throughout the experiments. Inhibitor concentrations were determined by others and us (Loufrani et al., 1999; Ansari et al., 2001; Cogolludo et al., 2003; Ding et al., 2004; Sakwe et al., 2005; Nayeem et al., 2008; Ansari et al., 2009; Chang et al., 2009; Matsumoto et al., 2011; Ponnoth et al., 2012a). Acetylcholine and PE were dissolved in distilled water, while NECA, CCPA, HET0016, Gö6976, and PD98059 were dissolved in DMSO. We have shown that previously these vehicles have no effect on smooth muscle contraction (Ansari et al., 2007a). 20-HETE was dissolved in ethanol and had no effect on the vasoconstrictive properties of the drug. Percentage of contraction was determined as a percent change from the maximum phenylephrine (PE) response. If $\mathrm{A}=$ maximum total tension in the presence of PE; B = maximum total tension when a drug is added after $\mathrm{PE} ; \mathrm{C}=$ minimum passive tension determined after the experiment, after a final wash; $\mathrm{D}$ $=\mathrm{PE}-$ induced active tension $=\mathrm{A}$ minus $\mathrm{C}$. Thus, $\%$ contraction $=[(\mathrm{B}-\mathrm{A}) / \mathrm{D}] \mathrm{X} 100 \%$

Immunoblots: Aortae from WT and $\mathrm{A}_{1} \mathrm{KO}$ mice were homogenized with $150 \mu \mathrm{L}$ RIPA, (Cell Signaling Technology); $20 \mathrm{mM}$ Tris-HCl (pH 7.5),(150 mM NaCl, $1 \mathrm{mM}$ $\mathrm{Na}_{2}$ EDTA, $1 \mathrm{mM}$ EGTA, $1 \% \mathrm{NP}-40,1 \%$ sodium deoxycholate, $2.5 \mathrm{mM}$ sodium pyrophosphate, $1 \mathrm{mM}$ beta-glycerophosphate, $1 \mathrm{mM} \mathrm{Na} \mathrm{VO}_{4}, 1 \mu \mathrm{g} / \mathrm{ml}$ leupeptin), vortexed, and centrifuged for $10 \mathrm{~min}$ at $13,800 \mathrm{~g}$ at $4^{\circ} \mathrm{C}$. Supernatants were stored at $80^{\circ} \mathrm{C}$. Protein was measured using the Bradford dye procedure with bovine serum albumin (BSA) as a standard (Bio-Rad Laboratories; Hercules, CA). The protein extract 
was divided into aliquots and stored at $-80^{\circ} \mathrm{C}$. Samples $(25 \mu \mathrm{g}$ of total protein) were loaded on slab gels (10\% acrylamide; $1 \mathrm{~mm}$ thick), separated by SDS-PAGE, and transferred to nitrocellulose membranes (Hybond-ECL). Protein transfer was confirmed by visualization of prestained molecular weight markers (Bio-Rad). Membranes were blocked with 5\% nonfat dry milk and incubated with primary antibody. 1:1000 dilutions were used for CYP4a (Abcam; Cambridge MA) and PKC- $\alpha$ (BD Transduction Labs; San Diego, CA) antibodies, while 1:500 dilutions were used for total ERK1/2 and p-ERK1/2 (both from Santa Cruz Biotechnology; Santa Cruz, CA) and 1:5000 for Cyp2c29 (Dr. Darryl C. Zeldin(NIH/NIEHS)). The phospho-ERK1/2 blots were stripped at room temperature for 15 minutes and re-probed for total-ERK1/2. All membranes were stripped and probed for $\beta$-actin (Santa Cruz); this served as an internal control to normalize protein expression in each lane. Secondary antibodies were horseradish peroxidase-conjugated. Membranes were developed using enhanced chemiluminescence (AmershamBioSciences) and X-ray film.

\section{Measurement and analysis of 20-HETE formation rates}

Equal numbers of male and female aortae were isolated on ice from WT and $\mathrm{A}_{1} \mathrm{KO}$ mice. Microsomes were prepared by pooling the aortae and homogenizing in 50mM/L Tris buffer (pH7.4) containing $150 \mathrm{mM} \mathrm{KCl,} 0.1 \mathrm{mM}$ DTT, $1 \mathrm{mM}$ EDTA and $20 \%$ glycerol. Each sample consisted of six aortae $(n=1)$. Microsomal fractions were isolated by differential centrifugation as previously described by us (Nayeem et al., 2008) and Dr. Poloyac's group (Poloyac et al., 2006; Miller et al., 2009) . Microsomal fractions containing $100 \mu \mathrm{g}$ total protein and $25 \mu \mathrm{M}$ AA were incubated in $1 \mathrm{ml}$ of $0.12 \mathrm{M} \mathrm{KH}_{2} \mathrm{PO}_{4}$ buffer containing $5 \mathrm{mM} \mathrm{MgCl}_{2}$. Reactions were initiated by addition of $1 \mathrm{mM} \mathrm{NADPH}$ at $37^{\circ} \mathrm{C}$ for an hour and were terminated by placing the reaction tubes on ice. $0.75 \mathrm{ng}$ of 20 - 
HETE d6 was added as an internal standard to each sample. HETE metabolites were separated along with others via reverse phase ultra-performance liquid chromatography

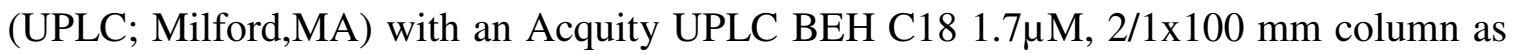
previously described (Miller et al., 2009). Analysis was carried out on the TSQ operated in negative electrospray ionization-selected reaction monitoring mode with unit resolutions at both Q1 and Q3 set at 0.70 full width at half maximum. The selected reaction monitoring transitions that were monitored were as follows: 20-HETE mass-tocharge ratio $(\mathrm{m} / \mathrm{z}) 319.3 \rightarrow 245.0$; and 20-HETE-d6 (internal standard) $\mathrm{m} / \mathrm{z} 325.3 \rightarrow$ 251.0. Collision energy was optimized for each transition and ranged from 11 to $25 \mathrm{eV}$ with a total scan time of $0.01 \mathrm{~s}$. Parameters were optimized to obtain the highest $[\mathrm{M}-\mathrm{H}]^{+}$ ion abundance and were as follows: capillary temperature $270^{\circ} \mathrm{C}$, spray voltage $3,800 \mathrm{kV}$, and source collision-induced dissociation set at $1 \mathrm{~V}$. Sheath gas, auxiliary gas, and ion sweep gas pressures were set to 60,50 , and $0 \mathrm{psi}$, respectively. Collision gas pressure was set to 1.2 mTorr. The data from two separate experiments have been combined for a significant ' $\mathrm{n}$ '.

\section{Real Time PCR}

The aortic tissues from WT and $\mathrm{A}_{1} \mathrm{KO}$ were processed for total RNA isolation using the TRI reagent (MRC, Cincinnati, OH) followed by purification of the RNA in aqueous phase and removal of genomic DNA by an RNeasy Plus Micro Kit (QIAGEN, Hilden, Germany).This was followed by conversion of $0.5 \mathrm{~g}$ of total RNA into cDNA using High Capacity cDNA archive kit (Applied Biosystems, Foster City, CA) in a total volume of $20 \mu 1$. Real-time PCR was performed using an ABI PRISM 7300 Detection System (Applied Biosystems) using Taqman Universal Mastermix (Applied Biosystems, Branchburg, NJ) according to the instructions of the manufacturer. The reaction volume 
(20 $\mu$ l) consisted of $10 \mu \mathrm{l}$ of $2 \mathrm{X}$ Taqman Universal Mastermix, $4 \mu \mathrm{l}$ of cDNA, and $1 \mu 1$ of 20X FAM-labeled Taqman gene expression assay. For the real-time PCR of the concerned genes (Cyp4a10, $\mathrm{A}_{1} \mathrm{AR}, \mathrm{A}_{2 \mathrm{~A}} \mathrm{AR}, \mathrm{A}_{2 \mathrm{~B}} \mathrm{AR}$ and $\mathrm{A}_{3} \mathrm{AR}$ ), the Taqman inventoried assays on-demand gene expression products were purchased from Applied Biosystems (Foster City, CA). 18S rRNA (ribosomal RNA) was used as an endogenous control. The fold difference in expression of target cDNA was determined using the comparative cycle threshold (Ct) method as described earlier(Livak and Schmittgen, 2001).

Statistical Analysis: Data are expressed as mean \pm SEM from $n$ number of mice. Concentration-response curves and 20-HETE/inhibitor experiments were analyzed by 2 way analysis of variance (ANOVA). Comparisons of two densitometry values were made with unpaired t-tests. $\mathrm{P}<0.05$ was considered significant in all tests. 


\section{Results}

\section{Cyp4a protein levels in $\mathrm{WT}$ and $\mathrm{A}_{1} \mathrm{KO}$ mice:}

Immunoblot analysis showed a $\sim 25 \%$ decrease in Cyp $4 a$ protein levels in $\mathrm{A}_{1} \mathrm{KO}$ as compared to WT $(74.5 \pm 3.7 \%$ vs. $100 \pm 10.61 \%$, Fig. $2.1 \mathrm{~A})$. However, there was no difference in Cyp4a10 mRNA levels (Fig 2.1B)

\section{Effect of Cyp4a inhibitor (HET0016) on NECA and CCPA induced vascular responses in aorta:}

To verify if Cyp $4 a$ plays a role in $\mathrm{A}_{1} \mathrm{AR}$ mediated vasoconstriction, we investigated the effect of Cyp4a inhibitor, HET0016 on NECA (a non-selective adenosine agonist) and CCPA (an $\mathrm{A}_{1} \mathrm{AR}$ agonist)-induced vascular responses. We found that NECA-elicited contraction in WT $\left(-4.02 \pm 1.2 \% ; 10^{-6} \mathrm{M}\right.$; Fig. $2.1 \mathrm{~A}$; closed squares) was changed to significant relaxation in the $\mathrm{A}_{1} \mathrm{KO}$ mice $\left(16.1 \pm 3.5 \% ; 10^{-6} \mathrm{M}\right.$; Fig $2.1 \mathrm{~A}$; closed circles). Relative to the WT mice, HET0016 alleviated the NECA-induced contraction (3.97 \pm $0.7 \% ; 10^{-6} \mathrm{M}$; Fig $2.1 \mathrm{~A}$; open squares). Similarly, in $\mathrm{A}_{1} \mathrm{KO}$ mice, Cyp $4 a$ inhibition enhanced the relaxation from $16.05 \pm 3.5 \%$ to $28.96 \pm 6.6 \%$ (fig2.1A; open circles) compared to the litter-matched controls at $10^{-6} \mathrm{M}$ NECA (Fig 2.1A). There was a significant difference between the treated WT and $\mathrm{A}_{1} \mathrm{KO}$ with HET0016 (3.97 $\pm 0.7 \%$ vs. $28.96 \pm 6.6 \% ; 10^{-6} \mathrm{M}$ NECA; Fig 2.1A). CCPA-evoked contraction in the WT $(-36.1 \pm$ $1.9 \% ; 10^{-6} \mathrm{M}$; Fig $2.2 \mathrm{~B}$; open circles) was significantly changed to relaxation in the $\mathrm{A}_{1} \mathrm{KO}$ (11.4 $\pm 8.5 \% ; 10^{-6} \mathrm{M}$; closed circles). Pharmacological inhibition of Cyp4a (HET0016) blunted the CCPA induced contraction by $26.7 \%$ from $-36.1 \pm 1.9 \%$ to $-9.4 \pm 2.9 \%$ $(\mathrm{p}<0.05)$ at $10^{-6} \mathrm{M}$ in WT mice (Fig 2.2B; open squares). CCPA induced vascular responses were unaltered in both the treated and untreated $\mathrm{A}_{1} \mathrm{KO}$ littermates as shown in 
Fig 2.2B (closed squares). However, on treatment with the Cyp $4 a$ inhibitor, the CCPA response showed higher relaxation in $\mathrm{A}_{1} \mathrm{KO}\left(11.3 \pm 8.5 \% ; 10^{-6} \mathrm{M}\right)$ as compared to WT ($\left.9.4 \pm 2.9 \% ; 10^{-6} \mathrm{M}\right)$. ACh-induced response in WT $(47 \pm 2 \%)$ was not significantly different from $\mathrm{A}_{1} \mathrm{KO}(51 \pm 3 \%, \mathrm{p}>0.05)$ (Fig 2.2C). These results are consistent with those demonstrated by Wang $\mathrm{Y}$ et al (Wang et al., 2010)in mouse aorta

\section{Effect of 20-HETE on vascular responses, and 20-HETE formation rates in $\mathrm{A}_{1} \mathrm{KO}$ and WT animals:}

We further investigated the effect of 20-HETE on vascular responses in both WT and $\mathrm{A}_{1} \mathrm{KO}$ mice aortae and mesenteric arteries, and determined the in vitro 20-HETE formation rate in WT and $\mathrm{A}_{1} \mathrm{KO}$ aortic microsomes. As shown in Fig 2.3E., 20-HETE elicited vasoconstriction in the WT, showed similar trend of being significantly higher in both the aortae $(59.18 \pm 6.09 \%$ vs. $41.32 \pm 4.49 \%)$ and the mesenteric arteries $(10.2 \pm 1.52 \%$ vs. $0.3 \pm 1.6 \%)$, compared to $\mathrm{A}_{1} \mathrm{KO}$ mice. We observed an unexpected increase in the contraction on addition of lowest concentration of $10^{-11} \mathrm{M}$ 20-HETE in both WT and $\mathrm{A}_{1} \mathrm{KO}$ (Fig. 2.3D) mice aortae. Furthermore, 20-HETE formation rate was observed to be significantly higher in aortic microsomes from WT $(0.31 \pm 0.012 \mathrm{pg} / \mathrm{mol} / \mathrm{min})$ than the $\mathrm{A}_{1} \mathrm{KO}(0.23 \pm 0.018 \mathrm{pg} / \mathrm{mol} / \mathrm{min} ;$ Fig 2.4).

\section{Cyp2c29protein levels in WT and $\mathrm{A}_{1} \mathrm{KO}$ mice:}

Measurement of Cyp2c29 showed an up-regulation of the protein by $73 \%$ in $\mathrm{A}_{1} \mathrm{KO}$ mice aortae, relative to its WT counterpart $(172.7 \pm 12.1 \%$ vs. $100 \pm 23.04 \%$, Fig $2.5 \mathrm{~A})$. Subsequently, we determined the effect of Cyp-epoxygenases inhibition on CCPA induced aortic response. In the WT littermates, MSPPOH (Cyp-epoxygenases inhibitor; 
$10^{-5} \mathrm{M}$ ), increased the CCPA-induced contraction by $15.3 \%$ from $-32.5 \pm 1.7 \%$ to -47.8 .4$ $\pm 6 \%$ at $10^{-7} \mathrm{M}$ (Fig. 4). Likewise, in $\mathrm{A}_{1} \mathrm{KO}$ mice, $\mathrm{MSPPOH}$ treatment increased the vascular response by $19.3 \%$ from $5.8 \pm 4 \%$ to $-13.5 \pm 7.4 \%$ at $10^{-7} \mathrm{M}$ (Fig. $2.5 \mathrm{~B}$ ).

\section{Role of PKC- $\alpha$ in 20-HETE-induced contraction}

20-HETE (100 nM), a CYP4a product, contracted aortae from WT and $\mathrm{A}_{1} \mathrm{KO}$ mice (Fig. 2.6B); however, the contractile response was less in aortic rings from $\mathrm{A}_{1} \mathrm{KO}$ mice. Inhibition of PKC- $\alpha$ (100 nM Gö6976) reduced 20-HETE-induced contraction in aortic rings from both WT (by 37\%) and $\mathrm{A}_{1} \mathrm{KO}$ (by 29\%) mice (Fig. 2.6B). The relative inhibitory effect of Gö6976 was the same in aortic rings from WT and $\mathrm{A}_{1} \mathrm{KO}$ mice (Fig. 2.6C). PKC- $\alpha$ protein was expressed in aortae from WT and $\mathrm{A}_{1} \mathrm{KO}$ mice (Fig. 2.6A); however, the expression of PKC- $\alpha$ was lower (by 47\%) in $\mathrm{A}_{1} \mathrm{KO}$ mice $(\mathrm{p}<0.05)$.

\section{Role of ERK1/2 kinase in 20-HETE-induced contraction}

The CYP4a product 20-HETE (100 $\mathrm{nM}$ ) contracted aortic rings from both WT and $\mathrm{A}_{1} \mathrm{KO}$ mice (Fig. 2.7B); however, the contractile response was less in aortae from $\mathrm{A}_{1} \mathrm{KO}$ mice. Inhibition of ERK1/2 (1 $\mu \mathrm{M}$ PD98059) reduced 20-HETE-induced contraction in aortae from WT (by 48\%) and $\mathrm{A}_{1} \mathrm{KO}$ (by 36\%) mice (Fig. 2.7B). The relative inhibitory effect of PD98059 was similar in aortic rings from WT and $\mathrm{A}_{1} \mathrm{KO}$ mice (Fig. 2.7C). ERK1/2 protein was expressed in aortae from $\mathrm{WT}$ and $\mathrm{A}_{1} \mathrm{KO}$ mice (Fig. 2.7A); however, the expression of total ERK (by 35\%) and phospho-ERK (by 15\%) were lower in $\mathrm{A}_{1} \mathrm{KO}$ mice $(\mathrm{p}<0.05)$. 


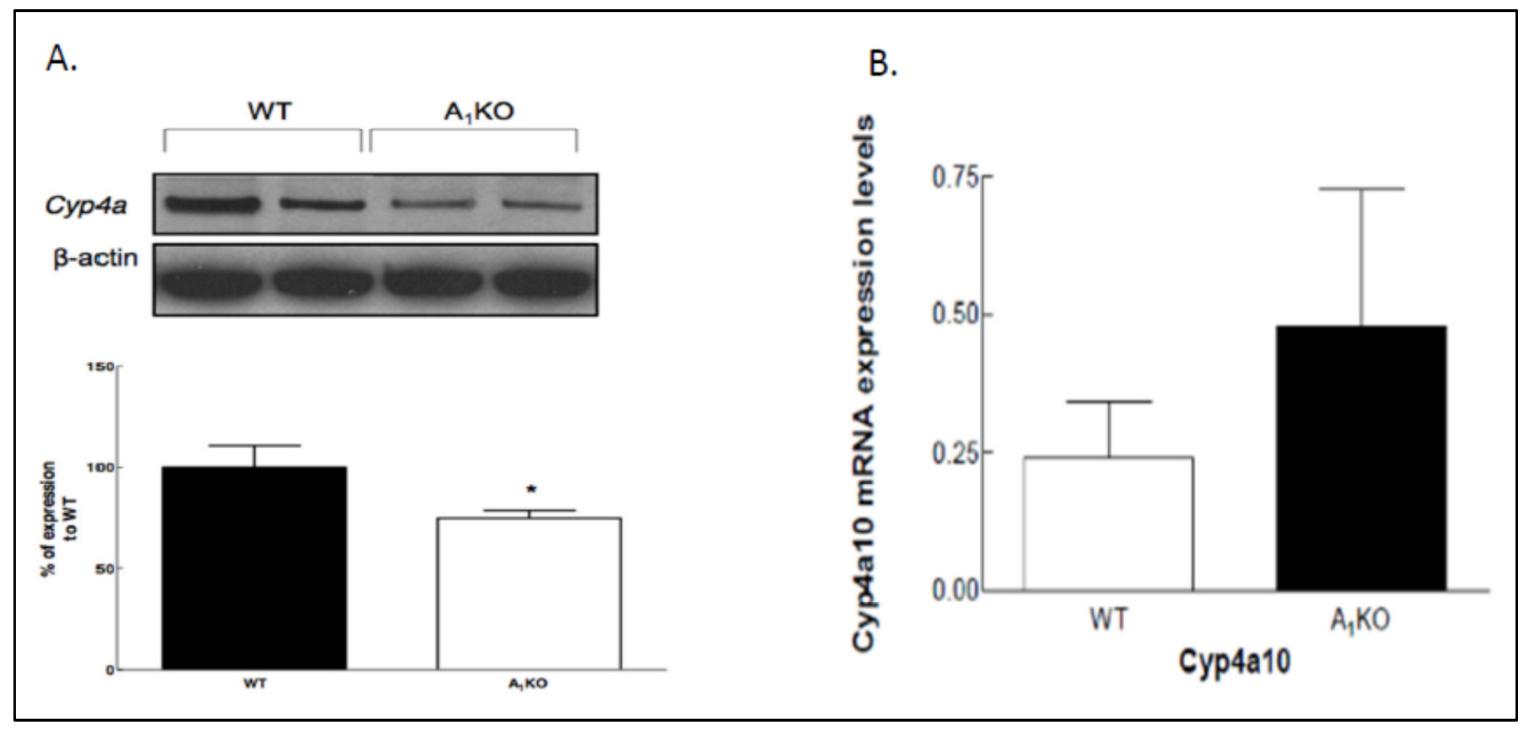

Figure 2.1: Cyp4a protein and mRNA levels in WT and $A_{1} K O$.

Western blots for CYP4a expression in the aorta (A). Mouse isoform Cyp4a10 levels in WT and $\mathrm{A}_{1} \mathrm{KO}$ mice aortae $(\mathrm{B})$. Data are expressed as mean \pm SEM; $\mathrm{n}=6-8 \mathrm{mRNA}$ level. $* \mathrm{p}<0.05$ between $\mathrm{WT}$ and $\mathrm{A}_{1} \mathrm{KO}$ 


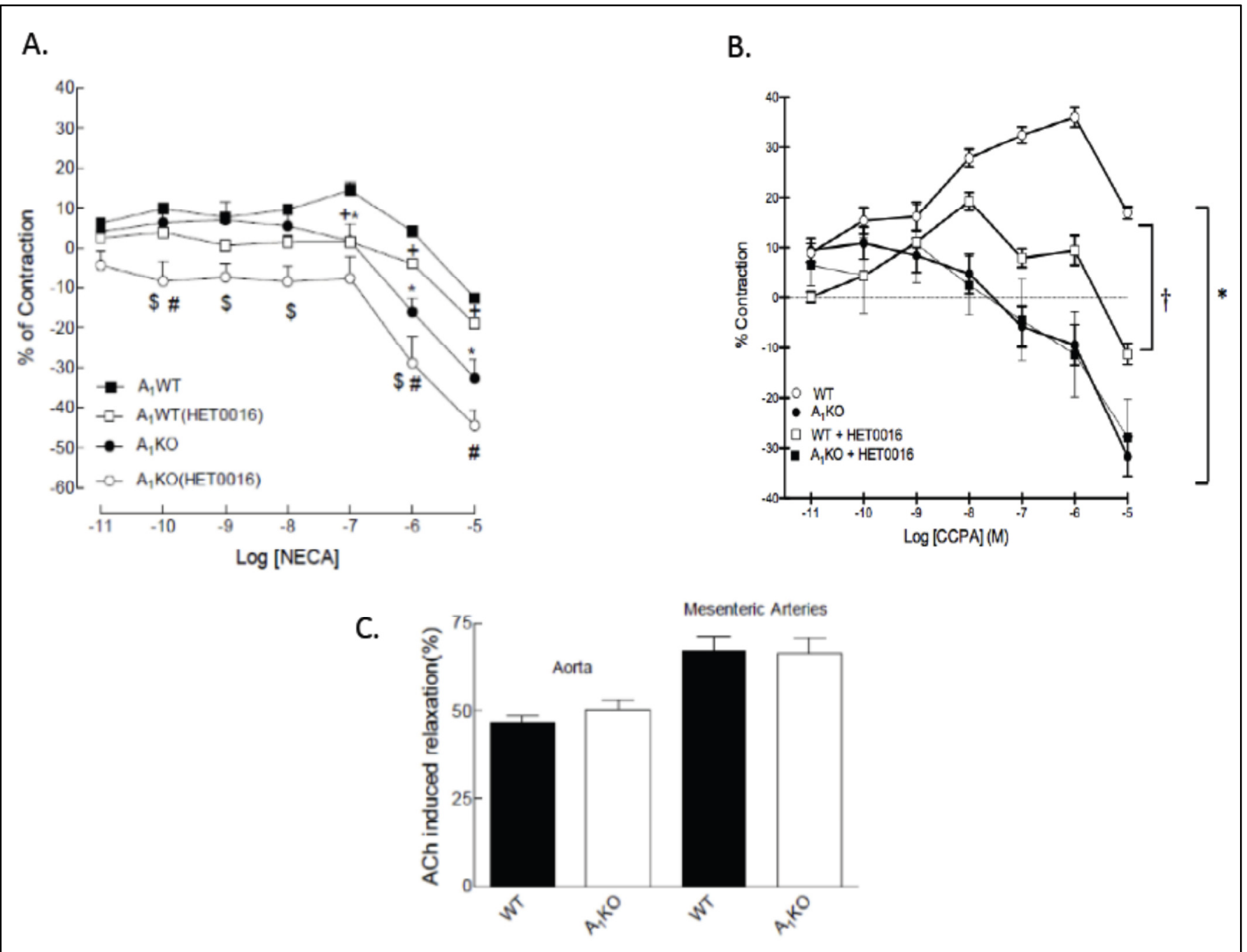

Figure 2.2: Effect of Adenosine Receptor agonists' and acetylcholine -induced responses in WT and $A_{1} K O$ aortae and mesenteric arteries

(A) Non selective adenosine agonist NECA mediated responses with Cyp4a inhibitor (10 $\mu \mathrm{M}$ HET0016); ${ }^{+} \mathrm{p}<0.05$ between $\mathrm{A}_{1} \mathrm{KO}$ and WT; ${ }^{*} \mathrm{p}<0.05$ between WT + HET0016 and WT; ${ }^{\#}$ p $<0.05$ between $\mathrm{A}_{1} \mathrm{KO}+$ HET0016 and WT + HET0016; ${ }^{\$} \mathrm{p}<0.05$ between $\mathrm{A}_{1} \mathrm{KO}+$ HET0016 and $A_{1} K O$. Data are expressed as mean \pm SEM (n=6-12); (B) The $A_{1}$-selective agonist CCPA-mediated contractions with CYP4a inhibitor $(10 \mu \mathrm{M}$ HET0016), $* \mathrm{p}<0.05$ between WT and $\mathrm{A}_{1} \mathrm{KO}$ and ${ }^{\dagger} \mathrm{p}<0.05$ between WT and WT + HET0016 (n=4-12). (C) Acetylcholine (ACh) responses in $\mathrm{WT}$ and $\mathrm{A}_{1} \mathrm{KO}$ mice aortae and mesenteric arteries responses. ${ }^{*} \mathrm{p}<0.05$ between $\mathrm{WT}$ and $\mathrm{A}_{1} \mathrm{KO}(\mathrm{n}=6-12)$. 


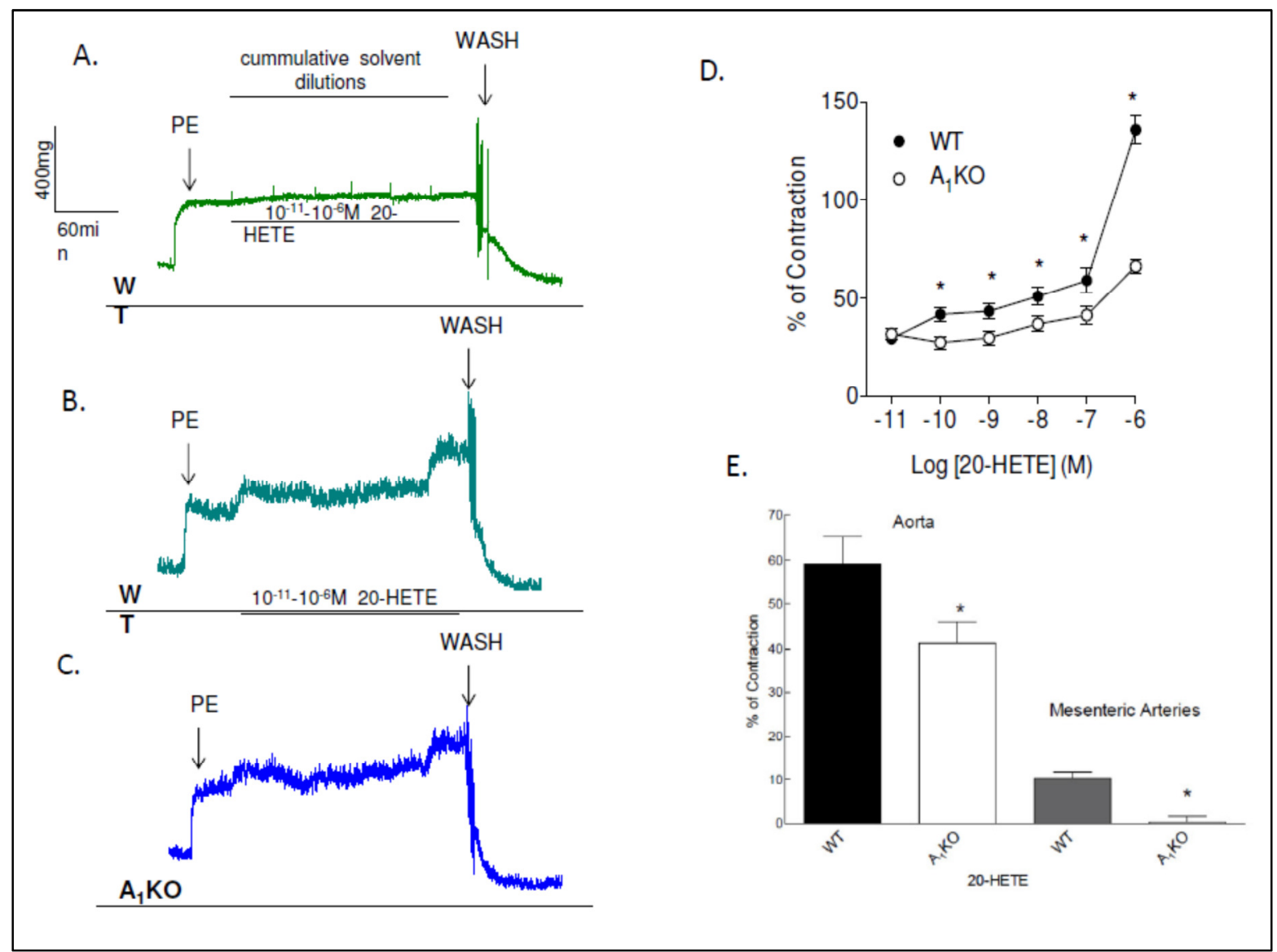

Figure 2.3: Effect of the CYP4a product, 20-HETE on smooth muscle contraction from WT and $A_{1} K O$ mice.

(A) Representative traces for concentration response curve for solvent (ethanol) in WT mice aortae $(n=4)$. (B) Representative traces for concentration response curve for 20HETE in WT mice aortae. (C) Representative traces for concentration response curve for 20-HETE in $\mathrm{A}_{1} \mathrm{KO}$ mice aortae. (D) Exogenous 20-HETE contracts aortic smooth muscle in a concentration-dependent manner. ${ }^{*} \mathrm{p}<0.05$ between WT and $\mathrm{A}_{1} \mathrm{KO}$ mice $(\mathrm{n}=8-12)$ (E) Exogenous 20-HETE responses in aortae and mesenteric arteries. Data are expressed as mean \pm SEM $(n=8) . * p<0.05$ compared to the WT in the respective tissue 


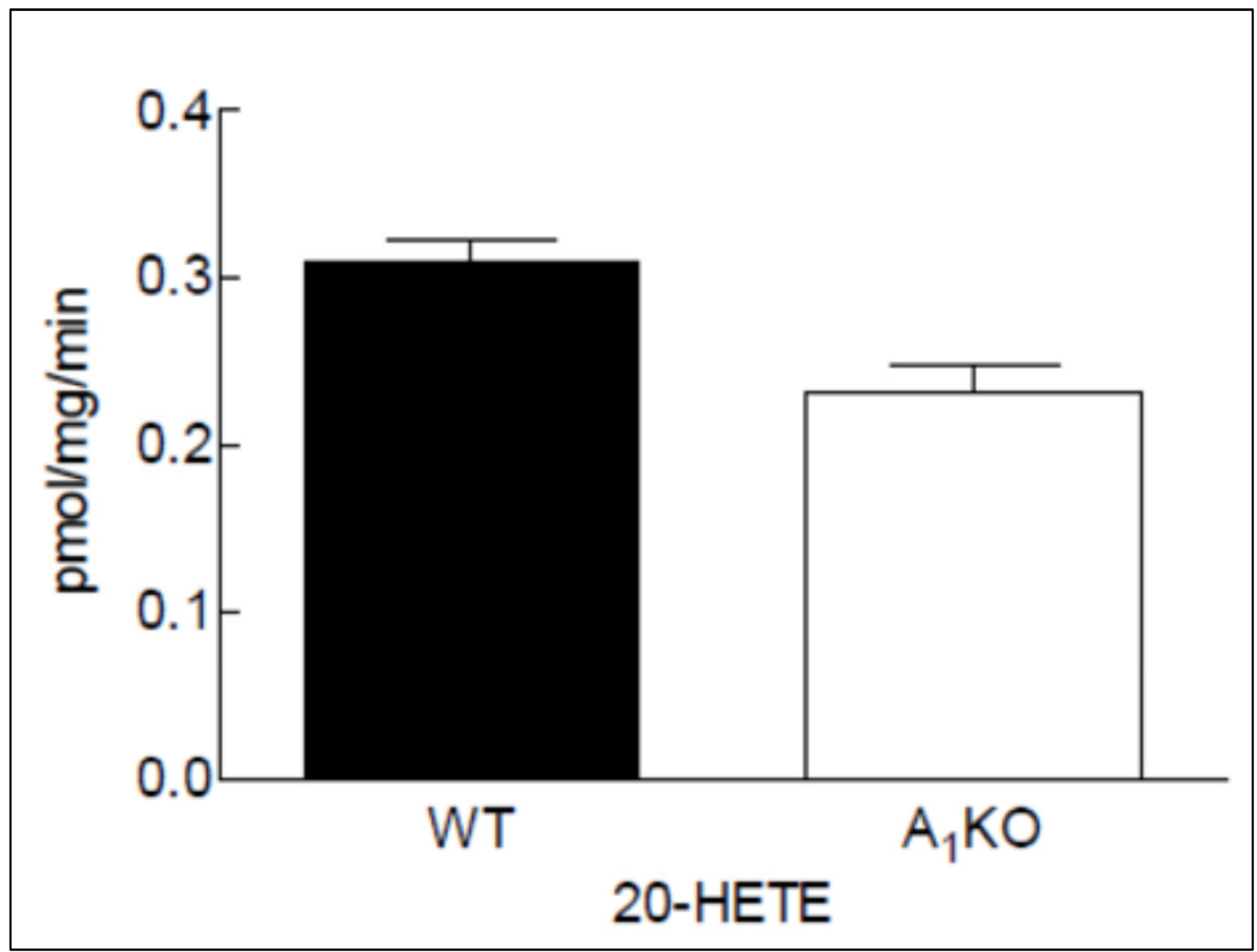

Figure 2.4: 20-HETE formation rate in microsomes from $\mathrm{WT}$ and $\mathrm{A}_{1} \mathrm{KO}$ mice $\operatorname{aortae}(n=6-8)$

Data are expressed as mean \pm SEM. 


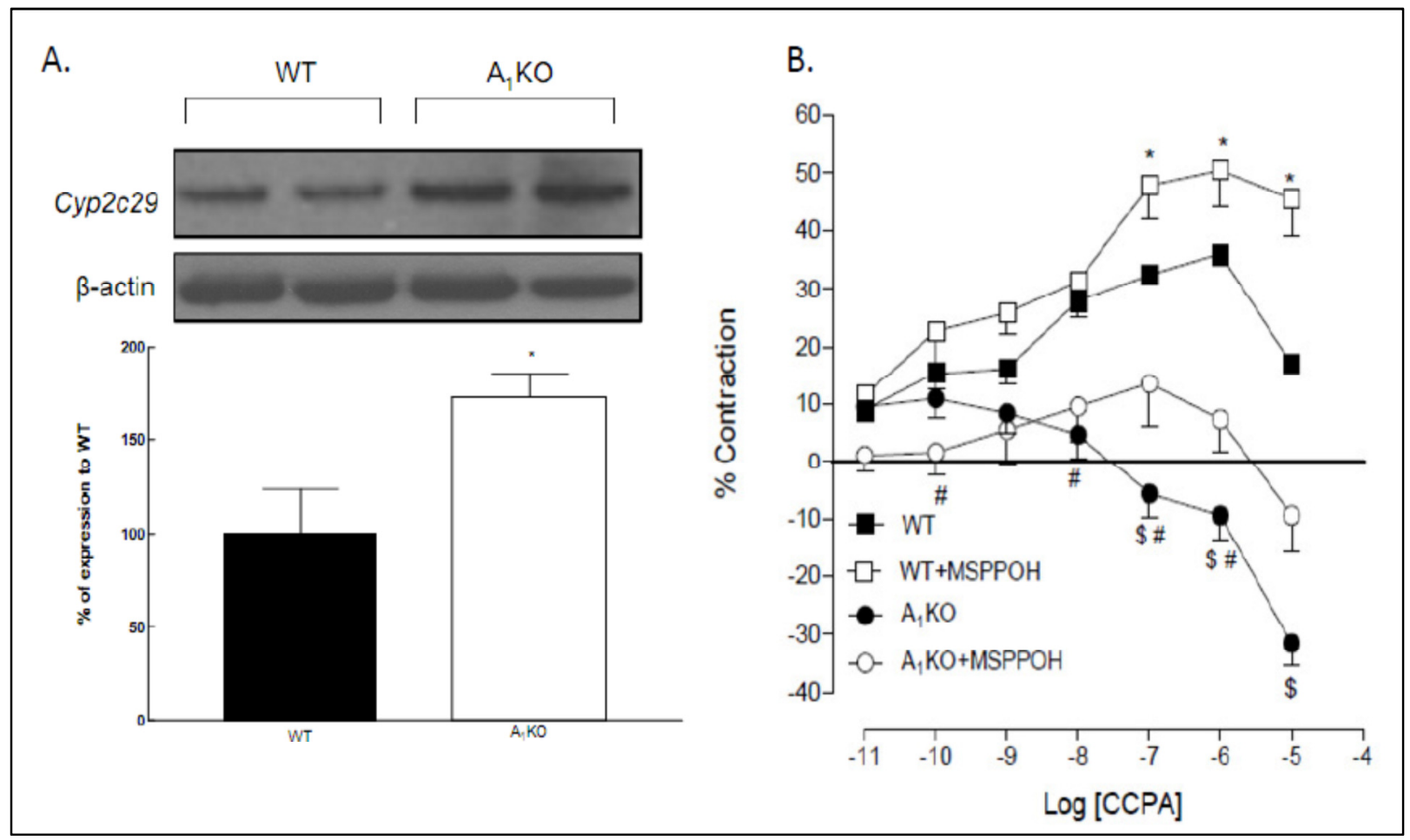

Figure 2.5: Role of Cyp2c29 in WT and $\mathrm{A}_{1} \mathrm{KO}$

(A) Cyp $2 c 29$ protein levels in aortae from $\mathrm{WT}$ and $\mathrm{A}_{1} \mathrm{KO}$. Data are expressed as mean \pm SEM and are presented as representative blot from 6 individual samples, ${ }^{*} \mathrm{p}<0.05$ as compared to WT (B) Effect of Cyp-epoxygenase inhibitor (MSPPOH; $10^{-5} \mathrm{M}$ ) on CCPA induced vascular response: Data are expressed as mean \pm SEM $(n=10) . * p<0.05$ compared to the WT, ${ }^{\#} \mathrm{p}<0.05$ compared to WT $+\mathrm{MSPPOH},{ }^{\$} \mathrm{p}<0.05$ compared to $\mathrm{A}_{1} \mathrm{KO}$. 


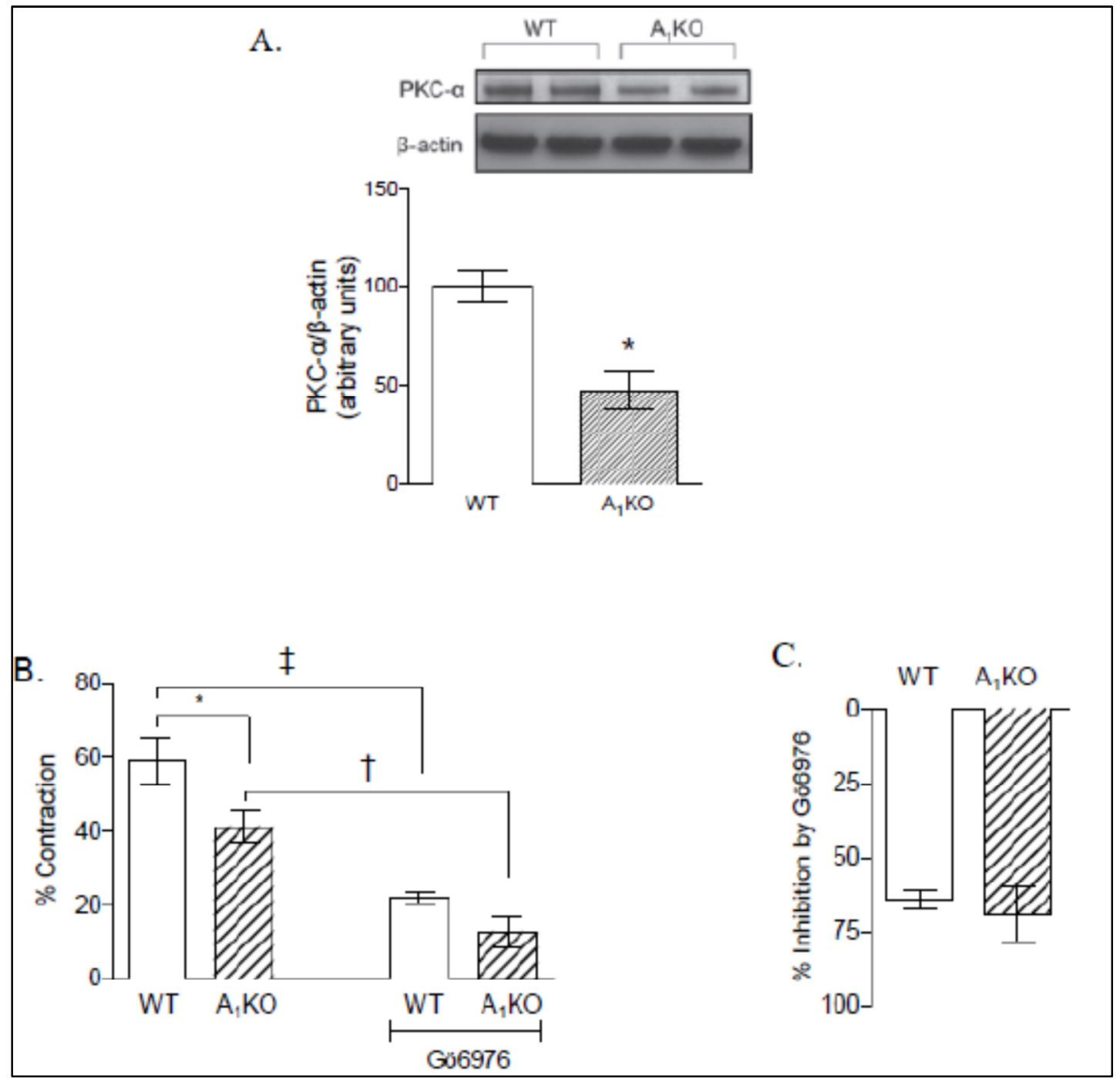

Figure 2.6: Effect of on PKC- $\alpha$ on $W T$ and $A_{1} K O$ contractile responses to 20-HETE.

(A) Western blots for PKC- $\alpha$ protein and $\beta$-actin; (B) Aortic smooth muscle contractions in response to $100 \mathrm{nM} 20$-HETE are shown for WT and $\mathrm{A}_{1} \mathrm{KO}$ mice with or without inhibition of PKC- $\alpha$ (100 nM Gö6976); (C) The inhibitory effect of Gö6976 on 20-HETE-induced contractions is equivalent in WT and $\mathrm{A}_{1} \mathrm{KO}$ mice, suggesting that the relative importance of PKC- $\alpha$ is unchanged. Data are expressed as mean \pm SEM; $n=6-16$ mice; ${ }^{*} \mathrm{p}<0.05$ between WT and $A_{1} K O ;{ }^{\dagger} p<0.05$, WT, $A_{1} K O$ vs. WT + Gö6976 \& $A_{1} K O+G o ̈ 6976$. 


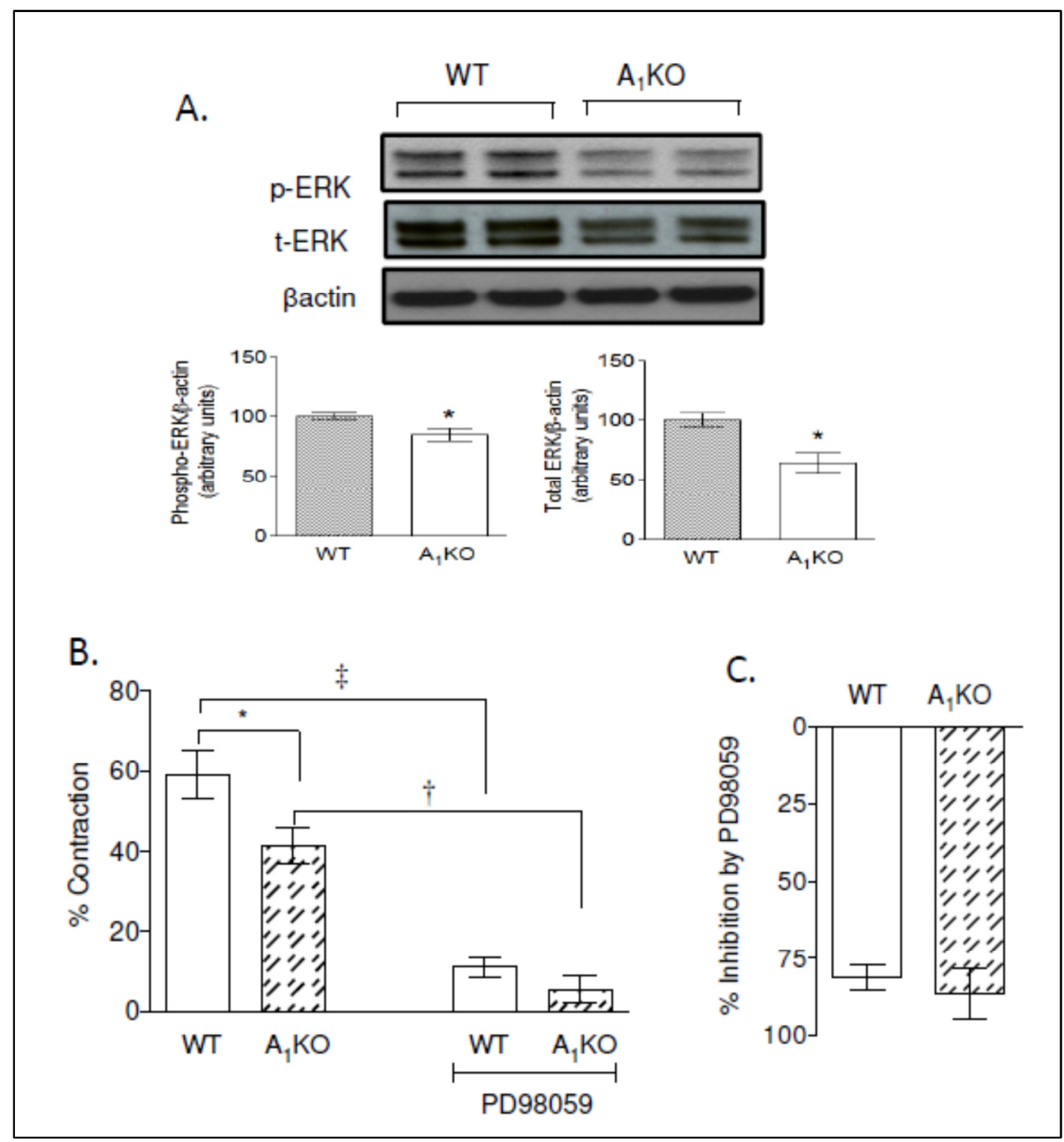

Figure 2.7 Effect of ERK 1/2 on WT and A1KO mice aortae contractile responses

(A) Western blots for total ERK1/2, phosphor-ERK1/2 and $\beta$-actin expression in the aorta; (B) Aortic contractile responses to $100 \mathrm{nM} 20$-HETE are shown for WT and $\mathrm{A}_{1} \mathrm{KO}$ mice with or without inhibition of ERK1/2 (1 $\mu \mathrm{M}$ PD98059); (C) The inhibitory effect of PD98059 on 20-HETE-induced contractions. $\mathrm{n}=8-16 * \mathrm{p}<0.05$ between $\mathrm{WT}$ and $\mathrm{A}_{1} \mathrm{KO}$; ${ }^{\ddagger} \mathrm{p}<0.05, \mathrm{WT}, \mathrm{A} 1 \mathrm{KO}$ vs. WT + PD98059 \& A $\mathrm{A}_{1} \mathrm{KO}+$ PD98059, respectively. 


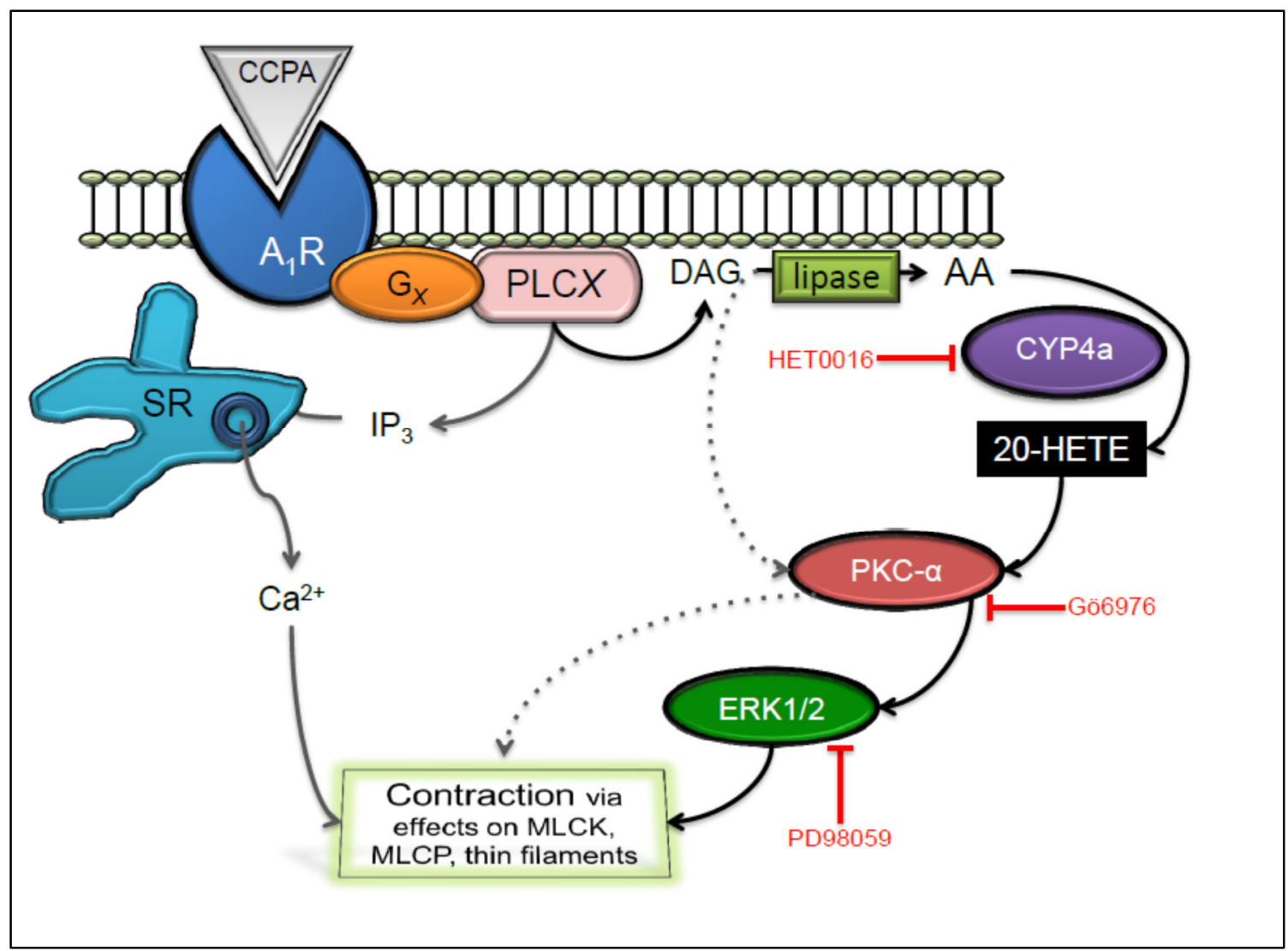

Figure 2.8 Adenosine $A_{1}$ receptors link to smooth muscle contraction via CYP4a, PKC-a, and ERK1/2.

This figure illustrates our understanding of signaling from the $\mathrm{A}_{1}$ receptor to smooth muscle contraction. Adenosine $A_{1}$ receptors $\left(A_{1} R\right)$ are sensitive to CCPA and coupled to phospholipase $\mathrm{C}$ (PLCX) by G-proteins $\left(\mathrm{G}_{X}\right)$. Candidates for PLCX include PLC $\beta 1$, PLC $\beta 3$, and PLC $\gamma 1$, while candidates for $G_{X}$ include $G_{i}, G_{0}, G_{q}, G_{11}$ as well as $G-\beta \gamma$ subunits (Jacobson and Gao, 2006; Ansari et al., 2009). PLCX produces two second messengers from phosphatidylinositol 4,5 bisphosphate: diacylglycerol (DAG) and inositol 1,4,5-trisphosphate $\left(\mathrm{IP}_{3}\right.$, which releases $\mathrm{Ca}^{2+}$ from the sarcoplasmic reticulum; SR). DAG can be metabolized by di- and monoacylglycerol lipases to produce arachidonic acid (AA). CYP4a metabolizes AA into 20-HETE, which activates PKC- $\alpha$ (DAG is also an activator; PKC- $\beta$ and $\gamma$ isoforms are also expressed (Ansari et al., 2009). The ERK1/2 pathway is activated downstream of PKC- $\alpha$. The culmination of this signaling is to contract smooth muscle through effects on, e.g., myosin light chain kinase (MLCK), myosin light chain phosphatase (MLCP), and thin filament regulatory proteins. Inhibiting CYP4a with HET0016 blocks CCPA-induced smooth muscle contraction (Fig. 2.1 and 2.2). Gö6976 and PD98095, which inhibit PKC- $\alpha$ and ERK1/2, inhibit smooth muscle contraction in response to 20-HETE (Fig. 2.6 and Fig 2.8) 


\section{Discussion}

It is well documented that $\mathrm{A}_{1} \mathrm{AR}$ on activation mediates vasoconstriction through $G_{i}$ and $G_{o}$ proteins(Jacobson and Gao, 2006). Our data show that NECA evoked contraction in WT was lower in the $\mathrm{A}_{1} \mathrm{KO}$ mice aortae (Fig. 2a). We also observed in the aortic tissue that CCPA-induced contraction was completely abolished in $\mathrm{A}_{1} \mathrm{KO}$ (Fig. 2b). Our results are consistent with previous findings from our laboratory and others (Tawfik et al., 2005; Wang et al., 2010) . We have found that NECA and CCPA induced responses in the mesenteric arteries are similar to those found in the aortae as reported earlier from our laboratory (Teng et al., 2011).The contractile responses elicited by these adenosine agonists are similar to those found in a wide variety of systems like mouse afferent arterioles (Hansen et al., 2003), human cultured prostatic stromal cells (Preston et al., 2004), cat esophageal smooth muscle cells (Shim et al., 2002), guinea pig aorta (Ford and Broadley, 1999) and mouse coronary artery cells, heart, aorta and carotid artery (Prentice et al., 2002; Talukder et al., 2002; Ansari et al., 2009)

The first evidence of an interaction between $\mathrm{A}_{1} \mathrm{AR}$ and Cyp4a is the significantly lower levels of Cyp $4 a$ protein expression in the $\mathrm{A}_{1} \mathrm{KO}$ mice as compared to the WT (Fig.1). To further examine, the functional interplay between Cyp4a and $\mathrm{A}_{1} \mathrm{AR}$, we studied the effect of Cyp $4 a$ inhibition on adenosine agonists' elicited contractile responses in WT and $\mathrm{A}_{1} \mathrm{KO}$ mice aortae. Due to the similar responses to adenosine agonists in the mice mesenteric arteries and aortae, we used aortae for these studies. HET0016 dramatically reduced the contraction responses induced by NECA, in both the WT and the $\mathrm{A}_{1} \mathrm{KO}$ mice aortae (Fig. 2a). Moreover, there was a 
significantly higher relaxation observed in NECA-induced aortic responses in $\mathrm{A}_{1} \mathrm{KO}$ with the pharmacological inhibition of Cyp4a (Fig. 2a).This suggested that Cyp4a may play a part in the $A_{1} A R$ mediated vasoconstriction. The above findings were confirmed when Cyp4a inhibitor, HET0016 attenuated the vasoconstriction evoked by the $A_{1}$ agonist, CCPA in the WT with no significant difference in the treated (HET0016) and untreated $\mathrm{A}_{1} \mathrm{KO}$ tissues (Fig. 2b). However, we observed a significant difference in both the NECA and CCPA induced vascular responses in the HET0016 treated WT and $\mathrm{A}_{1} \mathrm{KO}$ tissues (Fig 2). These results clearly implicate a role for Cyp4a in $\mathrm{A}_{1} \mathrm{AR}$ mediated vasoconstriction. These findings are congruent with previous studies in our lab (Nayeem et al., 2009) and others as well, which have shown an inhibition of Cyp4a with HET0016 in renal interlobar arteries from Sprague Dawley rats (Sodhi et al., 2010) and human and rat cerebral arteries(Toth et al., 2011).

20-HETE is a potent vasoconstrictor of renal, mesenteric, skeletal and cerebral arterioles across several species (Roman, 2002). Several investigators have shown that in both circulatory and pulmonary vascular beds, 20-HETE mediates vasoconstriction by uncoupling of nitric oxide synthase, resulting in reduction of endothelial dependent relaxation (Frisbee et al., 2000; Singh et al., 2007; Cheng et al., 2008). Our data show that 20-HETE vascular responses in aortae and mesenteric arteries are lower in $\mathrm{A}_{1} \mathrm{KO}$ as compared to the WT (Fig.3a). Moreover, the Cyp4a functional activity evaluated by the 20-HETE formation rates in the aortic microsomes were found to be lower in the $\mathrm{A}_{1} \mathrm{KO}$ (Fig $3 \mathrm{~b}$ ) as compared to the WT mice. This further underscores the role of Cyp $4 a$ in $\mathrm{A}_{1} \mathrm{AR}$ mediated vasoconstriction. 
There is a dynamic interplay between the metabolites of the two pathways of Cyp450 enzymes, EETs and 20-HETEs, in the modulation of vascular homeostasis. EETs are considered to be endothelium-derived hyperpolarizing factors that induce hyperpolarization of the endothelial cells and vascular smooth muscle cells resulting in vasodilation. 20-HETE in vascular smooth muscle causes vasoconstriction by depolarization of vascular smooth muscle cell (Miyata and Roman, 2005)(Miyata and Roman, 2005)(Miyata and Roman, 2005). As Cyp4a and Cyp2c products have functionally antagonistic effects, we investigated if $C y p 2 c 29$ has any relationship to the $\mathrm{A}_{1} \mathrm{AR}$ mediated vascular responses. We observed that Cyp2c29 protein levels were significantly up- regulated in $\mathrm{A}_{1} \mathrm{KO}$ mice as compared to the WT (Fig S.3.5). Since we have seen an up-regulation of $C y p 2 c 29$ in $\mathrm{A}_{1} \mathrm{KO}$ compared to WT mice, it is quite possible that relaxation observed in $\mathrm{A}_{1} \mathrm{KO}$ mice by Cyp $4 a$ inhibition is due to Cyp $2 c 29$ product EETs and due to the inhibition of Cyp4a that limits the production of 20-HETE. This observation was confirmed by the enhanced CCPA mediated vasoconstriction in the presence of the Cyp-epoxygenase inhibitor, MSPPOH (Fig.S.3.6). We have shown earlier that Сyp4a protein levels are up regulated with MSPPOH treatment (Nayeem et al., 2008). In the WT, although Cyp-epoxygenases were inhibited, a higher contraction observed with MSPPOH treatment is due to higher levels of Cyp4a and in the $\mathrm{A}_{1} \mathrm{KO}$, the higher vascular response is due to inhibition of the Cyp-epoxygenases. Thus, the downregulation of Cyp $4 a$ and an up-regulation of Cyp2c29 protein levels promote the relaxation observed in the $\mathrm{A}_{1} \mathrm{KO}$ littermates. This inverse relationship between Cyp $4 a$ and Cyp2c is consistent with findings from other investigators in rat afferent arterioles and preglomerular arterioles (Hercule and Oyekan, 2000; Imig et al., 2000). 
Several studies have reported that 20-HETE promotes constrictor responses by activating PKC, Src type tyrosine kinase, rho kinase and the MAPK pathways (Lange et al., 1997; Sun et al., 1999; Obara et al., 2002; Williams et al., 2010). Moreover, adenosine subsequent to binding to its receptors induces signaling cascades by activating MAPK through G-protein coupled mechanism. In addition, our laboratory has shown that in mouse coronary artery smooth muscle cells, $\mathrm{A}_{1} \mathrm{AR}$ mediates vasoconstriction through PKC- $\alpha$, leading to phosphorylation of $\mathrm{p} 42 / 44$ mitogen activated protein kinase (MAPK) via PLC $\beta$-III (Ansari et al., 2009). Given this evidence, we investigated the effect of PKC- $\alpha$ and ERK1/2 inhibition on 20HETE induced contraction in both WT and $\mathrm{A}_{1} \mathrm{KO}$ mice. The basal protein levels of PKC- $\alpha$, p-ERK1/2 and total ERK1/2 are higher in the WT as compared to the knockout littermates (Figs. 5 and 7). The lower PKC- $\alpha$ and p-ERK1/2 protein levels in the $\mathrm{A}_{1} \mathrm{KO}$ mice are consistent with our previous findings in the $\mathrm{A}_{1} \mathrm{KO}$ mouse coronary artery smooth muscle cells (Ansari et al., 2009). Exogenous administration of 20-HETE produced similar higher contraction response in WT than the $\mathrm{A}_{1} \mathrm{KO}$, both in the mice aortae and mesenteric arteries (Fig 3), thus, suggesting that the signaling proteins downstream of 20-HETE are essential in Cyp4a modulation of $A_{1} A R$ mediated vasoconstriction. The use of a specific PKC- $\alpha$ blocker, Gö6976, attenuated the 20-HETE mediated vasoconstrictor response in WT and $\mathrm{A}_{1} \mathrm{KO}$ mice aortae (Fig. 6). Similarly, pharmacological inhibition of ERK1/2 with PD98059 decreased the 20-HETE-elicited contraction in the WT and almost abolished the contractile tone in the $\mathrm{A}_{1} \mathrm{KO}$ (Fig. 8). However, the greater blockade of the vasoconstrictor responses with ERK inhibitor than with the PKC- $\alpha$ inhibitor implies 
that MAPK pathway activation may involve several kinases like PKA, PKC, rho kinases or Ras activation or a cross talk between the different tyrosine kinase receptors. These data substantiate the role of PKC- $\alpha$ and ERK1/2 in $\mathrm{A}_{1} \mathrm{AR}$ mediated vasoconstriction through 20-HETE.

Our current understanding of signaling for $\mathrm{A}_{1} \rightarrow$ CYP4a $\rightarrow$ PKC- $\alpha \rightarrow$ ERK pathway is summarized in Fig. 4. $\mathrm{A}_{1}$ receptor activation with, e.g., CCPA, activates CYP4a which metabolizes AA into 20-HETE. CCPA-induced contractions are almost entirely dependent upon signaling through CPY4a, as inhibition with HET0016 abrogates contraction (Fig. 3.1A). 20-HETE activates PKC- $\alpha$ and this is integral to contraction, as Gö6976 blocks the response (Fig. 3.3). The ERK1/2 pathway is activated downstream of PKC- $\alpha$, as Gö6976 blocks ERK activation (Ansari et al., 2009) and PD98059 blocks the contraction (Fig. 3.3). ERK1/2 integrates the signaling for contraction and transduces it to, e.g., myosin light chain kinase (MLCK), myosin light chain phosphatase (MLCP), and thin filament regulatory proteins.

In summary, we have shown that $\mathrm{A}_{1}$ receptor activation leads to smooth muscle contraction via CYP4a, PKC- $\alpha$, and ERK 1/2. Because $\mathrm{A}_{1}$ receptors and 20-HETE are implicated in a variety of cardiovascular disorders, a better understanding of this pathway will be important for identifying therapeutic targets and treatment opportunities. 


\section{References}

Abbracchio MP, Brambilla R, Ceruti S, Kim HO, von Lubitz DK, Jacobson KA, and Cattabeni F. G protein-dependent activation of phospholipase C by adenosine A3 receptors in rat brain. Mol Pharmacol 48: 1038-1045, 1995.

Alonso-Galicia M, Sun CW, Falck JR, Harder DR, and Roman RJ. Contribution of 20-HETE to the vasodilator actions of nitric oxide in renal arteries. Am J Physiol 275: F370-378, 1998.

Ansari HR, Husain S, and Abdel-Latif AA. Activation of p42/p44 mitogen-activated protein kinase and contraction by prostaglandin F2alpha, ionomycin, and thapsigargin in cat iris sphincter smooth muscle: inhibition by PD98059, KN-93, and isoproterenol. $J$ Pharmacol Exp Ther 299: 178-186, 2001.

Ansari HR, Nadeem A, Talukder MA, Sakhalkar S, and Mustafa SJ. Evidence for the involvement of nitric oxide in A2B receptor-mediated vasorelaxation of mouse aorta. Am J Physiol Heart Circ Physiol 292: H719-725, 2007.

Ansari HR, Teng B, Nadeem A, Roush KP, Martin KH, Schnermann J, and Mustafa SJ. A(1) adenosine receptor-mediated PKC and p42/p44 MAPK signaling in mouse coronary artery smooth muscle cells. Am J Physiol Heart Circ Physiol 297: H1032-1039, 2009.

Chang K, Xiao D, Huang X, Longo LD, and Zhang L. Chronic hypoxia increases pressure-dependent myogenic tone of the uterine artery in pregnant sheep: role of ERK/PKC pathway. Am J Physiol Heart Circ Physiol 296: H1840-1849, 2009.

Cheng MK, Doumad AB, Jiang H, Falck JR, McGiff JC, and Carroll MA. Epoxyeicosatrienoic acids mediate adenosine-induced vasodilation in rat preglomerular microvessels (PGMV) via A2A receptors. Br J Pharmacol 141: 441-448, 2004. 
Cogolludo A, Moreno L, Bosca L, Tamargo J, and Perez-Vizcaino F. Thromboxane A2-induced inhibition of voltage-gated $\mathrm{K}+$ channels and pulmonary vasoconstriction: role of protein kinase Czeta. Circ Res 93: 656-663, 2003.

Coulson R, Proch PS, Olsson RA, Chalfant CE, and Cooper DR. Upregulated renal adenosine $\mathrm{A} 1$ receptors augment $\mathrm{PKC}$ and glucose transport but inhibit proliferation. Am J Physiol 270: F263-274, 1996.

Ding Y, Schwartz D, Posner P, and Zhong J. Hypotonic swelling stimulates L-type Ca2+ channel activity in vascular smooth muscle cells through PKC. Am J Physiol Cell Physiol 287: C413-421, 2004.

Drury AN and Szent-Gyorgyi A. The physiological activity of adenine compounds with especial reference to their action upon the mammalian heart. J Physiol 68: 213-237, 1929. Ford WR and Broadley KJ. Effects of adenosine receptor agonists on induction of contractions to phenylephrine of guinea-pig aorta mediated via intra- or extracellular calcium. Gen Pharmacol 33: 143-150, 1999.

Gebremedhin D, Lange AR, Lowry TF, Taheri MR, Birks EK, Hudetz AG, Narayanan J, Falck JR, Okamoto H, Roman RJ, Nithipatikom K, Campbell WB, and Harder DR. Production of 20-HETE and its role in autoregulation of cerebral blood flow. Circ Res 87: 60-65, 2000.

Hansen PB, Castrop H, Briggs J, and Schnermann J. Adenosine induces vasoconstriction through Gi-dependent activation of phospholipase $\mathrm{C}$ in isolated perfused afferent arterioles of mice. J Am Soc Nephrol 14: 2457-2465, 2003.

Harder DR, Gebremedhin D, Narayanan J, Jefcoat C, Falck JR, Campbell WB, and Roman R. Formation and action of a P-450 4A metabolite of arachidonic acid in cat cerebral microvessels. Am J Physiol 266: H2098-2107, 1994. 
Hill KJ, Webber AC, and Hill SJ. A role of protein kinase C mu in signalling from the human adenosine A1 receptor to the nucleus. Br J Pharmacol 139: 721-732, 2003.

Hoagland KM, Maier KG, Moreno C, Yu M, and Roman RJ. Cytochrome P450 metabolites of arachidonic acid: novel regulators of renal function. Nephrol Dial Transplant 16: 2283-2285, 2001.

Jacobson KA and Gao ZG. Adenosine receptors as therapeutic targets. Nat Rev Drug Discov 5: 247-264, 2006.

Lange A, Gebremedhin D, Narayanan J, and Harder D. 20-Hydroxyeicosatetraenoic acid-induced vasoconstriction and inhibition of potassium current in cerebral vascular smooth muscle is dependent on activation of protein kinase C. J Biol Chem 272: 2734527352, 1997.

Lee HT and Emala CW. Characterization of adenosine receptors in human kidney proximal tubule (HK-2) cells. Exp Nephrol 10: 383-392, 2002.

Lo RK and Wong YH. Transcriptional activation of c-Fos by constitutively active Galpha(16)QL through a STAT1-dependent pathway. Cell Signal 18: 2143-2153, 2006.

Loufrani L, Lehoux S, Tedgui A, Levy BI, and Henrion D. Stretch induces mitogenactivated protein kinase activation and myogenic tone through 2 distinct pathways. Arterioscler Thromb Vasc Biol 19: 2878-2883, 1999.

Matsumoto T, Tostes RC, and Webb RC. Uridine adenosine tetraphosphate-induced contraction is increased in renal but not pulmonary arteries from DOCA-salt hypertensive rats. Am J Physiol Heart Circ Physiol 301: H409-417, 2011.

Miyata N and Roman RJ. Role of 20-hydroxyeicosatetraenoic acid (20-HETE) in vascular system. J Smooth Muscle Res 41: 175-193, 2005. 
Nayeem MA, Poloyac SM, Falck JR, Zeldin DC, Ledent C, Ponnoth DS, Ansari HR, and Mustafa SJ. Role of CYP epoxygenases in A2A AR-mediated relaxation using A2A AR-null and wild-type mice. Am J Physiol Heart Circ Physiol 295: H2068-2078, 2008.

Nayeem MA, Ponnoth DS, Boegehold MA, Zeldin DC, Falck JR, and Mustafa SJ. High-salt diet enhances mouse aortic relaxation through adenosine A2A receptor via CYP epoxygenases. Am J Physiol Regul Integr Comp Physiol 296: R567-574, 2009.

Obara K, Koide M, and Nakayama K. 20-Hydroxyeicosatetraenoic acid potentiates stretch-induced contraction of canine basilar artery via PKC alpha-mediated inhibition of KCa channel. Br J Pharmacol 137: 1362-1370, 2002.

Ponnoth DS, Nadeem A, and Mustafa SJ. Adenosine-mediated alteration of vascular reactivity and inflammation in a murine model of asthma. Am J Physiol Heart Circ Physiol 294: H2158-2165, 2008.

Ponnoth DS, Nayeem MA, Kunduri SS, Tilley SL, Zeldin DC, Ledent C, and Mustafa SJ. Role of omega-hydroxylase in adenosine-mediated aortic response through MAP kinase using A2A-receptor knockout mice. Am J Physiol Regul Integr Comp Physiol 302: R400-408, 2012.

Prentice DJ, Kelly MD, Ledent C, and Hourani SM. Relaxation of the mouse isolated aorta and carotid artery in response to adenosine analogues in genetically-modified mice lacking the adenosine A(2A) receptor. Naunyn Schmiedebergs Arch Pharmacol 366: 127$133,2002$.

Preston A, Frydenberg M, and Haynes JM. A1 and A2A adenosine receptor modulation of alpha 1-adrenoceptor-mediated contractility in human cultured prostatic stromal cells. Br J Pharmacol 141: 302-310, 2004. 
Randriamboavonjy V, Kiss L, Falck JR, Busse R, and Fleming I. The synthesis of 20HETE in small porcine coronary arteries antagonizes EDHF-mediated relaxation. Cardiovasc Res 65: 487-494, 2005.

Roman RJ. P-450 metabolites of arachidonic acid in the control of cardiovascular function. Physiol Rev 82: 131-185, 2002.

Sakwe AM, Rask L, and Gylfe E. Protein kinase C modulates agonist-sensitive release of $\mathrm{Ca} 2+$ from internal stores in HEK293 cells overexpressing the calcium sensing receptor. J Biol Chem 280: 4436-4441, 2005.

Shim JO, Shin CY, Lee TS, Yang SJ, An JY, Song HJ, Kim TH, Huh IH, and Sohn UD. Signal transduction mechanism via adenosine A1 receptor in the cat esophageal smooth muscle cells. Cell Signal 14: 365-372, 2002.

Singh TU, Choudhury S, Parida S, Maruti BS, and Mishra SK. Arachidonic acid inhibits Na-K-ATPase via cytochrome P-450, lipoxygenase and protein kinase Cdependent pathways in sheep pulmonary artery. Vascul Pharmacol 56: 84-90, 2012.

Sodhi K, Wu CC, Cheng J, Gotlinger K, Inoue K, Goli M, Falck JR, Abraham NG, and Schwartzman ML. CYP4A2-induced hypertension is 20-hydroxyeicosatetraenoic acid- and angiotensin II-dependent. Hypertension 56: 871-878, 2010.

Sun CW, Falck JR, Harder DR, and Roman RJ. Role of tyrosine kinase and PKC in the vasoconstrictor response to 20-HETE in renal arterioles. Hypertension 33: 414-418, 1999.

Talukder MA, Morrison RR, and Mustafa SJ. Comparison of the vascular effects of adenosine in isolated mouse heart and aorta. Am J Physiol Heart Circ Physiol 282: H49$57,2002$. 
Tawfik HE, Schnermann J, Oldenburg PJ, and Mustafa SJ. Role of A1 adenosine receptors in regulation of vascular tone. Am J Physiol Heart Circ Physiol 288: H14111416, 2005.

Toth P, Rozsa B, Springo Z, Doczi T, and Koller A. Isolated human and rat cerebral arteries constrict to increases in flow: role of 20-HETE and TP receptors. J Cereb Blood Flow Metab, 2011. 


\title{
CHAPTER THREE: ADENOSINE A RECEPTORS INHIBIT BK CHANNELS THROUGH PKC- $\alpha$ DEPENDENT MECHANISM IN MOUSE AORTIC SMOOTH MUSCLE CONTRACTION
}

\begin{abstract}
Adenosine receptors $\left(A R ; A_{1}, A_{2 A}, A_{2 B}\right.$, and $A_{3}$ ) contract and relax smooth muscle through different signaling mechanisms. Deciphering these complex responses remains difficult because relationships between AR subtypes and various end-effectors (e.g., enzymes and ion channels) remain to be identified. $\mathrm{A}_{1} \mathrm{AR}$ stimulation is associated with the production of 20-hydroxyeicosatetraenoic acid (20-HETE) and activation of protein kinase C (PKC). 20-HETE and PKC can inhibit large conductance $\mathrm{Ca}^{2+} /$ voltage-sensitive $\mathrm{K}^{+}(\mathrm{BK})$ channels that regulate smooth muscle contraction. We tested the hypothesis that activation of $\mathrm{A}_{1} \mathrm{AR}$ inhibits $\mathrm{BK}$ channels via a PKC-dependent mechanism. Patch clamp recordings and Western blots were performed using aortae of wild type (WT) and $\mathrm{A}_{1} \mathrm{AR}$ knockout $\left(\mathrm{A}_{1} \mathrm{KO}\right)$ mice. There were no differences in whole-cell $\mathrm{K}^{+}$current or $\alpha$ and $\beta 1$ subunits expression between WT and $\mathrm{A}_{1}$ KO. 20-HETE (100 nM) inhibited BK current similarly in WT and $\mathrm{A}_{1} \mathrm{KO}$ mice. NECA (5'-N-ethylcarboxamidoadenosine; $\left.10 \mu \mathrm{M}\right)$, a non-selective AR agonist, increased $\mathrm{BK}$ current in myocytes from both WT and $\mathrm{A}_{1} \mathrm{KO}$ mice, but the increase was greater in $\mathrm{A}_{1} \mathrm{KO}(52 \pm 15$ vs. $17 \pm 3 \%$; $<<0.05)$. This suggests that $\mathrm{A}_{1} \mathrm{AR}$ signaling negatively regulates $\mathrm{BK}$ channel activity. Accordingly, CCPA (2-chloro-N(6)-cyclopentyladenosine; $100 \mathrm{nM}$ ), an $\mathrm{A}_{1} \mathrm{AR}$-selective agonist, inhibited $\mathrm{BK}$ current in myocytes from WT but not $\mathrm{A}_{1} \mathrm{KO}$ mice $(81 \pm 4$ vs. $100 \pm 7 \%$ of control; $\mathrm{p}<0.05)$. Gö6976 (100 nM), a PKC $\alpha$ inhibitor, abolished the effect of CCPA to inhibit BK current (99 $\pm 3 \%$ of control). These data lead us to conclude that, in aortic smooth muscle, $A_{1} A R$ inhibits BK channel activity and that this occurs via a mechanism involving PKC $\alpha$.
\end{abstract}




\section{Introduction}

Adenosine exerts its effects through four G-protein coupled receptors: the known adenosine receptor (AR) subtypes are $A_{1}, A_{2 A}, A_{2 B}$ and $A_{3}$. These $A R$ subtypes play important roles in vascular reactivity, as $A_{1} A R$ and $A_{3} A R$ contract smooth muscle, whereas $\mathrm{A}_{2 \mathrm{~A}} \mathrm{AR}$ and $\mathrm{A}_{2 \mathrm{~B}} \mathrm{AR}$ relax smooth muscle (Fredholm et al., 2001; Tawfik et al., 2005; Jacobson and Gao, 2006; Ansari et al., 2007b; Ponnoth et al., 2009). It is well accepted that metabolites of arachidonic acid (AA) regulate vascular tone; however, only recently have these pathways been recognized to function downstream of $A_{1} A R$ and $\mathrm{A}_{2 \mathrm{~A}} \mathrm{AR}$ (Harder et al., 1997; Cheng et al., 2004; Nayeem et al., 2008; Ponnoth et al., 2012a). Epoxyeicosatrienoic acids (EETs) and 20-hydroxyeicosatetraenoic acid (20HETE) are produced from arachidonate by epoxygenases and $\omega$-hydroxylases, respectively. EETs are considered to be endothelium-derived hyperpolarizing factors that activate $\mathrm{Ca}^{2+}$-dependent $\mathrm{K}^{+}$channels and $\mathrm{Na}^{+}-\mathrm{K}^{+}$-ATPase (Roman et al., 2000). 20HETE in vascular smooth muscle functions as a second messenger to promote depolarization, $\mathrm{Ca}^{2+}$ influx, and contraction of vascular smooth muscle that acts, in part, through protein kinase C (PKC) (Miyata and Roman, 2005; Williams et al., 2010).

Ion channels are important determinants of vascular tone, as they control membrane potential and the intracellular $\mathrm{Ca}^{2+}$ concentration. Large conductance, $\mathrm{Ca}^{2+} /$ voltage-sensitive $\mathrm{K}^{+}(\mathrm{BK})$ channels participate in this electromechanical coupling (Nelson et al., 1995; Brenner et al., 2000). BK channels are activated by membrane depolarization and increases in intracellular $\mathrm{Ca}^{2+} \cdot$ 20-HETE has been shown to inhibit BK channels in canine basilar artery (Obara et al., 2002) and rat renal arterioles (Zou et al., 1996). BK channels can also be regulated by phosphorylation and are targets of PKC, which reduces open probability (Zhou et al., 2009). 
We have shown previously that activation of $A_{1} A R$ couples with the Cyp4a metabolite, 20-HETE and mediates contraction of the aortic smooth muscle through a pathway involving PKC $\alpha$ and/or p-ERK1/2. However, genetic ablation of the $\mathrm{A}_{1} \mathrm{AR}$ reduced the contractions in response to 20-HETE, in part, by reducing the expression of downstream signaling molecules (PKC $\alpha$ and p-ERK1/2) (Kunduri et al., 2013). To further understand the signaling transduction of $\mathrm{A}_{1} \mathrm{AR}$ and 20-HETE, we performed studies designed to test the hypothesis that activation of $\mathrm{A}_{1} \mathrm{AR}$ inhibits $\mathrm{BK}$ channels via a PKC-dependent mechanism. 


\section{Materials and Methods}

\section{Animals}

$\mathrm{A}_{1} \mathrm{KO}$ mice (originally obtained from Dr. Jurgen Schnermann, NIDDK, NIH) were on C57BL/6 background. $\mathrm{A}_{1} \mathrm{KO}$ mice were backcrossed 4 generations with C57BL/6 (WT); genotypes were confirmed by polymerase chain reaction. C57BL/6 (WT) mice (originally purchased from The Jackson Laboratory, Bar Harbor, ME) were bred in-house. Equal number of males and females of 14-18 weeks of age were used in our studies, as no gender differences were observed. The Institutional Animal Care and Use Committee of West Virginia University provided regulatory oversight and protocols followed guidelines set forth in The Guide for the Care and Use of Laboratory Animals (National Research Council, 2011). Mice had free access to food and water and were housed on a 12:12 hr light-dark cycle. Mice were killed with an overdose of sodium pentobarbital (150 mg/kg ip) and aortae were quickly harvested into ice-cold physiological saline solution. Adipose and connective tissue were removed under the magnification of a dissecting microscope.

Isometric tension: Isometric tension experiments were conducted with small segments of WT and $\mathrm{A}_{1} \mathrm{KO}$ mice aortae as described previously in (Kunduri SS et al, 2012). After equilibration, the responsiveness and stability of individual rings were checked by administration of PE $\left(10^{-6} \mathrm{M}\right)$ (Ansari et al., 2007b; Ponnoth et al., 2008; Ansari et al., 2009). The integrity of the vascular endothelium was assessed pharmacologically by acetylcholine (ACh, $10^{-6} \mathrm{M}$ ) (Ansari et al., 2007a; Ansari et al., 2009) to produce relaxation of PE pre-contracted rings. The rings were washed several times with Krebs-Henseleit solution and allowed to equilibrate for $60 \mathrm{~min}$ before the experimental protocol began. The concentration-response curves (CRC) for 5'-N- 
ethylcarboxamido adenosine (NECA; $\left.10^{-11}-10^{-5} \mathrm{M}\right)$ and 2-chloro-N

cyclopentyladenosine (CCPA; $\left.10^{-11}-10^{-5} \mathrm{M}\right)$ were run in parallel in aortic rings from WT and $\mathrm{A}_{1} \mathrm{KO}$ mice. In all cases, drugs were administered to yield the next higher concentration only when the response to the earlier dose reached a steady state. A single concentration of 20-HETE $\left(10^{-7} \mathrm{M}\right)$ was used for all the 20-HETE experiments (Ponnoth et al., 2012a). In all cases, 20-HETE was administered only when the PE response reached a steady state. In experiments where the effect of the antagonist was studied, the drug was added 30 min prior to the contraction of the tissue with PE and was present throughout the experiments. In all CRC figures, contraction (represented as positive (+) values) and relaxation (represented as negative (-) values) responses were expressed as a percentage of increase/decrease in the contraction with respect to PE (alone) in response to each concentration of agonist used. The concentration used for Penitrem A (Pen A) was $10^{-6} \mathrm{M}$ (Borbouse et al., 2009; Asano et al., 2012). For the rest of the drugs, CRCs were made (NS1619, KCl, PE, ACh, SNP and adenosine agonists) and the sub-maximal concentrations were chosen.

\section{Immunoblot analysis}

Aortae from $\mathrm{WT}$ and $\mathrm{A}_{1} \mathrm{KO}$ mice were homogenized with $150 \mu \mathrm{L}$ radio-immuno precipitation assay buffer containing (mM) 20 Tris-HCl, $150 \mathrm{NaCl}, 1 \mathrm{Na}_{2}$ EDTA, 1 EGTA, 2.5 sodium pyrophosphate, 1 beta-glycerophosphate, and $1 \mathrm{Na}_{3} \mathrm{VO}_{4}$; plus $1 \% \mathrm{NP}$ 40, $1 \%$ sodium deoxycholate, and $1 \mu \mathrm{g} / \mathrm{ml}$ leupeptin. Samples were vortexed and then centrifuged for $10 \mathrm{~min}$ at $13,800 \mathrm{~g}$ at $4^{\circ} \mathrm{C}$. Protein was measured using the Bradford dye procedure with bovine serum albumin as a standard (Bio-Rad Laboratories; Hercules, CA). The protein extract was divided into aliquots and stored at $-80^{\circ} \mathrm{C}$. Samples $(25 \mu \mathrm{g}$ of total protein) were loaded on slab gels (10\% acrylamide; $1 \mathrm{~mm}$ thick), separated by SDS- 
PAGE, and transferred to nitrocellulose membranes (Hybond-ECL). Protein transfer was confirmed by visualization of prestained molecular weight markers (Bio-Rad). Membranes were blocked with 5\% nonfat dry milk and incubated with primary antibody. A 1:5,000 primary antibody dilution used for BK $\alpha$ and $\beta 1$ subunits (Alomone labortatories, Israel), while 1:10,000 dilutions were used for secondary antibody and $\beta$ actin.

\section{Electrophysiology}

WT and $\mathrm{A}_{1} \mathrm{KO}$ mice aortae were digested in a physiological saline solution containing $(\mathrm{mg} / \mathrm{ml}) 2$ collagenase type-II, 1 soybean trypsin inhibitor, 1 bovine serum albumin, and 1 elastase for 30 minutes at $37^{\circ} \mathrm{C}$. Single cells were liberated by passing the tissue through the tip of a fire-polished Pasteur pipette. The suspension was passed through a $100 \mu \mathrm{m}$ nylon mesh and spun for 10 minutes at 10,000g. The pellet was resuspended in

low $\mathrm{Ca}^{2+}$ physiological saline solution and cells were stored on ice for use within $8 \mathrm{hr}$. Cells were allowed to attach to glass coverslip, which was then transferred to the recording chamber. Solutions flowed into the recording chamber by gravity at a rate of 2-3 $\mathrm{ml} / \mathrm{min}$ and the chamber had a volume of 0.2-0.3 $\mathrm{ml}$. BK channel currents were recorded at room temperature from whole-cell patches as described previously (Asano et al., 2010). Bath solution contained (mM) $135 \mathrm{NaCl}, 5 \mathrm{KCl}, 2 \mathrm{CaCl}_{2}, 1 \mathrm{MgCl}_{2}, 10$ glucose, 10 HEPES free acid and 5 Tris base; pH 7.4. Pipette solution contained (mM) $140 \mathrm{KCl}, 1$ $\mathrm{MgCl}_{2}, 1$ EGTA and 0.281 $\mathrm{CaCl}_{2}$ (pCa 7), 10 HEPES, $1 \mathrm{Mg}$-ATP, $0.1 \mathrm{Na}-\mathrm{GTP}$, and 5 Tris; pH 7.1. pClamp software and an Axopatch 200B amplifier were used (Molecular Devices; Sunnyvale, CA). Currents were low pass filtered at $1 \mathrm{kHz}$ and digitized at $5 \mathrm{kHz}$. 


\section{Real Time PCR}

The aortic tissues from $\mathrm{WT}$ and $\mathrm{A}_{1} \mathrm{KO}$ were processed for total RNA isolation using the TRI reagent (MRC, Cincinnati, OH) followed by purification of the RNA in aqueous phase and removal of genomic DNA by an RNeasy Plus Micro Kit (QIAGEN, Hilden, Germany).This was followed by conversion of $0.5 \mathrm{~g}$ of total RNA into cDNA using High Capacity cDNA archive kit (Applied Biosystems, Foster City, CA) in a total volume of $20 \mu 1$. Real-time PCR was performed using an ABI PRISM 7300 Detection System (Applied Biosystems) using Taqman Universal Mastermix (Applied Biosystems, Branchburg, NJ) according to the instructions of the manufacturer. The reaction volume (20 $\mu \mathrm{l})$ consisted of $10 \mu \mathrm{l}$ of $2 \mathrm{X}$ Taqman Universal Mastermix, $4 \mu \mathrm{l}$ of cDNA, and $1 \mu \mathrm{l}$ of 20X FAM-labeled Taqman gene expression assay. For the real-time PCR of the concerned genes (Cyp4a10, $\mathrm{A}_{1} \mathrm{AR}, \mathrm{A}_{2 \mathrm{~A}} \mathrm{AR}, \mathrm{A}_{2 \mathrm{~B}} \mathrm{AR}$ and $\mathrm{A}_{3} \mathrm{AR}$ ), the Taqman inventoried assays on-demand gene expression products were purchased from Applied Biosystems (Foster City, CA). 18S rRNA (ribosomal RNA) was used as an endogenous control. The fold difference in expression of target cDNA was determined using the comparative cycle threshold (Ct) method as described earlier(Livak and Schmittgen, 2001).

\section{Statistics}

Data are expressed as mean \pm SEM from $n$ number of mice, because the treatment level (i.e., genotype) is on a per mouse basis. For patch clamp experiments, that means results from all cells from a single mouse aorta were averaged to represent $n=1$. Currentvoltage relationships were analyzed by two-way repeated measures analysis of variance (ANOVA). This was followed with Bonferroni post hoc test to determine where 
differences existed. When only two values were compared (e.g., BK subunit expression) an unpaired t-test was used. $\mathrm{P}<0.05$ was considered significant in all tests. 


\section{Results}

\section{Total BK current and BK subunit expression in WT and $A_{1} K O$ mice aortic myocytes}

We performed whole-cell patch recordings on aortic smooth muscle cells from WT (Fig. 3.1A) and $\mathrm{A}_{1} \mathrm{KO}$ (Fig. 3.1B) mice; we observed no difference in $\mathrm{BK}$ current. That is, whole-cell $\mathrm{K}^{+}$current in smooth muscle cells was indistinguishable between WT and $\mathrm{A}_{1} \mathrm{KO}$ mice. Currents were normalized to cell capacitance (i.e., current density). The group data are shown in Fig.3.1C. BK $\alpha$ and $\beta 1$ proteins were expressed in aortae from both WT and $\mathrm{A}_{1} \mathrm{KO}$ mice. $\mathrm{BK} \alpha$ and $\beta 1$ subunit proteins migrated at 100 and $25 \mathrm{kDa}$, respectively. There were no differences observed in the two protein levels between genotypes (Figs.3.1D and 3.1E). Thus, the molecular (protein) and functional (current) expression of $\mathrm{BK}$ channels was similar in smooth muscle cells from WT and $\mathrm{A}_{1} \mathrm{KO}$ mice.

\section{Effect of 20-HETE on BK current in WT and $A_{1} K O$ mice aortic myocytes}

To assess the reported inhibitory effect of 20-HETE on BK channels (Zou et al., 1996; Lange et al., 1997), whole-cell recordings were performed on WT and $\mathrm{A}_{1} \mathrm{KO}$ myocytes. We observed a decrease in the BK current in both WT (Fig.3.2A and 3.2B) and $\mathrm{A}_{1} \mathrm{KO}$ (Fig. 3.2D and 3.2E) smooth muscle cells. Mean current density at $+100 \mathrm{mV}$ in WT under control conditions was $76.4 \pm 12.5 \mathrm{pA} / \mathrm{pF}(\mathrm{n}=4)$; this was decreased to $51.6 \pm 10.3$ pA/pF by 20-HETE (Fig. 3.2C). In smooth muscle cells from WT mice, 20-HETE decreased current density $33 \pm 7 \%$. Similarly in smooth muscle cells from $\mathrm{A}_{1} \mathrm{KO}$ mice, mean current density was $55.6 \pm 10.3 \mathrm{pA} / \mathrm{pF}(\mathrm{n}=4)$ and this was decreased to $41.4 \pm 7$ pA/pF by 20-HETE (Fig. 3.2F). Thus, in myocytes from $\mathrm{A}_{1} \mathrm{KO}$ mice, 20-HETE decreased current density $24 \pm 11 \%$. 


\section{Effect of NECA on BK current in WT and $A_{1} K O$ mice aortic myocytes}

Whole-cell patch recordings were made in WT and $\mathrm{A}_{1} \mathrm{KO}$ aortic myocytes to determine the effect of NECA on BK current. NECA is a nonselective adenosine receptor agonist and can activate multiple AR subtypes simultaneously. Whole-cell recordings showed prominent $\mathrm{BK}$ current in smooth muscle cells from $\mathrm{WT}$ and $\mathrm{A}_{1} \mathrm{KO}$ mice. Caffeine (5 $\mathrm{mM}$ ) was used as a positive control to release $\mathrm{Ca}^{2+}$ and increase BK current in both WT and $\mathrm{A}_{1} \mathrm{KO}$ aortic smooth muscle cells (Figs. 3.3E and 3.3F). There was very little change in the BK current in the WT aortic myocytes when stimulated with $10 \mu \mathrm{M}$ NECA (Fig. 3.3E). In contrast, the $\mathrm{BK}$ current in $\mathrm{A}_{1} \mathrm{KO}$ aortic myocytes was significantly increased by $10 \mu \mathrm{M}$ NECA (Fig.3.3F). The time-dependent increase in BK current with $10 \mu \mathrm{M}$ NECA in $A_{1} \mathrm{KO}$ smooth muscle cells was $52 \pm 15 \%(n=7)$; this was significantly higher than the response to NECA in smooth muscle cells from WT mice $(17 \pm 3 \%$; $=9$; Fig. 3.3G). The disparate responses to NECA in smooth muscle cells from $\mathrm{WT}$ and $\mathrm{A}_{1} \mathrm{KO}$ mice suggest that multiple AR subtypes are simultaneously regulating BK channels. Thus, the next experiment was to determine the effect of an $A_{1} A R$-specific agonist on $B K$ channels in smooth muscle cells from WT and $\mathrm{A}_{1} \mathrm{KO}$ mice.

\section{Effect of CCPA on BK current in WT and $A_{1} K O$ mice aortic myocytes}

CCPA (100 nM), an $\mathrm{A}_{1}$-selective agonist, decreased BK current in aortic smooth muscle cells from WT mice (Figs. 3.4A and 3.4B). The mean current density at $+100 \mathrm{mV}$ in WT was $52.1 \pm 5.0 \mathrm{pA} / \mathrm{pF}(\mathrm{n}=4)$ and decreased with the application of CCPA to $42.8 \pm 6.2$ $\mathrm{pA} / \mathrm{pF}$ (Fig. 3.4C). That is, CCPA decreased current density $19 \pm 4 \%$ in smooth cells from WT mice. In contrast, CCPA had no effect on BK current in smooth muscle cells from $\mathrm{A}_{1} \mathrm{KO}$ mice (Figs. 3.4D and 3.4E). The mean current density at $+100 \mathrm{mV}$ in smooth muscle cells from $\mathrm{A}_{1} \mathrm{KO}$ mice was $55.2 \pm 7.7$ and $54.1 \pm 3.9 \mathrm{pA} / \mathrm{pF}(\mathrm{n}=4)$ in the absence 
or presence of $100 \mathrm{nM}$ CCPA, respectively (Fig. 3.4F). That is, current density in the presence of CCPA was $98 \pm 7 \%$ of control in smooth muscle cells from $\mathrm{A}_{1} \mathrm{KO}$ mice.

\section{Effect of PKCa inhibition on BK current in WT and $A_{1} K O$ mice aortic myocytes}

As shown previously (Ponnoth et al., 2012a; Kunduri et al., 2013), PKC $\alpha$ is downstream of $\mathrm{A}_{1} \mathrm{AR}$ activation, 20-HETE production, and mediates contraction of smooth muscle. We determined if inhibition of $\mathrm{PKC} \alpha$ affected regulation of $\mathrm{BK}$ current by $\mathrm{A}_{1} \mathrm{AR}$ activation in smooth muscle cells from WT and $\mathrm{A}_{1} \mathrm{KO}$ mice. When $\mathrm{PKC} \alpha$ was inhibited with Gö6976 (100 nM) in WT smooth muscle cells, subsequent addition of CCPA (100 $\mathrm{nM}$ ) was no longer able to inhibit current (Figs. 3.5A and 3.5B; compare to Fig. 3.4A-C). In smooth muscle cells from WT mice, mean current density at $+100 \mathrm{mV}$ for Gö6976 was $65.9 \pm 18.6 \mathrm{pA} / \mathrm{pF}$ vs. $64.2 \pm 16.6 \mathrm{pA} / \mathrm{pF}$ for CCPA + Gö6976 (Fig. 3.5C). That is, current density in the presence of CCPA was $99 \pm 3 \%$ of control in smooth muscle cells from WT mice treated with Gö6976. There was no effect of CCPA on BK current in $\mathrm{A}_{1} \mathrm{KO}$ smooth muscle cells whether Gö6976 was present or not (Fig 4.5D-F; note that this is a result similar to that shown in Fig. 3.4D-F). The mean current density at +100 $\mathrm{mV}$ in cells from $\mathrm{A}_{1} \mathrm{KO}$ mice for Gö6976 was $68.5 \pm 13.6 \mathrm{pA} / \mathrm{pF}$ vs. $66.6 \pm 13.2 \mathrm{pA} / \mathrm{pF}$ for CCPA + Gö6976 (Fig. 3.5F). That is, current density in the presence of CCPA was 97 $\pm 1 \%$ of control in Gö6976-treated smooth muscle cells from $\mathrm{A}_{1} \mathrm{KO}$ mice.

Effect of NS1619 and Penitrem A on adenosine agonists' induced response: BK channel opener NS1619 had significantly increased relaxation in $\mathrm{A}_{1} \mathrm{KO}$, but had no effect in the WT. We observed that the BK channel inhibitor Pen A had no effect on NECA induced responses in both the WT and $\mathrm{A}_{1} \mathrm{KO}$ (Fig. 3.5A). However, Pen A increased NECA induced contraction in WT $\left(14.5 \pm 1.9 \% ; 10^{-7} \mathrm{M}\right)$ as compared to the $\mathrm{A}_{1} \mathrm{KO}$ $\left(3.7 \pm 4.5 \% ; 10^{-7} \mathrm{M}\right)$. On using the $\mathrm{A}_{1}$ selective agonist, CCPA, we observed no difference 
in contraction with the use of Pen A in WT, except at $10^{-5} \mathrm{M}$, where higher relaxation was observed with Pen A treatment (-6.6 $\pm 2.8 \%$ vs. $17 \pm 1.2 \%$; Fig. 3.5B).

Effect of NS1619 and Penitrem A on 20-HETE induced contraction: 20-HETE induced contraction in both the WT and $\mathrm{A}_{1} \mathrm{KO}$, however it was lower in $\mathrm{A}_{1} \mathrm{KO}$. The $\mathrm{BK}$ channel opener, NS1619 $(10 \mu \mathrm{M})$ decreased the contraction in both the WT $(17.3 \pm 1.2 \%$ vs $33.4 \pm 2.9 \%$. $)$ and $\mathrm{A}_{1} \mathrm{KO}(5.7 \pm 4.2 \%)$. NS1619 had further significantly decreased the contraction in the $\mathrm{A}_{1} \mathrm{KO}(5.7 \pm 4.2 \%)$ as compared to WT $(17.3 \pm 1.2 \%)$. However, on using Pen A the contraction was restored to the control levels in both WT $(26.1 \pm 2.5 \%)$ and $\mathrm{A}_{1} \mathrm{KO}(16.3 \pm 2.9 \%)$ (Fig. 3.6).

mRNA expression of adenosine receptors in WT and $A_{1} \mathrm{KO}$ mice: As expected, $A_{1}$ receptor expression was observed in $\mathrm{WT}$ and not in $\mathrm{A}_{!} \mathrm{KO} . \mathrm{A}_{2 \mathrm{~A}} \mathrm{AR}, \mathrm{A}_{2 \mathrm{~B}} \mathrm{AR}$ and $\mathrm{A}_{3} \mathrm{AR}$ were expressed in both WT and $\mathrm{A}_{1} \mathrm{KO}$. However, $\mathrm{A}_{2 \mathrm{~A}} \mathrm{AR}$ was the highest in $\mathrm{A}_{1} \mathrm{KO}$ mice (Fig 3.7). 


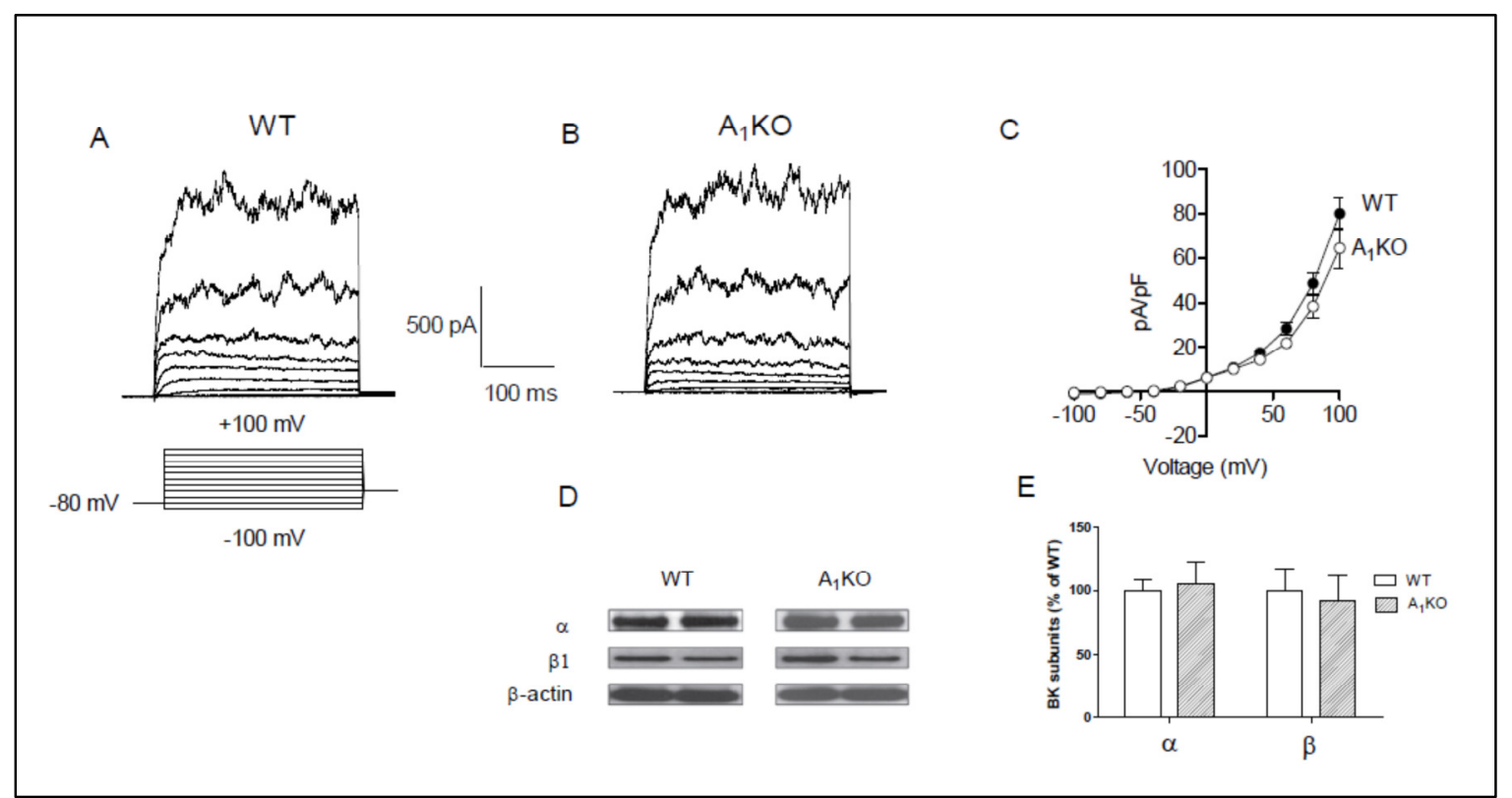

Figure 3.1: Whole-cell $\mathrm{K}^{+}$current and BK channel subunit expression is similar in smooth muscle from WT and $A_{1} K O$ mice.

Representative traces of whole-cell $\mathrm{K}^{+}$current in aortic smooth muscle cells from WT (A) and $\mathrm{A}_{1} \mathrm{KO}$ mice $(\mathrm{B})$. The voltage template used to elicit the currents in this and subsequent figures is shown below the trace in $\mathrm{A}$; cells were held at $-80 \mathrm{mV}$ and stepped from -100 to $+100 \mathrm{mV}$ in $20 \mathrm{mV}$ increments. (C) Group data representing whole-cell $\mathrm{K}^{+}$ current in aortic smooth muscle cells from WT $(n=13)$ and $A_{1} K O(n=20)$ mice. (D) Representative Western blots from mouse aortae for BK channel subunit expression relative to $\beta$-actin $(\alpha=100 \mathrm{kDa} ; \beta 1=25 \mathrm{kDa} ; \beta$-actin $=42 \mathrm{kDa})$. (E) Group data for $\mathrm{BK}$ $\alpha$ and $\beta 1$ subunit expression in the aortae of WT $(n=6)$ and $A_{1} K O(n=6)$ mice. 


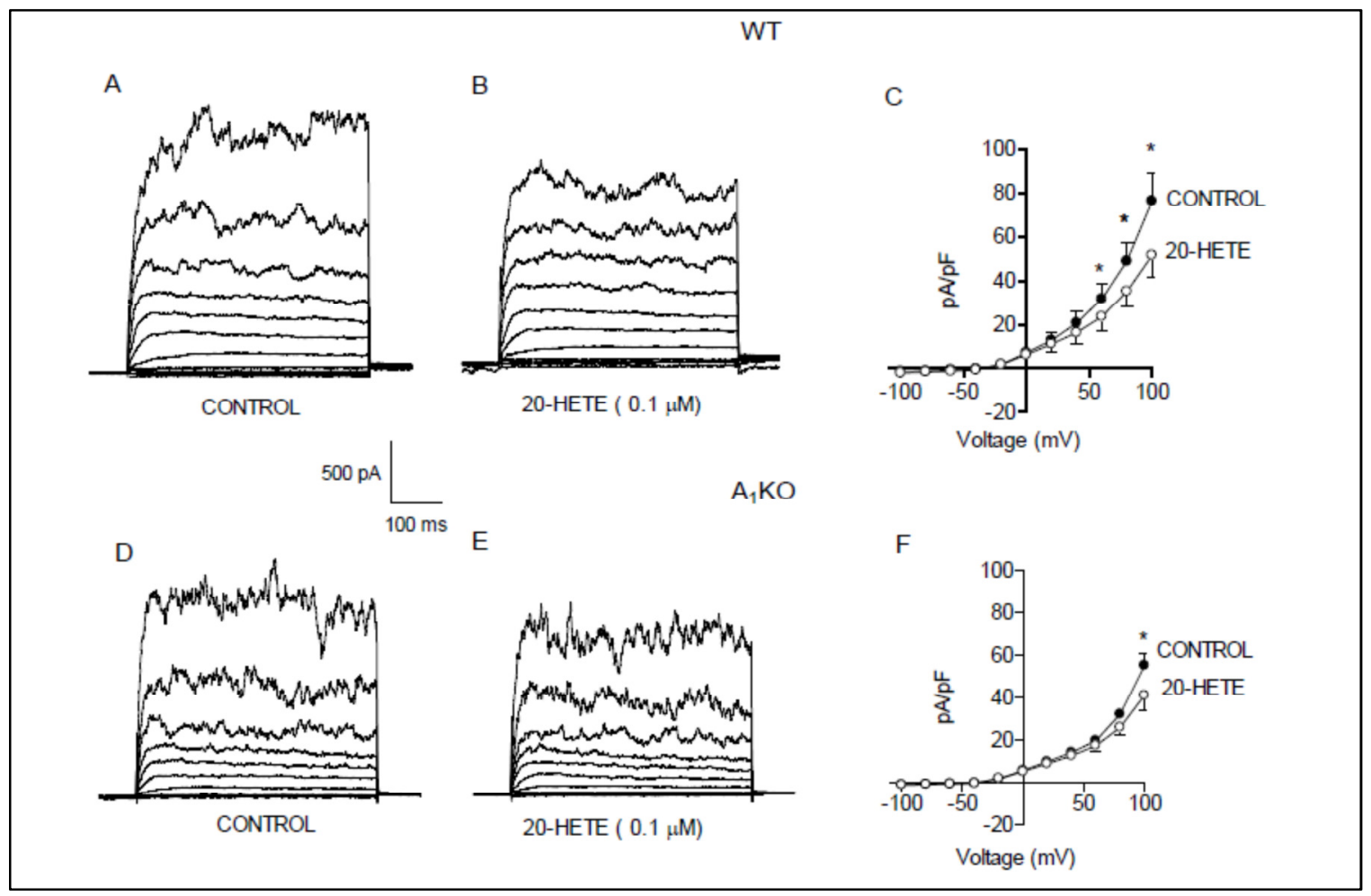

Figure3.2: Effect of 20-HETE on BK current in WT and $A_{1} K O$ aortic myocytes:

Representative current traces are shown under control conditions (A) and with $0.1 \mu \mathrm{M}$ 20-HETE (B) in a smooth muscle cell from a WT mouse. The voltage template was the same as Fig. 4.1. (C) Group data $(n=5)$ show the decrease in the BK current by 20HETE in smooth muscle cells from WT mice. Representative traces are shown under control conditions (D) and with $0.1 \mu \mathrm{M}$ 20-HETE (E) for a smooth muscle cell from an $\mathrm{A}_{1} \mathrm{KO}$ mouse. (F) Group data $(\mathrm{n}=5)$ show the decrease in BK current by $0.1 \mu \mathrm{M} 20$ HETE in smooth muscle cells from $\mathrm{A}_{1} \mathrm{KO}$ mice. ${ }^{*} \mathrm{p}<0.05$ compared to the respective control. 


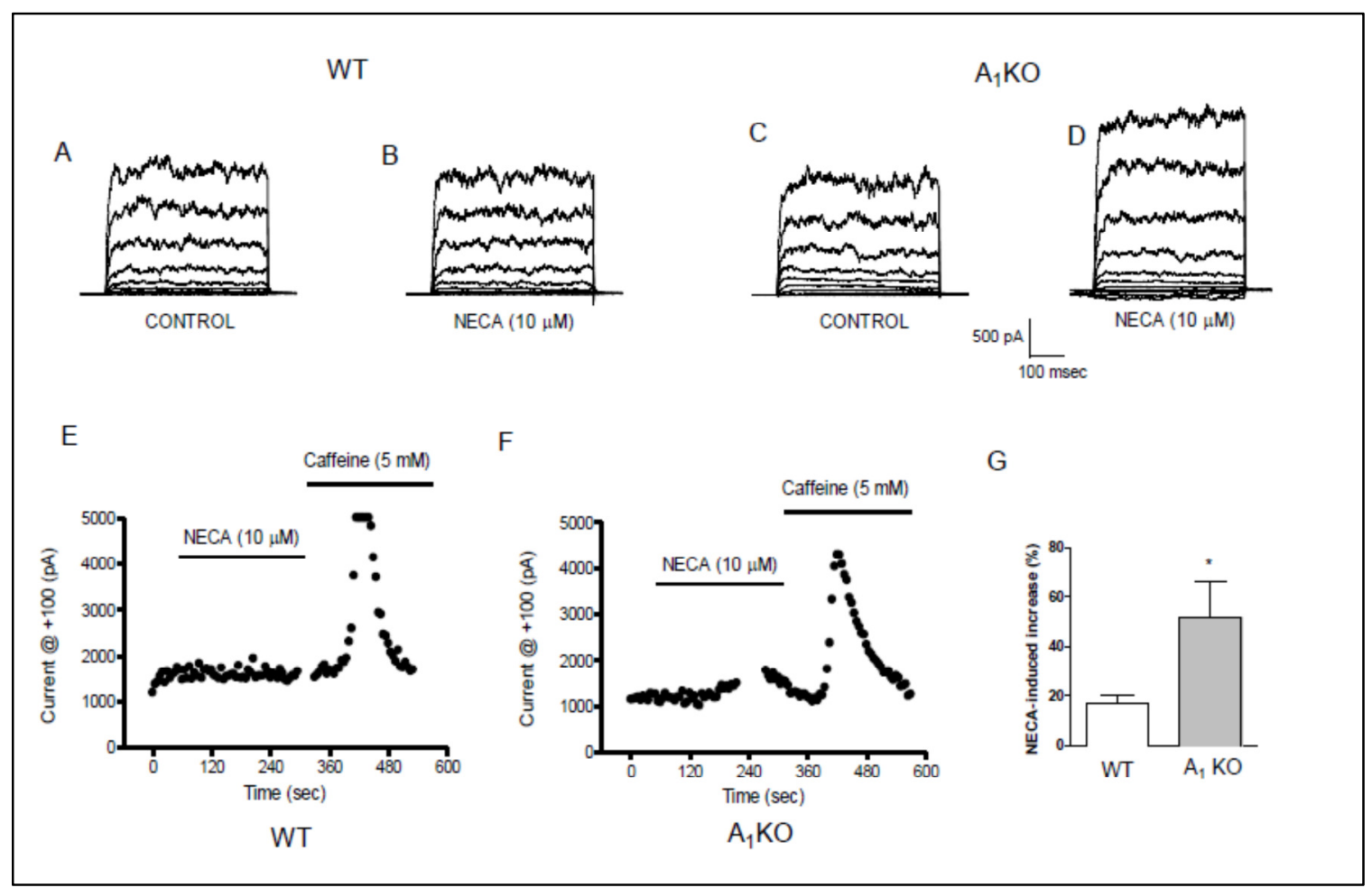

Figure3.3: Effect of NECA on BK current in WT and $A_{1} K O$ aortic myocytes

Representative currents under control conditions (A) and with $10 \mu \mathrm{M}$ NECA (B) in WT. The voltage template was the same as Fig.4.1. Representative currents under control conditions (C) and with $10 \mu \mathrm{M}$ NECA (D) in smooth muscle cells from $\mathrm{A}_{1} \mathrm{KO}$ mice. Data showing currents vs. time for $10 \mu \mathrm{M}$ NECA and $5 \mathrm{mM}$ caffeine in smooth muscle cells from WT $(\mathrm{E})$ and in $\mathrm{A}_{1} \mathrm{KO}(\mathrm{F})$ mice (blank areas in the time course represent where the protocol was stopped to perform voltage steps) (G) Group data show that NECA increases the $\mathrm{BK}$ current more in smooth muscle cells from $\mathrm{A}_{1} \mathrm{KO}$ mice compared to $\mathrm{WT}$ mice. ${ }^{*} \mathrm{p}<0.05$ for WT vs. $\mathrm{A}_{1} \mathrm{KO} ; \mathrm{n}=7-9$. 


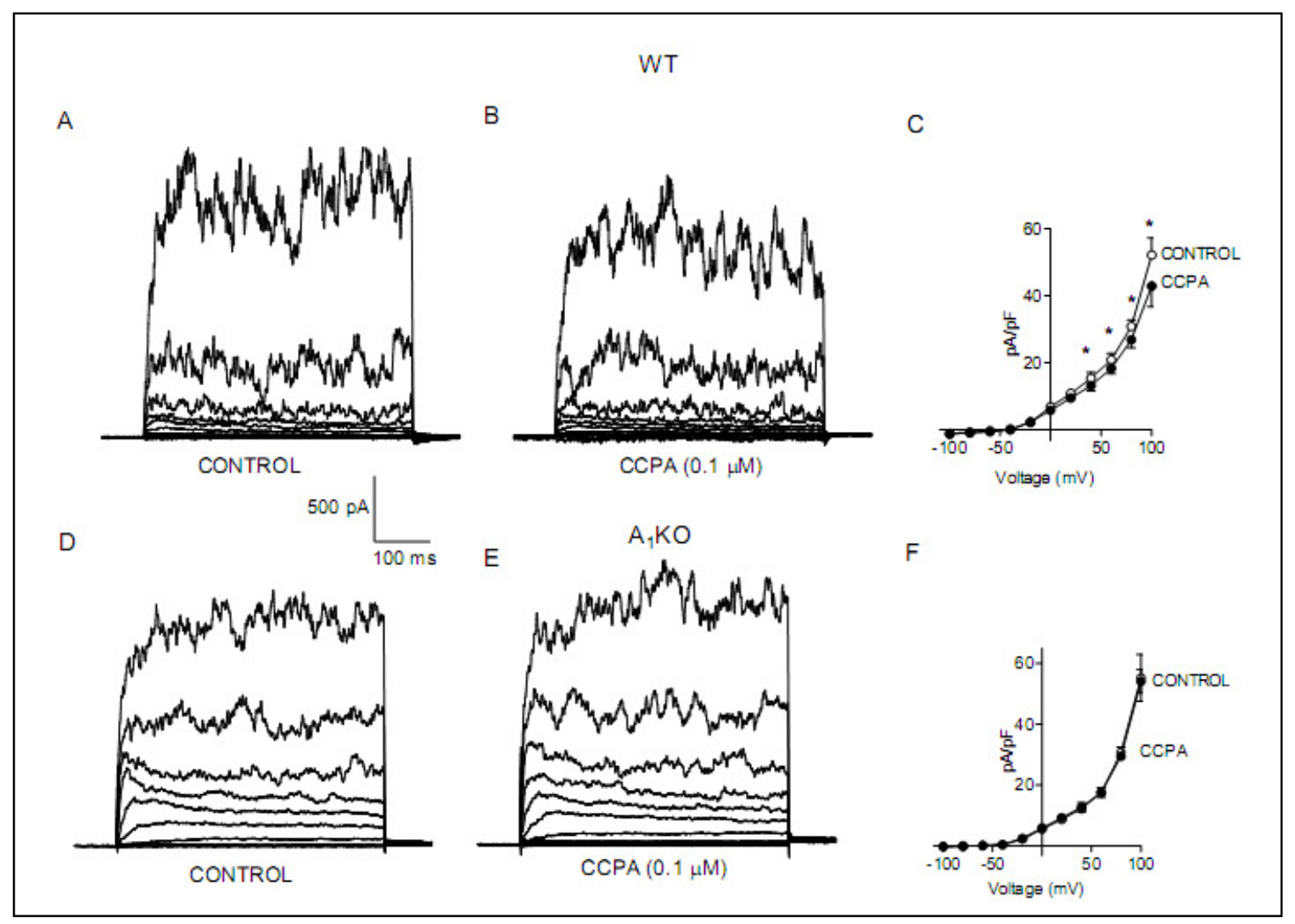

Figure 3.4: Effect of CCPA on BK current in WT and $A_{1} K O$ aortic myocytes

Representative traces under control conditions (A) and with $0.1 \mu \mathrm{M} \mathrm{CCPA} \mathrm{(B)} \mathrm{in} \mathrm{a}$ smooth muscle cell from a WT mouse. The voltage template was the same as Fig.4.1. (C) Group data representing the decrease in the BK current by CCPA in the WT mice $(n=4)$. Representative traces show current under control conditions (D) and with $0.1 \mu \mathrm{M}$ CCPA (E) in a smooth muscle cell from an $\mathrm{A}_{1} \mathrm{KO}$ mouse. (F) Group data illustrate that there is no effect of CCPA on BK current in smooth muscle cells from $\mathrm{A}_{1} \mathrm{KO}$ mice. ${ }^{*} \mathrm{p}<0.05$ compared to untreated WT $(n=4)$. 


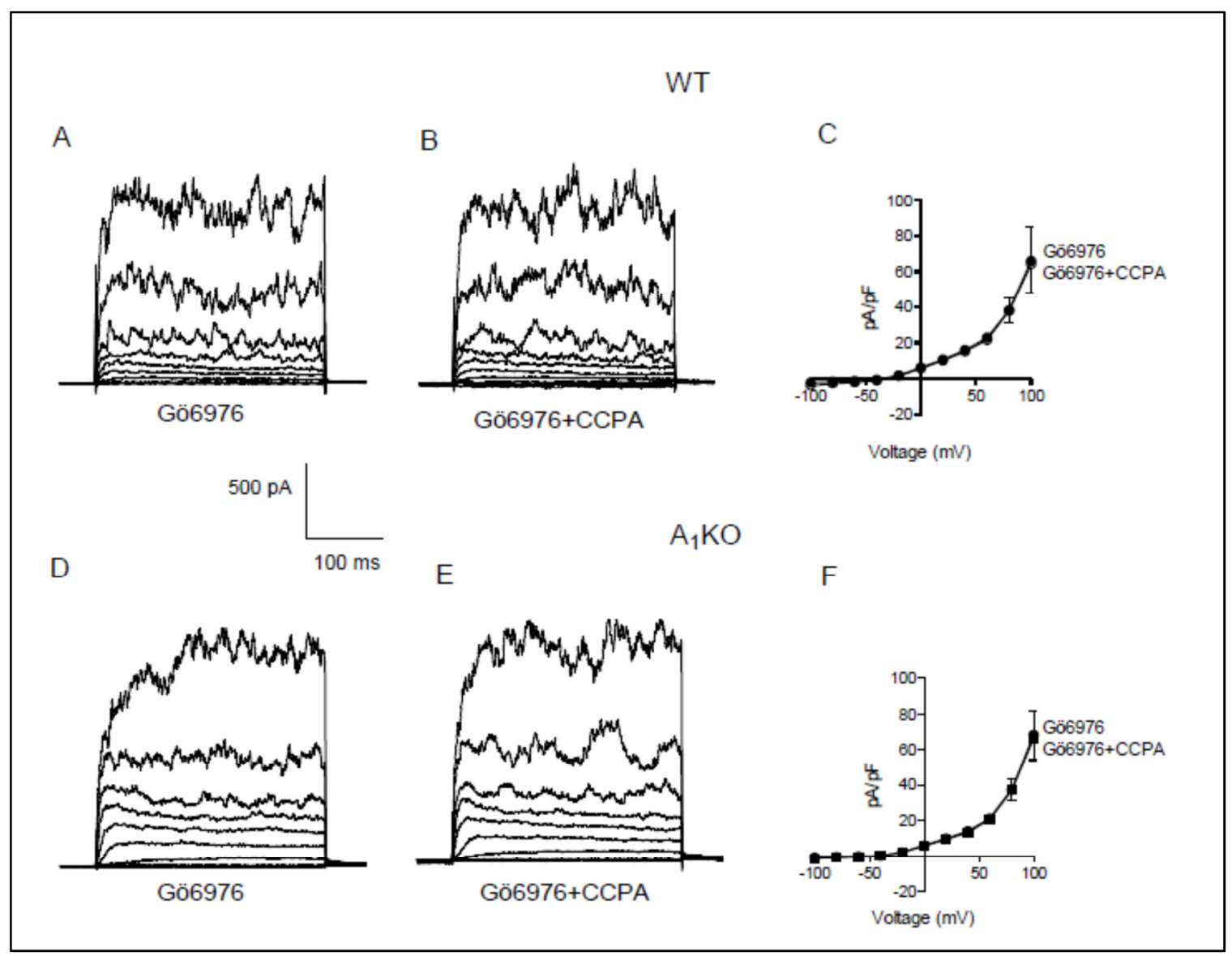

Figure 3.5: Effect of PKCa inhibitor, Gö6976 on BK current in WT and $A_{1} K O$ aortic myocytes

Representative traces with $0.1 \mu \mathrm{M}$ Gö6976 (A) and with $0.1 \mu \mathrm{M}$ Gö6976 + $0.1 \mu \mathrm{M}$ CCPA (B) in a smooth muscle cell from a WT mouse. The voltage template was the same as Fig.4.1. (C) Group data demonstrate the effect of Gö6976 to prevent CCPA-induced inhibition of BK current in smooth muscle cells from WT mice $(n=4)$. Representative traces with $0.1 \mu \mathrm{M}$ Gö6976 (D) and with $0.1 \mu \mathrm{M}$ Gö6976 + 0.1 $\mu \mathrm{M}$ CCPA (E) in a smooth muscle cell from an $\mathrm{A}_{1} \mathrm{KO}$ mouse. (F) Group data representing BK current in Gö6976-treated smooth muscle cells from $\mathrm{A}_{1} \mathrm{KO}$ mice $(\mathrm{n}=4)$. 


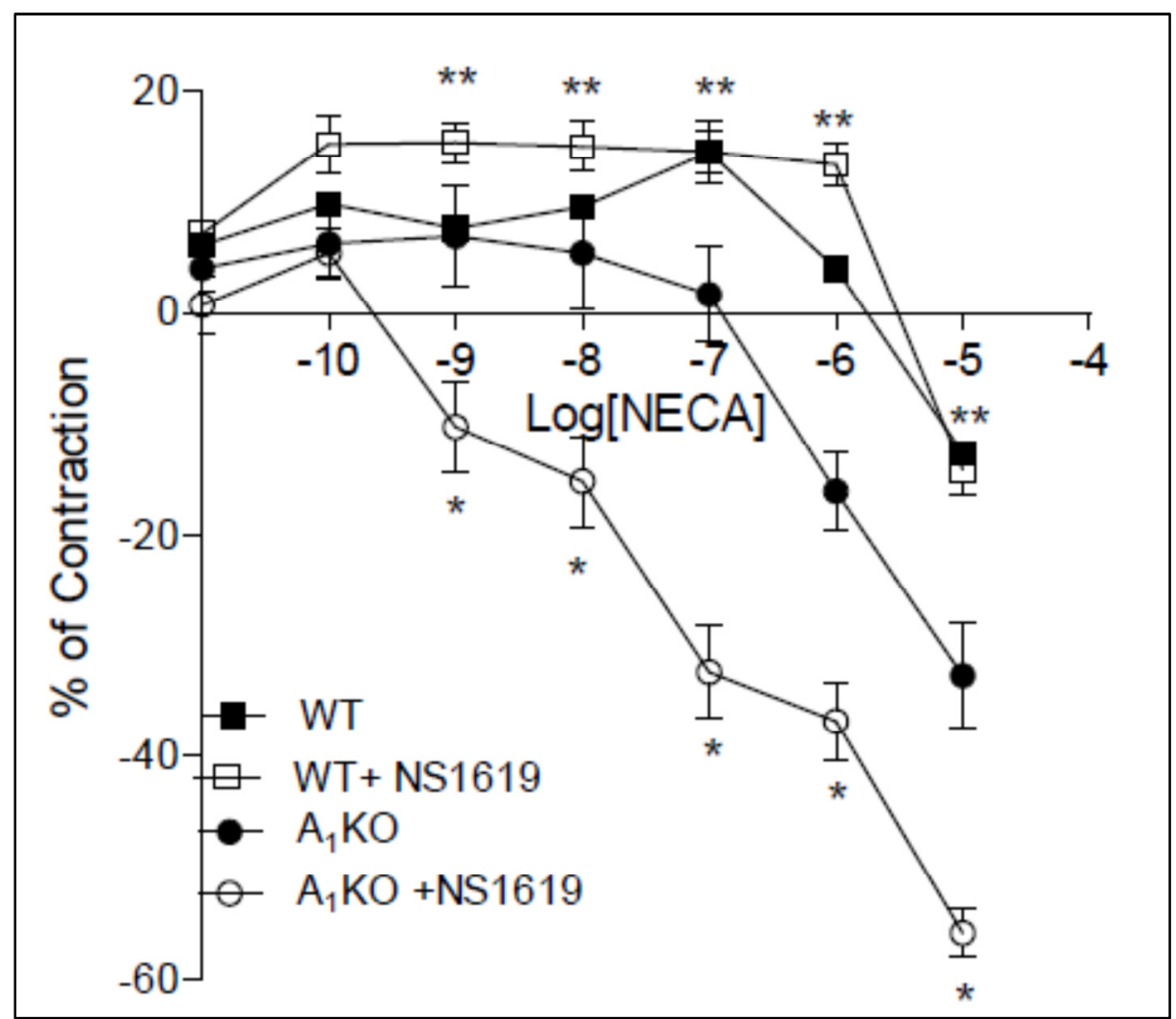

Figure 3.6 Effect of NS1619 on NECA induced relaxation.

Data are expressed as mean $\pm \mathrm{SEM} ; * * \mathrm{p}<0.05$ between $\mathrm{WT}+\mathrm{NS} 1619$ and $\mathrm{A}_{1} \mathrm{KO}+\mathrm{NS} 1619$ and ${ }^{*} \mathrm{p}<0.05$ as compared to $\mathrm{A}_{1} \mathrm{KO}$ and $\mathrm{A}_{1} \mathrm{KO}+\mathrm{NS} 1619$. 

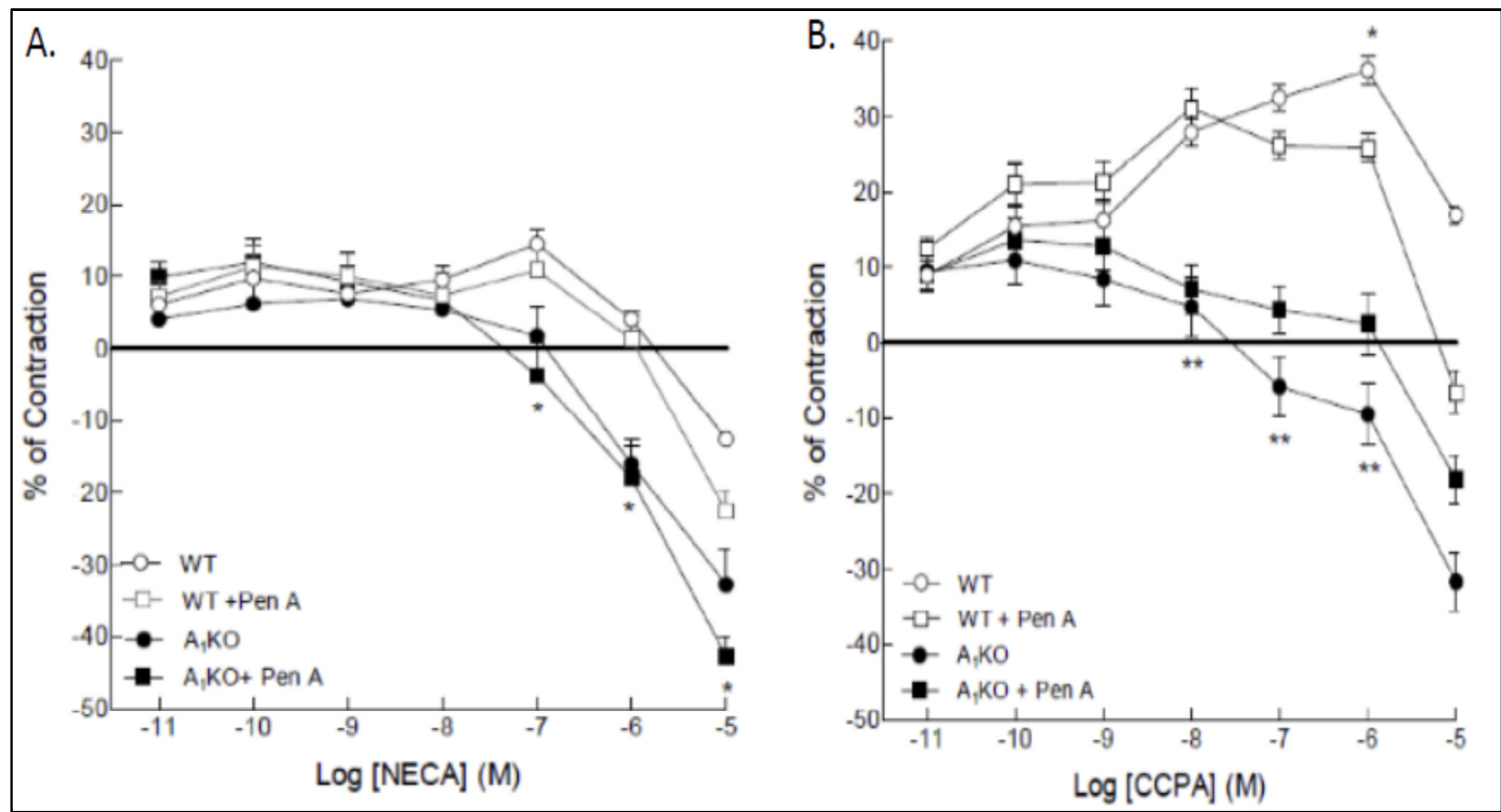

Figure 3.7 Effect of Penitrem A (Pen A) on adenosine agonists' induced responses: (A)Effect of Penitrem A on NECA induced vascular response

Data are expressed as Mean \pm SEM; ${ }^{*} \mathrm{p}<0.05$ as between $\mathrm{WT}+\mathrm{Pen} \mathrm{A}$ and $\mathrm{A}_{1} \mathrm{KO}+\mathrm{Pen} \mathrm{A}$; n=6-12; (B) Effect of CCPA on Penitrem A induced contraction: Data are expressed as Mean \pm SEM; ${ }^{*} \mathrm{p}<0.05$ as between $\mathrm{WT}+$ Pen $\mathrm{A}$ and $\mathrm{A}_{1} \mathrm{KO}+\mathrm{Pen} \mathrm{A} ;{ }^{*} \mathrm{p}<0.05$ as between WT and WT + Pen A; n=8-12 


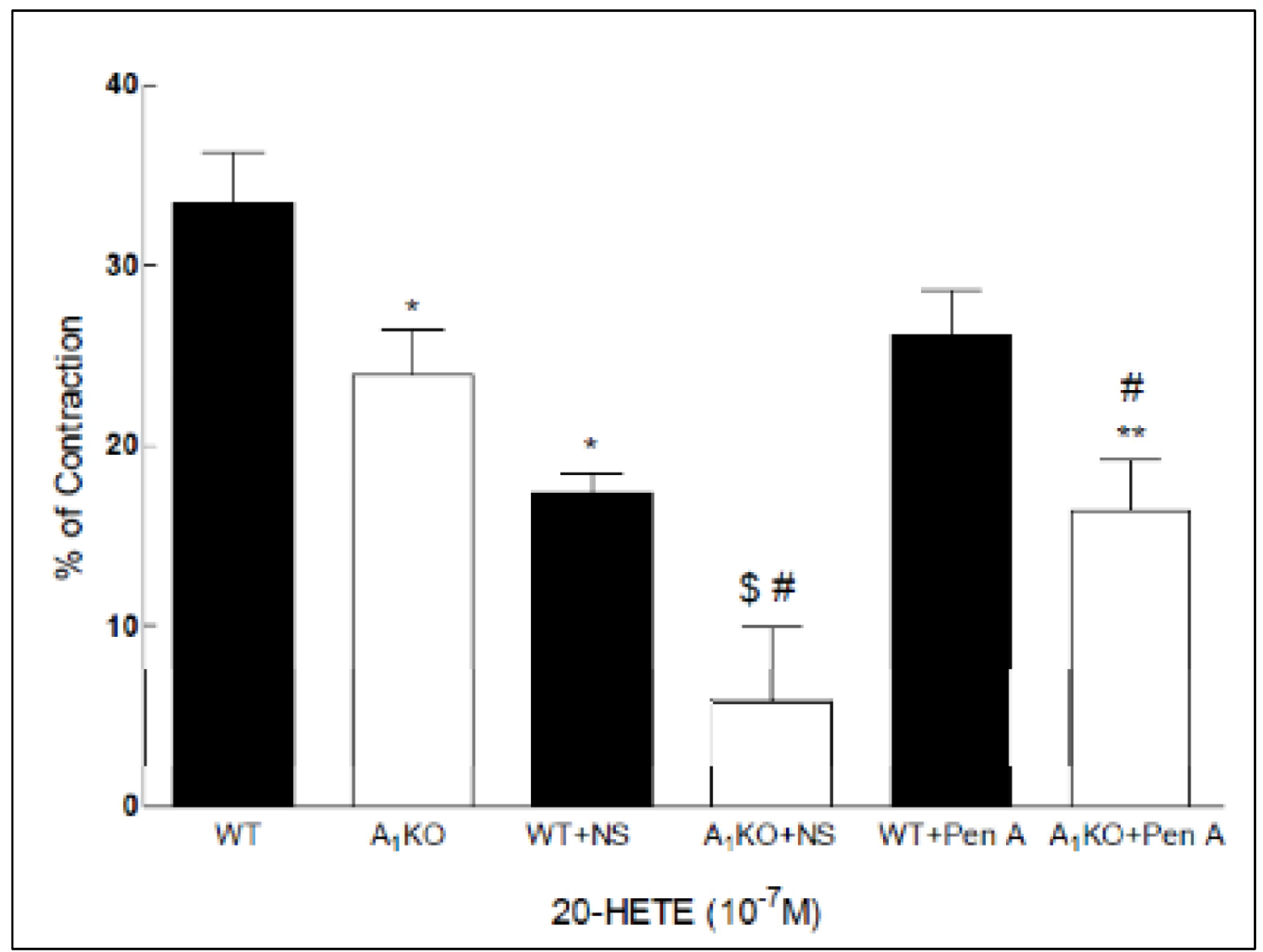

Figure 3.8 Effect of Penitrem A (BK channel inhbitor; Pen A) and NS1619 (BK channel opener;NS) on CCPA induced contraction.

Values are mean $\pm \mathrm{SEM} ; \mathrm{n}=6-12 ;{ }^{*} \mathrm{p}<0.05$ as compared to $\mathrm{WT} ;{ }^{*} \mathrm{p}<0.05$ as compared to $\mathrm{A}_{1} \mathrm{KO} ;{ }^{\$} \mathrm{p}<0.05$ as compared to $\mathrm{WT}+\mathrm{NS} ;{ }^{*}{ }^{*} \mathrm{p}<0.05$ as compared to $\mathrm{WT}+\mathrm{Pen} \mathrm{A}$ 


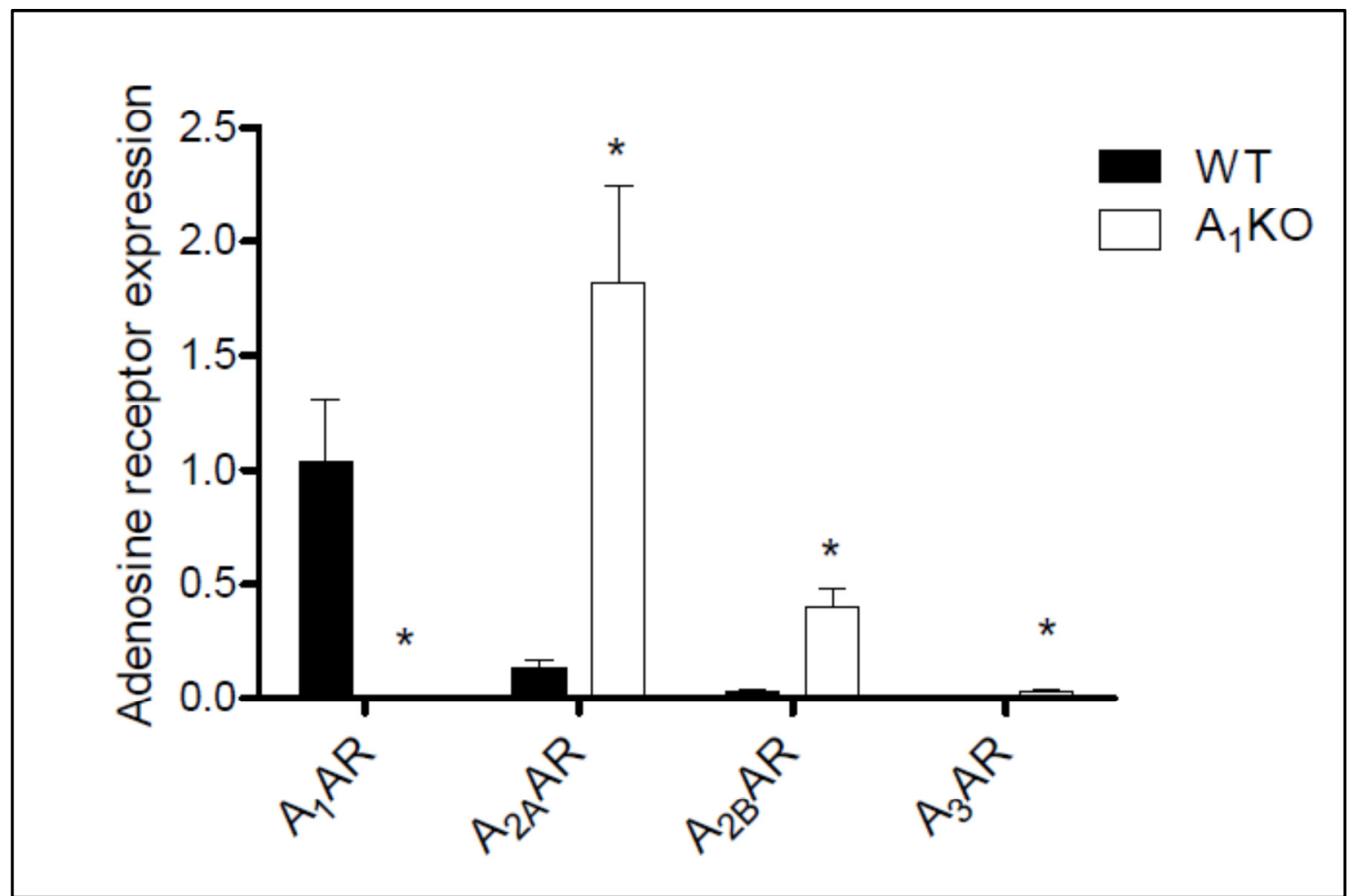

Figure 3.9 Adenosine receptor expression in WT and $\mathrm{A}_{1} \mathrm{KO}$ mice aortae

Data are expressed as mean \pm SEM $(n=10) .{ }^{*} \mathrm{p}<0.05$ compared to the WT 


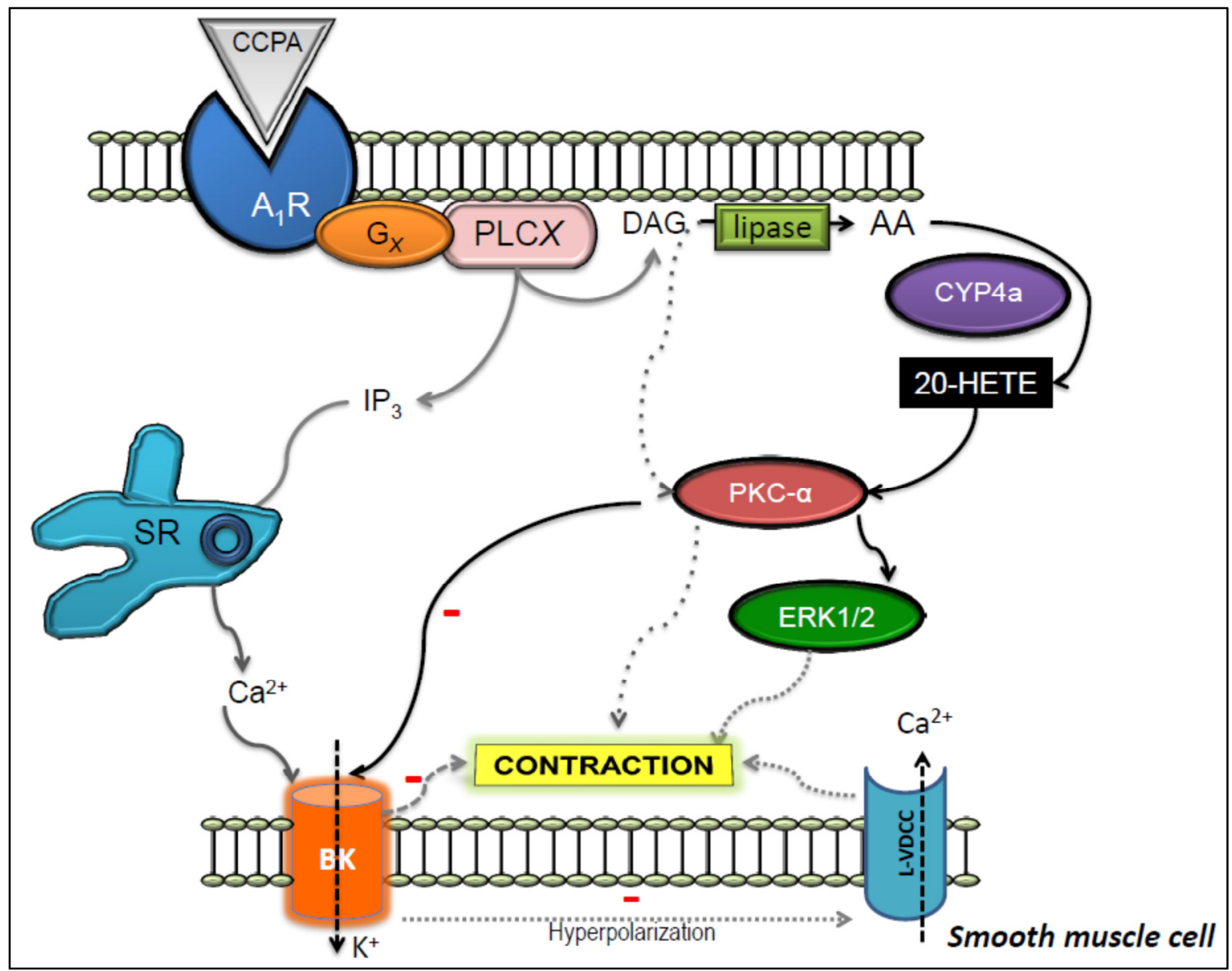

Figure 3.10: Adenosine $A_{1}$ receptors regulate aortic smooth muscle contraction by inhibiting $B K$ channels via PKC- $\alpha$ dependent mechanism.

As shown previously in Fig 3.4, activation of $A_{1} A R$ by CCPA couples with PLCX via Gx. $\mathrm{IP}_{3}$, a metabolites of PLC action on phosphatidylinositol 4,5-bisphosphate, releases $\mathrm{Ca}^{2+}$ from the sarcoplasmic reticulum (SR) and activates BK channels. AA released by the DAG lipases is metabolized to 20-HETE by Cyp4a, which activates PKC- $\alpha$. The latter apart from activating ERK1/2, inhibits the BK channels and results in the contraction of the aortic smooth muscle. Activation of BK channels results in hyperpolarization of the smooth muscle membrane which promotes a closure of L-type voltage dependent $\mathrm{Ca}^{2+}$ channels that are major players of smooth muscle contraction. 


\section{Discussion}

We tested the hypothesis that activation of $\mathrm{A}_{1} \mathrm{AR}$ inhibits $\mathrm{BK}$ channels in aortic smooth muscle via a PKC-dependent mechanism. This hypothesis was based on previous studies indicating: 1) that $\mathrm{A}_{1} \mathrm{AR}$ stimulation is associated with 20-HETE production and activation of PKC (Ponnoth et al., 2012a; Kunduri et al., 2013) and 2) 20-HETE and PKC can inhibit BK channels (Zou et al., 1996; Nowicki et al., 1997; Schubert et al., 1999; Zhou et al., 2009). We performed whole-cell patch clamp and Western blot studies using aortic smooth muscle cells and aortae of WT and $\mathrm{A}_{1} \mathrm{KO}$ mice. Our major findings included: 1) There were no differences in whole-cell $\mathrm{K}^{+}$current in aortic smooth muscle cells from $\mathrm{WT}$ and $\mathrm{A}_{1} \mathrm{KO}$ mice, nor were there any differences in the expression of poreforming $\alpha$ or regulatory $\beta 1$ subunit proteins. 2) Inhibition of BK current by 20-HETE was similar in aortic smooth muscle cells from WT and $\mathrm{A}_{1} \mathrm{KO}$ mice. 3) NECA, a nonselective AR agonist increased BK current in aortic smooth muscle cells from both WT and $\mathrm{A}_{1} \mathrm{KO}$ mice, but the increase was greater in smooth muscle cells from mice lacking the $A_{1} A R$. 4) CCPA, an $A_{1} A R$-selective agonist, inhibited BK current in smooth muscle cells from WT, but not $A_{1} K O$, mice. 5) Inhibition of PKC $\alpha$ with Gö6976 abolished the effect of CCPA to inhibit BK current in smooth muscle cells from WT mice. Together, these data lead us to conclude that, in aortic smooth muscle, $\mathrm{A}_{1} \mathrm{AR}$ stimulation inhibits BK channel activity and that this occurs via a mechanism involving PKC $\alpha$.

BK channels are ubiquitously expressed on the sarcolemma of vascular smooth muscles. BK channels are composed of pore-forming $\alpha$ subunits with or without regulatory $\beta$ subunits. The $\beta 1$ subunit, however, is commonly found in vascular smooth muscles (Nelson and Quayle, 1995; Ledoux et al., 2006; Asano et al., 2010). The $\alpha$ 
subunit is the voltage- and $\mathrm{Ca}^{2+}$-sensitive pore, while $\beta$ subunits can modify many characteristics including pharmacology and $\mathrm{Ca}^{2+}$-sensitivity. We observed no difference in the expression of $\alpha$ or $\beta 1 \mathrm{BK}$ subunits (Fig.3.1), suggesting that the channels are equally expressed in aortic smooth muscle cells from WT and $\mathrm{A}_{1} \mathrm{KO}$ mice. Further, there were no differences in BK current magnitude between WT and $\mathrm{A}_{1} \mathrm{KO}$ mice (Fig.3.1). We have previously shown that $A_{1} A R$ mediates contraction of smooth muscle via the arachidonic acid metabolite 20-HETE (Ponnoth et al., 2012a; Kunduri et al., 2013). 20HETE has been shown to inhibit BK channels in rat renal arteriolar smooth muscle cells (Zou et al., 1996; Sun et al., 1999). We have observed similar results in whole-cell patch recordings (Fig. 3.2). That is, 20-HETE decreased BK current similarly in smooth muscle cells from both WT and $\mathrm{A}_{1} \mathrm{KO}$ mice (Fig. 3.2). 20-HETE is a potent vasoconstrictor as shown previously by significant contractions in the aortae of both WT and $\mathrm{A}_{1} \mathrm{KO}$ mice (Ponnoth et al., 2012a; Kunduri et al., 2013). The BK channel opener NS1619 decreased this contraction with significantly higher reduction in the $\mathrm{A}_{1} \mathrm{KO}$, implying the role of $\mathrm{BK}$ channels in the $A_{1} A R-20-H E T E$ mediated signaling in the vascular response. On using Pen $\mathrm{A}$ in $\mathrm{WT}$ and $\mathrm{A}_{1} \mathrm{KO}$, the contraction is restored to their respective control levels. This further underscores that $\mathrm{A}_{1} \mathrm{AR}$ via 20-HETE inhibits $\mathrm{BK}$ channel and attenuates relaxation of the smooth muscle cell 20-HETE activates PKC (Lange et al., 1997; Nowicki et al., 1997; Ponnoth et al., 2012a; Kunduri et al., 2013) and PKC may mediate contraction by inhibiting BK channel activity in rat cerebral arteries (Bonev and Nelson, 1996), rabbit portal vein (Kitamura et al., 1992), canine basilar artery(Obara et al., 2002) and rat tail artery (Schubert et al., 1999). This inhibition depends on the sequential phosphorylation of two serines in the C-terminus of the BK $\alpha$ subunit (Zhou et al., 2009). In the present study, when PKC $\alpha$ was antagonized with Gö6976, CCPA could no longer 
inhibit BK channel current (compare Figs. 3.4 and 3.5). This suggests that $A_{1} A R$ signaling through PKC $\alpha$ is negatively coupled to BK channels, perhaps by 20-HETE.

The non-selective adenosine agonist NECA relaxes smooth muscle by acting on $\mathrm{A}_{2} \mathrm{AR}$ (Rump et al., 1999; Tawfik et al., 2005; Ponnoth et al., 2009), whereas the $\mathrm{A}_{1} \mathrm{AR}$ selective agonist CCPA contracts smooth muscle (Ponnoth et al., 2012a; Kunduri et al., 2013). Activation of $\mathrm{BK}$ channels by $\mathrm{A}_{2} \mathrm{AR}$ could lead to membrane potential hyperpolarization and contribute to the relaxation of smooth muscle, whereas inhibition of $\mathrm{BK}$ channels by $\mathrm{A}_{1} \mathrm{AR}$ could cause depolarization and contribute to contraction. We observed that NECA increased $\mathrm{BK}$ current significantly in $\mathrm{A}_{1} \mathrm{KO}$ as compared to the WT (Fig. 3.3). This suggests that the increase in the BK current could be due to the absence of $A_{1}$ and the non-selective action of NECA on other adenosine receptors (e.g. $\left.A_{2} A R\right)$ in the $A_{1} \mathrm{KO}$. We have shown that the $A_{2 \mathrm{~A}}$ receptor expression is upregulated in $\mathrm{A}_{1} \mathrm{KO}$ mice and this might also be a factor in the larger responses to NECA. There is evidence showing that $\mathrm{A}_{2 \mathrm{~A}} \mathrm{AR}$, through EETs, activate BK channels (Carroll et al., 2006; Ray and Marshall, 2006). Furthermore, by using the $A_{1}$ selective agonist CCPA we demonstrated a decrease in BK current in smooth muscle cells from WT mice, but no effect in smooth muscle cells from the $\mathrm{A}_{1} \mathrm{KO}$ mice. This is the first evidence in the literature showing that $\mathrm{A}_{1} \mathrm{AR}$ activation inhibits $\mathrm{BK}$ current. As the $\mathrm{A}_{1} \mathrm{AR}$ is known to mediate contraction (Tawfik et al., 2005; Wang et al., 2010; Kunduri et al., 2013), we suggest this may be mediated by inhibition of BK channels. It should be noted, however, that there are reports of $A_{1}$ activating $\mathrm{K}_{\mathrm{ATP}}$ channels (Dart and Standen, 1993) and linking to nitric oxide-dependent smooth muscle relaxation (Ray and Marshall, 2006). The reasons for such differences are not readily apparent, but may perhaps be attributed to the vascular beds and species. 
However, it was surprising to observe in vascular reactivity experiments that the use of BK channel inhibitor, Pen A did not alter the contraction in NECA induced or CCPA induced concentration responses (Fig.3.7A and Fig.3.7B). Previous studies using adenosine or $\mathrm{A}_{2 \mathrm{~A}}$ receptor agonist in other vessels have produced differing results depending on the tissue and species used. In renal arteries, combination of calcium dependent potassium channel inhibitors, apamin and charybdotoxin didnot have any effect on the $\mathrm{A}_{2 \mathrm{~A}}$ agonist dilation, but Ibtx at $0.1 \mu \mathrm{mol} / \mathrm{L}$ had very little effect (Rump et al., 1999). Similar results were obtain ned by Carroll MA et al (Carroll et al., 2006) in renal preglomerular vessels. In their study, adenosine mediated dilation via $\mathrm{A}_{2 \mathrm{~A}}$ through EETs of renal preglomerular vessels was inhibited by 100nM Ibtx. However, there has been no study showing the interaction of adenosine-mediated response via $\mathrm{A}_{1}$ and $\mathrm{BK}$ channels. Though $A_{1}$ is primarily know to mediate contraction, there is evidence showing that $A_{1}$ mediates vasodilation through $\mathrm{K}_{\mathrm{ATP}}$ channel in the rat aortic endothelium (Ray and Marshall, 2006), in rat diaphragmatic arterioles(Danialou et al., 1997), in the rat skeletal muscle (Bryan and Marshall, 1999). Thus, it is quite possible in the present study that the adenosine in the whole tissue consisting of endothelium and the smooth muscle might cause contraction through the $\mathrm{A}_{1}$ receptors via inhibition of $\mathrm{K}_{\mathrm{ATP}}$ channels or other $\mathrm{K}^{+}$ channels. This suggests that there could be another pathway in the whole tissue via which $\mathrm{A}_{1} \mathrm{AR}$ mediates contraction.

Adenosine, via multiple receptor subtypes, contracts and relaxes vascular smooth muscle through several mechanisms, including the regulation of $\mathrm{K}^{+}$channels (Dart and Standen, 1993). While adenosine-mediated increases in $\mathrm{K}_{\mathrm{ATP}}$ channel activity are generally well accepted (Sharifi Sanjani et al., 2013), reports regarding the role of BK channels in adenosine-induced smooth muscle relaxation vary widely. In canine coronary 
arterioles, vasodilation in response to adenosine is inhibited by iberiotoxin (a very selective BK channel antagonist) (Cabell et al., 1994). Blocking BK channels inhibits vasodilation to 2-chloroadenosine in pig coronary arterioles (Borbouse et al., 2009); however, the role of BK channels in this response is abolished in pigs with metabolic syndrome (Borbouse et al., 2009). Thus, it could be pathology that explains why BK channels play no role in adenosine-induced vasodilation human coronary arterioles (Sato et al., 2005), as they are typically collected from patients with heart disease. Conversely, it may be that BK channels play little, if any role, in adenosine-induced vasodilation, as this has been reported in the majority of studies from pig coronary arterioles (Hein and Kuo, 1999; Hein et al., 2001; Heaps and Bowles, 2002). However, it cannot be ignored that BK channels are reported to contribute to adenosine-induced relaxation or vasodilation of rat cerebral arterioles (Paterno et al., 1996), rabbit renal arteries (Rump et al., 1999), rat aortas (Ray and Marshall, 2006), and rat preglomerular microvessels (Carroll et al., 2006). Further, adenosine increases a $\mathrm{Ca}^{2+}$-dependent $\mathrm{K}^{+}$current in smooth muscle cells from the rat mesenteric artery that may be mediated by BK channels (Li and Cheung, 2000). At present, there is little consensus regarding the role of BK channels in adenosine-induced smooth muscle relaxation and very little data directly addressing whether adenosine increases BK current in smooth muscle cells isolated from those same arteries or arterioles. Thus, from our data, we conclude that $\mathrm{A}_{1} \mathrm{AR}$ signaling inhibits $\mathrm{BK}$ channels via 20-HETE and PKC $\alpha$. However, in the whole tissue consisting of the endothelium and smooth muscle, there could be other potassium channels or ion channels playing role in mediating contraction through $\mathrm{A}_{1} \mathrm{AR}$ and this needs to be further explored to have a complete understanding of the signaling mechanism involved in $A_{1} A R$ mediated contraction. 


\section{References}

Ansari HR, Nadeem A, Tilley SL, and Mustafa SJ. Involvement of COX-1 in A3 adenosine receptor-mediated contraction through endothelium in mice aorta. Am $J$ Physiol Heart Circ Physiol 293: H3448-3455, 2007.

Asano S, Tune JD, and Dick GM. Bisphenol A activates Maxi-K (K(Ca)1.1) channels in coronary smooth muscle. Br J Pharmacol 160: 160-170, 2010.

Bonev AD and Nelson MT. Vasoconstrictors inhibit ATP-sensitive K+ channels in arterial smooth muscle through protein kinase C. J Gen Physiol 108: 315-323, 1996.

Borbouse L, Dick GM, Asano S, Bender SB, Dincer UD, Payne GA, Neeb ZP, Bratz IN, Sturek M, and Tune JD. Impaired function of coronary $\mathrm{BK}(\mathrm{Ca})$ channels in metabolic syndrome. Am J Physiol Heart Circ Physiol 297: H1629-1637, 2009.

Brenner R, Perez GJ, Bonev AD, Eckman DM, Kosek JC, Wiler SW, Patterson AJ, Nelson MT, and Aldrich RW. Vasoregulation by the beta1 subunit of the calciumactivated potassium channel. Nature 407: 870-876, 2000.

Cabell F, Weiss DS, and Price JM. Inhibition of adenosine-induced coronary vasodilation by block of large-conductance $\mathrm{Ca}(2+)$-activated $\mathrm{K}+$ channels. Am J Physiol 267: H1455-1460, 1994.

Carroll MA, Doumad AB, Li J, Cheng MK, Falck JR, and McGiff JC. Adenosine2A receptor vasodilation of rat preglomerular microvessels is mediated by EETs that activate the cAMP/PKA pathway. Am J Physiol Renal Physiol 291: F155-161, 2006.

Cheng MK, Doumad AB, Jiang H, Falck JR, McGiff JC, and Carroll MA. Epoxyeicosatrienoic acids mediate adenosine-induced vasodilation in rat preglomerular microvessels (PGMV) via A2A receptors. Br J Pharmacol 141: 441-448, 2004. 
Dart C and Standen NB. Adenosine-activated potassium current in smooth muscle cells isolated from the pig coronary artery. J Physiol 471: 767-786, 1993.

Fredholm BB, AP IJ, Jacobson KA, Klotz KN, and Linden J. International Union of Pharmacology. XXV. Nomenclature and classification of adenosine receptors. Pharmacol Rev 53: 527-552, 2001.

Harder DR, Lange AR, Gebremedhin D, Birks EK, and Roman RJ. Cytochrome P450 metabolites of arachidonic acid as intracellular signaling molecules in vascular tissue. J Vasc Res 34: 237-243, 1997.

Heaps CL and Bowles DK. Gender-specific K(+)-channel contribution to adenosineinduced relaxation in coronary arterioles. J Appl Physiol 92: 550-558, 2002.

Hein TW and Kuo L. cAMP-independent dilation of coronary arterioles to adenosine : role of nitric oxide, G proteins, and K(ATP) channels. Circ Res 85: 634-642, 1999.

Hein TW, Wang W, Zoghi B, Muthuchamy M, and Kuo L. Functional and molecular characterization of receptor subtypes mediating coronary microvascular dilation to adenosine. J Mol Cell Cardiol 33: 271-282, 2001.

Jacobson KA and Gao ZG. Adenosine receptors as therapeutic targets. Nat Rev Drug Discov 5: 247-264, 2006.

Kitamura K, Xiong Z, Teramoto N, and Kuriyama H. Roles of inositol trisphosphate and protein kinase $\mathrm{C}$ in the spontaneous outward current modulated by calcium release in rabbit portal vein. Pflugers Arch 421: 539-551, 1992.

Kunduri S, Mustafa S, Ponnoth D, Dick G, and Nayeem M. Adenosine A1 receptors link to smooth muscle contraction via CYP4a, PKC-alpha, and ERK1/2. J Cardiovasc Pharmacol, 2013. 
Lange A, Gebremedhin D, Narayanan J, and Harder D. 20-Hydroxyeicosatetraenoic acid-induced vasoconstriction and inhibition of potassium current in cerebral vascular smooth muscle is dependent on activation of protein kinase C. J Biol Chem 272: 2734527352, 1997.

Ledoux J, Werner ME, Brayden JE, and Nelson MT. Calcium-activated potassium channels and the regulation of vascular tone. Physiology (Bethesda) 21: 69-78, 2006.

Li G and Cheung DW. Modulation of $\mathrm{Ca}(2+)$-dependent $\mathrm{K}(+)$ currents in mesenteric arterial smooth muscle cells by adenosine. Eur J Pharmacol 394: 35-40, 2000.

Miyata N and Roman RJ. Role of 20-hydroxyeicosatetraenoic acid (20-HETE) in vascular system. J Smooth Muscle Res 41: 175-193, 2005.

Nayeem MA, Poloyac SM, Falck JR, Zeldin DC, Ledent C, Ponnoth DS, Ansari HR, and Mustafa SJ. Role of CYP epoxygenases in A2A AR-mediated relaxation using A2A AR-null and wild-type mice. Am J Physiol Heart Circ Physiol 295: H2068-2078, 2008.

Nelson MT, Cheng H, Rubart M, Santana LF, Bonev AD, Knot HJ, and Lederer WJ. Relaxation of arterial smooth muscle by calcium sparks. Science 270: 633-637, 1995. Nelson MT and Quayle JM. Physiological roles and properties of potassium channels in arterial smooth muscle. Am J Physiol 268: C799-822, 1995.

Nowicki S, Chen SL, Aizman O, Cheng XJ, Li D, Nowicki C, Nairn A, Greengard P, and Aperia A. 20-Hydroxyeicosa-tetraenoic acid (20 HETE) activates protein kinase C. Role in regulation of rat renal Na+,K+-ATPase. J Clin Invest 99: 1224-1230, 1997.

Obara K, Koide M, and Nakayama K. 20-Hydroxyeicosatetraenoic acid potentiates stretch-induced contraction of canine basilar artery via PKC alpha-mediated inhibition of KCa channel. Br J Pharmacol 137: 1362-1370, 2002. 
Paterno R, Faraci FM, and Heistad DD. Role of $\mathrm{Ca}(2+)$-dependent $\mathrm{K}+$ channels in cerebral vasodilatation induced by increases in cyclic GMP and cyclic AMP in the rat. Stroke 27: 1603-1607; discussion 1607-1608, 1996.

Ponnoth DS, Nayeem MA, Kunduri SS, Tilley SL, Zeldin DC, Ledent C, and Mustafa SJ. Role of omega-hydroxylase in adenosine-mediated aortic response through MAP kinase using A2A-receptor knockout mice. Am J Physiol Regul Integr Comp Physiol 302: R400-408, 2012.

Ponnoth DS, Sanjani MS, Ledent C, Roush K, Krahn T, and Mustafa SJ. Absence of adenosine-mediated aortic relaxation in $\mathrm{A}(2 \mathrm{~A})$ adenosine receptor knockout mice. Am $J$ Physiol Heart Circ Physiol 297: H1655-1660, 2009.

Ray CJ and Marshall JM. The cellular mechanisms by which adenosine evokes release of nitric oxide from rat aortic endothelium. J Physiol 570: 85-96, 2006.

Roman RJ, Maier KG, Sun CW, Harder DR, and Alonso-Galicia M. Renal and cardiovascular actions of 20-hydroxyeicosatetraenoic acid and epoxyeicosatrienoic acids. Clin Exp Pharmacol Physiol 27: 855-865, 2000.

Rump LC, Jabbari TJ, von Kugelgen I, and Oberhauser V. Adenosine mediates nitric-oxide-independent renal vasodilation by activation of A2A receptors. $J$ Hypertens 17: 1987-1993, 1999.

Sato A, Terata K, Miura H, Toyama K, Loberiza FR, Jr., Hatoum OA, Saito T, Sakuma I, and Gutterman DD. Mechanism of vasodilation to adenosine in coronary arterioles from patients with heart disease. Am J Physiol Heart Circ Physiol 288: H16331640, 2005.

Schubert R, Noack T, and Serebryakov VN. Protein kinase C reduces the KCa current of rat tail artery smooth muscle cells. Am J Physiol 276: C648-658, 1999. 
Sharifi Sanjani M, Zhou X, Asano S, Tilley SL, Ledent C, Teng B, Dick GM, and Mustafa SJ. Interactions between A2A adenosine receptors, hydrogen peroxide, and KATP channels in coronary reactive hyperemia. Am J Physiol Heart Circ Physiol, 2013.

Sun CW, Falck JR, Harder DR, and Roman RJ. Role of tyrosine kinase and PKC in the vasoconstrictor response to 20-HETE in renal arterioles. Hypertension 33: 414-418, 1999.

Tawfik HE, Schnermann J, Oldenburg PJ, and Mustafa SJ. Role of A1 adenosine receptors in regulation of vascular tone. Am J Physiol Heart Circ Physiol 288: H14111416, 2005.

Wang Y, Yang JN, Arner A, Boels PJ, and Fredholm BB. Adenosine A(1) receptors and vascular reactivity. Acta Physiol (Oxf) 199: 211-220, 2010.

Williams JM, Murphy S, Burke M, and Roman RJ. 20-hydroxyeicosatetraeonic acid: a new target for the treatment of hypertension. J Cardiovasc Pharmacol 56: 336-344, 2010.

Zhou XB, Wulfsen I, Utku E, Sausbier U, Sausbier M, Wieland T, Ruth P, and Korth M. Dual role of protein kinase C on BK channel regulation. Proc Natl Acad Sci U S A 107: 8005-8010, 2009.

Zou AP, Fleming JT, Falck JR, Jacobs ER, Gebremedhin D, Harder DR, and Roman RJ. 20-HETE is an endogenous inhibitor of the large-conductance $\mathrm{Ca}(2+)$ activated K+ channel in renal arterioles. Am J Physiol 270: R228-237, 1996. 


\section{CHAPTER FOUR: CONCLUSIONS}

The work presented in this dissertation establishes a relationship between $A_{1} A R$ and Cyp4a.We have shown that $A_{1} A R$ mediated contraction of the smooth muscle involves Cyp4a product, 20-HETE via PKC- $\alpha$ and ERK 1/2 dependent pathway. Furthermore, this effect on the smooth muscle occurs by the inhibition of BK channel in a PKC- $\alpha$ dependent manner.

The first evidence for an interaction between $A_{1} A R$ and Cyp4a is the effect of the Cyp4a inhibitor (HET0016) on adenosine agonists' (NECA and CCPA) elicited vascular responses in WT and $\mathrm{A}_{1} \mathrm{KO}$ mice aortae. Due to the similar responses to adenosine agonists in the mice mesenteric arteries and aortae, we used aortae for these studies(Teng et al., 2011). Pharmacological inhibition of Cyp4a dramatically reduced the contraction responses induced by NECA, in both the WT and the $\mathrm{A}_{1} \mathrm{KO}$ mice aortae and a significantly higher relaxation was observed in NECA-induced aortic responses in $\mathrm{A}_{1} \mathrm{KO}$ (Fig. 2.2A).

These findings were further confirmed when Cyp4a inhibitor (HET0016) attenuated the vasoconstriction evoked by the $\mathrm{A}_{1}$ agonist, CCPA in the WT with no significant difference in the treated and untreated $\mathrm{A}_{1} \mathrm{KO}$ tissues (Fig.2.2B). This coupled with lower Cyp4a protein levels in $\mathrm{A}_{1} \mathrm{KO}$ mice aortae (Fig. 2.1A) as compared to WT suggest a role for Cyp4a in adenosine-elicited contraction of the smooth muscle through the $\mathrm{A}_{1} \mathrm{AR}$.

20-HETE is known to be a potent vasoconstrictor in several vascular beds. When administered exogenously in our experiments, it elicited contraction responses in both WT and $\mathrm{A}_{1} \mathrm{KO}$ at very low concentrations of $10^{-11} \mathrm{M}$ (Fig 2.3A-D). Our data show that 
20-HETE vascular responses in aortae and mesenteric arteries are lower in $\mathrm{A}_{1} \mathrm{KO}$

compared to the WT (Fig.2.3E). Moreover, the Cyp4a functional activity evaluated by the 20-HETE formation rates in the aortic microsomes was found to be lower in the $\mathrm{A}_{1} \mathrm{KO}$ as compared to the WT mice (Fig 2.4). This further underscores the role of Cyp4a in $\mathrm{A}_{1} \mathrm{AR}$ mediated vasoconstriction.

There is a dynamic interplay between the metabolites of the two pathways of Cyp450 enzymes, EETs and 20-HETEs, in the modulation of vascular homeostasis. As Cyp $4 a$ and Cyp2c products have functionally antagonistic effects, we investigated if Cyp2c29 has any relationship to the $\mathrm{A}_{1} \mathrm{AR}$ mediated vascular responses. We observed that Cyp2c29 protein levels were significantly up- regulated in $\mathrm{A}_{1} \mathrm{KO}$ mice as compared to the WT (Fig 2.5A). Since we have seen an up-regulation of Cyp $2 c 29$ in $\mathrm{A}_{1} \mathrm{KO}$ compared to WT mice, it is quite possible that relaxation observed in $\mathrm{A}_{1} \mathrm{KO}$ mice by Cyp4a inhibition is due to Cyp2c29 product EETs and due to the inhibition of Cyp4a that limits the production of 20-HETE. This observation was confirmed by the enhanced CCPA mediated vasoconstriction in the presence of the Cyp-epoxygenase inhibitor, MSPPOH (Fig.2.5B). We have shown earlier that Cyp4a protein levels are up regulated with MSPPOH treatment (Nayeem et al., 2008). In the WT, although Cyp-epoxygenases were inhibited, a higher contraction observed with MSPPOH treatment is due to higher levels of Cyp4a and in the $\mathrm{A}_{1} \mathrm{KO}$, the higher vascular response is due to inhibition of the Cyp-epoxygenases. Thus, the down-regulation of Cyp $4 a$ and an up-regulation of $C y p 2 c 29$ protein levels promote the relaxation observed in the $\mathrm{A}_{1} \mathrm{KO}$ littermates. This inverse relationship between Cyp4a and Cyp2c is consistent with findings from other investigators in rat afferent arterioles and preglomerular arterioles (Hercule and Oyekan, 2000; Imig et al., 2000). 
The next aim was to determine the signaling mechanism by which adenosine $A_{1}$ receptor-20-HETE pathway mediates contraction of the smooth muscle downstream. Exogenous administration of 20-HETE produced similar higher contraction response in WT than the $\mathrm{A}_{1} \mathrm{KO}$, both in the mice aortae and mesenteric arteries (Fig.2.3), thus, suggesting that the signaling proteins downstream of 20-HETE are essential in Cyp4a modulation of $A_{1} A R$ mediated vasoconstriction. The use of a specific PKC- $\alpha$ blocker attenuated the 20-HETE mediated vasoconstrictor response in WT and $\mathrm{A}_{1} \mathrm{KO}$ mice aortae (Fig.2.6A-C). Similarly, pharmacological inhibition of ERK1/2 with PD98059 decreased the 20-HETE-elicited contraction in the WT and almost abolished the contractile tone in the $\mathrm{A}_{1} \mathrm{KO}$ (Fig2.7A-C). However, the greater blockade of the vasoconstrictor responses with ERK inhibitor than with the PKC- $\alpha$ inhibitor implies that MAPK pathway activation may involve several kinases like PKA, PKC, rho kinases or Ras activation or a cross talk between the different tyrosine kinase receptors. These data substantiate the role of PKC- $\alpha$ and ERK1/2 in $\mathrm{A}_{1} \mathrm{AR}$ mediated vasoconstriction through 20-HETE (Fig. 2.6 and 2.7).

Electrophysiological studies have revealed that BK channels negatively regulate the $\mathrm{A}_{1} \mathrm{AR}-20$-HETE mediated aortic smooth muscle contraction. Our data showed that the total BK current and BK protein expression was unchanged in both WT and $\mathrm{A}_{1} \mathrm{KO}$ aortic smooth muscle cells (Fig.3.1). 20-HETE decreased the BK current in our studies as reported by several groups in different vascular beds and species (Fig.3.2). 20-HETE is a potent vasoconstrictor as shown by the significant contraction in WT and $\mathrm{A}_{1} \mathrm{KO}$ (Ponnoth et al., 2012a; Kunduri et al., 2013). The BK channel opener NS1619 decreased this contraction with significantly higher reduction in the $\mathrm{A}_{1} \mathrm{KO}$, implying the role of BK channels in the $\mathrm{A}_{1} \mathrm{AR}-20$-HETE mediated signaling in the vascular response. On using Pen A in WT and $\mathrm{A}_{1} \mathrm{KO}$, the contraction is restored to their respective control 
levels. This further underscores that $\mathrm{A}_{1} \mathrm{AR}$ via 20-HETE inhibits $\mathrm{BK}$ channel and attenuates relaxation of the smooth muscle cell (Fig 3.8)

Adenosine receptor stimulation with NECA increased the $\mathrm{BK}$ current in $\mathrm{A}_{1} \mathrm{KO}$ and not in WT (Fig.3.3). This suggests that $\mathrm{A}_{1} \mathrm{AR}$ negatively regulates the BK channel and the lack of it removes the inhibition. As cited previously, $\mathrm{A}_{2 \mathrm{~A}} \mathrm{R}$ is known to couple with EETs and BK channels in mediating relaxation. We have shown in this dissertation that $\mathrm{A}_{2 \mathrm{~A}} \mathrm{R}$ is up-regulated in $\mathrm{A}_{1} \mathrm{KO}$ mice aortae (Fig.3.9). It is quite plausible that the increase in $\mathrm{BK}$ current could also be contributed by $\mathrm{A}_{2 \mathrm{~A}} \mathrm{R}$ receptors via EETs. Use of the $\mathrm{A}_{1}$ selective agonist CCPA decreased the $\mathrm{BK}$ current in WT with no effect on the $\mathrm{A}_{1} \mathrm{KO}$ aortic smooth muscle cells (Fig.3.4).

However, it was surprising to observe in vascular reactivity experiments that the use of BK channel inhibitor, Pen A did not alter the contraction in NECA induced or CCPA induced concentration responses (Fig.3.7). Previous studies using adenosine or $\mathrm{A}_{2 \mathrm{~A}}$ receptor agonist in other vessels have produced differing results depending on the tissue and species used. In renal arteries, combination of calcium dependent potassium channel inhibitors, apamin and charybdotoxin didnot have any effect on the $\mathrm{A}_{2 \mathrm{~A}}$ agonist dilation, but Ibtx at $0.1 \mu \mathrm{mol} / \mathrm{L}$ had very little effect (Rump et al., 1999). Similar results were obtain ned by Carroll MA et al (Carroll et al., 2006) in renal preglomerular vessels. In their study, adenosine mediated dilation via $\mathrm{A}_{2 \mathrm{~A}}$ through EETs of renal preglomerular vessels was inhibited by 100nM Ibtx. However, there has been no study showing the interaction of adenosine-mediated response via $A_{1}$ and $B K$ channels. Though $A_{1}$ is primarily know to mediate contraction, there is evidence showing that $A_{1}$ mediates vasodilation through $\mathrm{K}_{\mathrm{ATP}}$ channel in the rat aortic endothelium (Ray and Marshall, 2006), in rat diaphragmatic arterioles(Danialou et al., 1997), in the rat skeletal muscle (Bryan 
and Marshall, 1999). Thus, it is quite possible in the present study that the adenosine in the whole tissue consisting of endothelium and the smooth muscle might cause contraction through the $A_{1}$ receptors via inhibition of $K_{\text {ATP }}$ channels or other $\mathrm{K}^{+}$channels. This suggests that there could be another pathway in the whole tissue via which $A_{1} A R$ mediates contraction.

Thus, in summary we conclude that adenosine $\mathrm{A}_{1}$ receptor by coupling with 20HETE and PKC- $\alpha$ limits adenosine-mediated relaxation in the aortic smooth muscle cells by inhibiting BK channels. However, in the whole tissue consisting of the endothelium and smooth muscle, there could be other potassium channels or ion channels playing role in mediating contraction through $\mathrm{A}_{1} \mathrm{AR}$ and this needs to be further explored to have a complete understanding of the signaling mechanism involved in $\mathrm{A}_{1} \mathrm{AR}$ mediated contraction. 


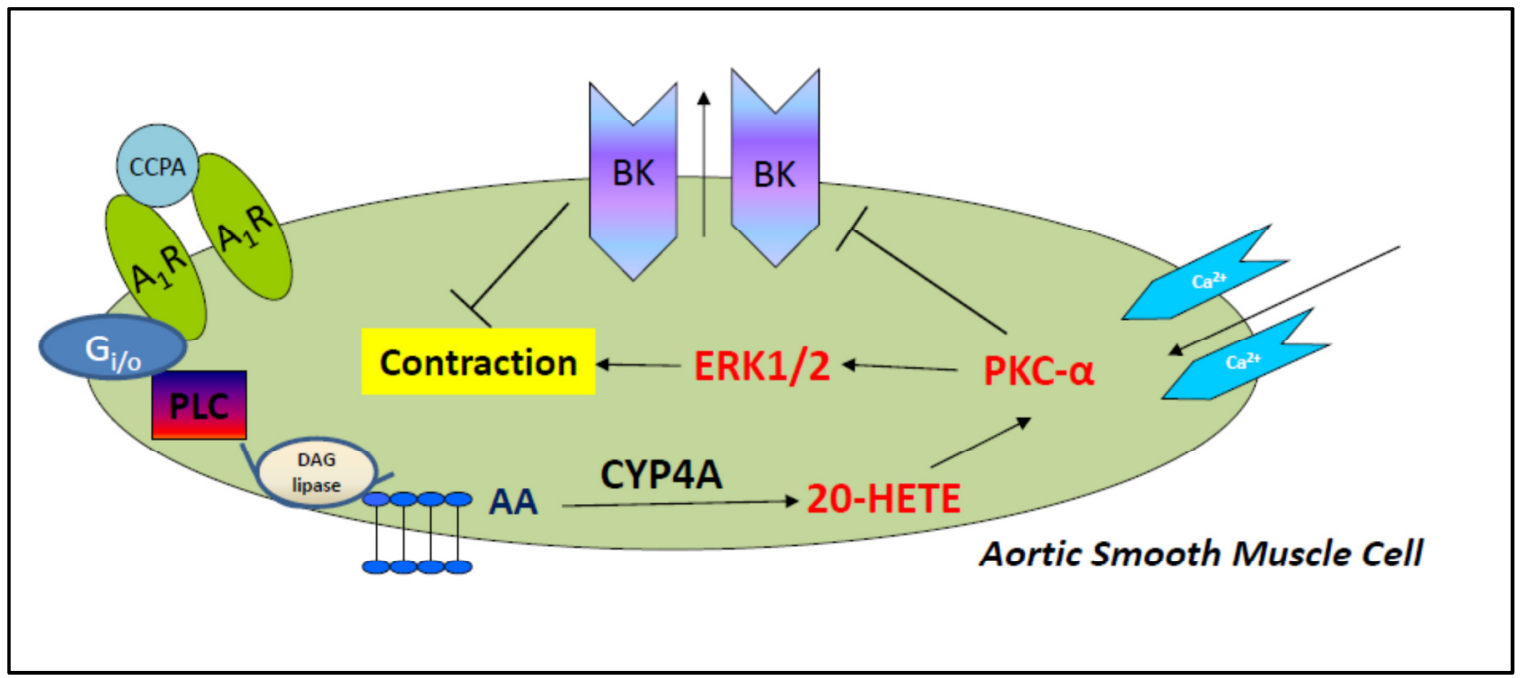

Figure 4.1: Schematic showing the events leading from activation of $A_{1} A R$ coupled to Cyp4a product, 20-HETE and mediating contraction through PKC- $\alpha$ and pERK1/2 and BK channels 


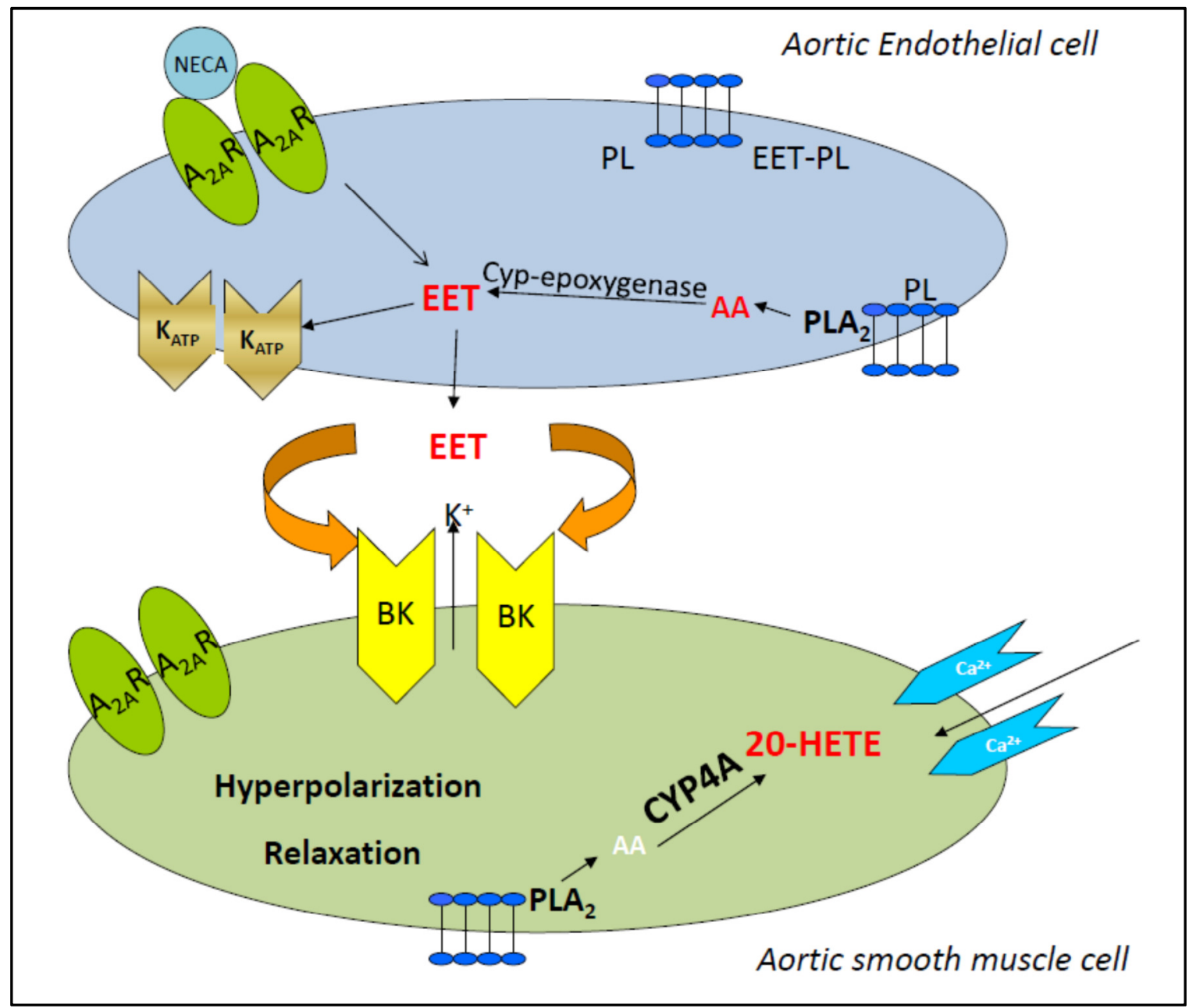

Figure 4.2: Schematic showing the events in the absence of $A_{1} A R$. NECA possibly activates $A_{2 A} R$, leading to activation of Cyp-epoxygenases, which produce EETs and actiavte $K_{\mathrm{ATP}}$ channels

(Nayeem et al., 2008; Ponnoth et al., 2012a; Ponnoth et al., 2012b); EETs diffuse out of the endothelial cell and are also known to activate BK channels in the smooth muscle. 


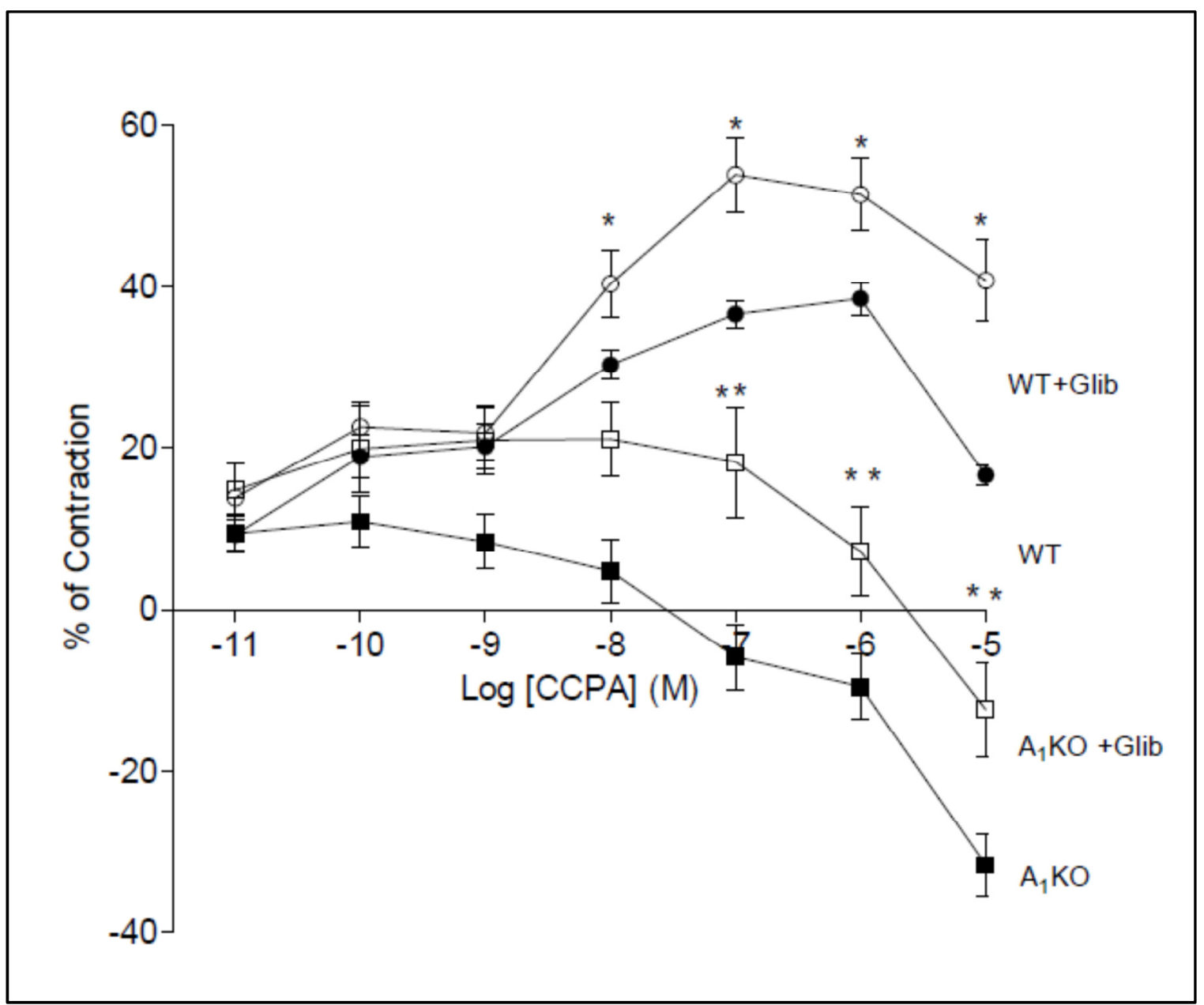

Figure 4.3: Effect of Glibenclamide $(G l i b ; 10 \mu M)$ on CCPA induced contraction.

Data are expressed Mean $\pm \mathrm{SEM} ;{ }^{*} \mathrm{p}<0.05$ between WT and $\mathrm{WT}+\mathrm{Glib}$ and $* * \mathrm{p}<0.05$ between $\mathrm{A}_{1} \mathrm{KO}$ and $\mathrm{A}_{1} \mathrm{KO}+\mathrm{Glib} ; \mathrm{n}=6$ 


\section{Future Directions}

The next step for this project would be to determine the ion channels in the endothelium that could be involved in the regulation of the vascular tone by $\mathrm{A}_{1} \mathrm{AR}$ and Cyp450 metabolites. Our preliminary vascular reactivity experiments showed that $\mathrm{K}_{\mathrm{ATP}}$ inhibitor, Glibenclamide (Glib) significantly increased the CCPA induced contraction in WT as well as $\mathrm{A}_{1} \mathrm{KO}$ (Fig.4.3). This suggests that Glib- sensitive $\mathrm{K}_{\mathrm{ATP}}$ channels contribute to adenosine-mediated relaxation and inhibition of these channels contribute to the $\mathrm{A}_{1}$ mediated contraction.

$\mathrm{K}_{\mathrm{ATP}}$ channels are octameric complexes composed of four SUR and four Kir subunits. They are found in the vascular smooth muscle of both resistance and conduit arteries (Quayle et al., 1997). Several studies have shown that $A_{1}$ AR mimics adenosine effects by coupling with $\mathrm{K}_{\mathrm{ATP}}$ in the rat aortic endothelium and causing release of nitric oxide (NO) (Ray and Marshall, 2006) in pig coronary arterioles smooth muscle cells (Dart and Standen, 1993), rat diaphragmatic arterioles (Danialou et al., 1997) and in the rat skeletal muscle (Bryan and Marshall, 1999). Our lab has shown previously that $\mathrm{A}_{1} \mathrm{AR}$ is up-regulated in $\mathrm{A}_{2 \mathrm{~A}} \mathrm{KO}$ mice aortae (Ponnoth et al., 2012b) and Glib causes higher contraction to NECA in $\mathrm{A}_{2 \mathrm{~A}} \mathrm{KO}$ (Ponnoth et al., 2012b). This meshes well with our preliminary data suggesting that inhibition of the $\mathrm{K}_{\mathrm{ATP}}$ channel is involved in the $\mathrm{A}_{1} \mathrm{AR}$ regulation of vascular tone. Furthermore, our lab has shown that the endothelial $\mathrm{K}_{\mathrm{ATP}}$ channels are activated by the $\mathrm{A}_{2 \mathrm{~A}} \mathrm{AR}$-Cyp-epoxygenases pathway in the mouse aorta (Ponnoth et al., 2012a). Given this evidence, we speculate that in the endothelium, the activation of $A_{1} A R$ causes inhibition of $K_{A T P}$ channels and this signal is transduced to smooth muscle resulting in its contraction. 
However, more experiments such as vascular reactivity studies to confirm the involvement of endothelial $\mathrm{K}_{\mathrm{ATP}}$ channels in $\mathrm{A}_{1} \mathrm{AR}$ mediated responses are needed. Electrophysiological experiments can be done to further confirm the findings using the $\mathrm{A}_{1} \mathrm{KO}$ and WT aortic endothelial cells. However, the signaling and the role of Cyp450 metabolites pathway in mediating this vascular function is unknown and needs to be studied. Since both the Cyp450 metabolites and adenosine play a role in the preservation of a normal endothelial functioning, understanding the relationship between them will provide a deeper insight of the factors underlying endothelial dysfunction, a major contributor to several cardiovascular diseases.

The role of Cyp4a metabolite, 20-HETE in blood pressure regulation is well documented, and 20-HETE functions as a pro-hypertensive or as an antihypertensive eicosanoid depending on its expression site. In the renal tubules, it functions as an antihypertensive by inhibiting the $\mathrm{Na}^{+}$transport and increasing $\mathrm{Na}^{+}$loss. In contrast, in the peripheral vessels it functions as a pro-hypertensive, by increasing the vascular tone, thereby increasing the peripheral vascular resistance and the arterial pressure (Williams et al., 2010) . There is overwhelming evidence that mutations in Cyp4al1 and Cyp4f2 lead to the development of hypertension in human population studies. Moreover, prolonged hypertension is a harbinger for atrial fibrillation, left ventricular hypertrophy, myocardial infarction, congestive heart failure leading to end stage renal disease and stroke (Kraja et al.; Dobbelsteyn et al., 2001).

There are conflicting reports of involvement of $\mathrm{A}_{1} \mathrm{AR}$ in blood pressure regulation. Brown et al, 2001 and Wang et al, 2010 (Brown et al., 2001; Wang et al., 2010) have shown that blood pressure levels are elevated in A1KO mice, whereas, Sun et al, 2001 and Schweda et al, 2005 (Sun et al., 2001; Schweda et al., 2005) have shown no 
difference in blood pressure between the WT and $\mathrm{A}_{1} \mathrm{KO}$ mice. Although the role of $\mathrm{A}_{1} \mathrm{AR}$ in regulation of heart rate and cardio-protective action after an ischemic insult is well-documented (Jacobson and Gao, 2006), its role in blood pressure regulation remains ambiguous.

Thus, the findings of this dissertation, which shed some light on the relationship between $\mathrm{A}_{1} \mathrm{AR}$ and 20-HETE, can serve as the basis for further exploration of the role of $\mathrm{A}_{1} \mathrm{AR}$ in blood pressure. 


\section{References}

Abbracchio MP, Boeynaems JM, Barnard EA, Boyer JL, Kennedy C, Miras-Portugal MT, King BF, Gachet C, Jacobson KA, Weisman GA and Burnstock G (2003) Characterization of the UDP-glucose receptor (re-named here the P2Y14 receptor) adds diversity to the P2Y receptor family. Trends Pharmacol Sci 24:5255.

Abbracchio MP, Brambilla R, Ceruti S, Kim HO, von Lubitz DK, Jacobson KA and Cattabeni F (1995) G protein-dependent activation of phospholipase C by adenosine A3 receptors in rat brain. Mol Pharmacol 48:1038-1045.

Abebe W and Mustafa SJ (1998) A1 adenosine receptor-mediated Ins(1,4,5)P3 generation in allergic rabbit airway smooth muscle. Am J Physiol 275:L990-997.

Alonso-Galicia M, Hudetz AG, Shen H, Harder DR and Roman RJ (1999) Contribution of 20-HETE to vasodilator actions of nitric oxide in the cerebral microcirculation. Stroke 30:2727-2734; discussion 2734.

Alonso-Galicia M, Sun CW, Falck JR, Harder DR and Roman RJ (1998) Contribution of 20-HETE to the vasodilator actions of nitric oxide in renal arteries. Am J Physiol 275:F370-378.

Ansari HR, Husain S and Abdel-Latif AA (2001) Activation of p42/p44 mitogenactivated protein kinase and contraction by prostaglandin F2alpha, ionomycin, and thapsigargin in cat iris sphincter smooth muscle: inhibition by PD98059, KN93, and isoproterenol. J Pharmacol Exp Ther 299:178-186.

Ansari HR, Nadeem A, Talukder MA, Sakhalkar S and Mustafa SJ (2007a) Evidence for the involvement of nitric oxide in $\mathrm{A} 2 \mathrm{~B}$ receptor-mediated vasorelaxation of mouse aorta. Am J Physiol Heart Circ Physiol 292:H719-725. 
Ansari HR, Nadeem A, Tilley SL and Mustafa SJ (2007b) Involvement of COX-1 in A3 adenosine receptor-mediated contraction through endothelium in mice aorta. Am J Physiol Heart Circ Physiol 293:H3448-3455.

Ansari HR, Teng B, Nadeem A, Roush KP, Martin KH, Schnermann J and Mustafa SJ (2009) A(1) adenosine receptor-mediated PKC and p42/p44 MAPK signaling in mouse coronary artery smooth muscle cells. Am J Physiol Heart Circ Physiol 297:H1032-1039.

Asano S, Bratz IN, Berwick ZC, Fancher IS, Tune JD and Dick GM (2012) Penitrem A as a tool for understanding the role of large conductance $\mathrm{Ca}(2+) /$ voltage-sensitive $\mathrm{K}(+)$ channels in vascular function. J Pharmacol Exp Ther 342:453-460.

Asano S, Tune JD and Dick GM (2010) Bisphenol A activates Maxi-K (K(Ca)1.1) channels in coronary smooth muscle. Br J Pharmacol 160:160-170.

Basora N, Boulay G, Bilodeau L, Rousseau E and Payet MD (2003) 20hydroxyeicosatetraenoic acid (20-HETE) activates mouse TRPC6 channels expressed in HEK293 cells. J Biol Chem 278:31709-31716.

Berczi V, Stekiel WJ, Contney SJ and Rusch NJ (1992) Pressure-induced activation of membrane $\mathrm{K}+$ current in rat saphenous artery. Hypertension 19:725-729.

Biaggioni I, King LS, Enayat N, Robertson D and Newman JH (1989) Adenosine produces pulmonary vasoconstriction in sheep. Evidence for thromboxane A2/prostaglandin endoperoxide-receptor activation. Circ Res 65:1516-1525.

Bonev AD and Nelson MT (1996) Vasoconstrictors inhibit ATP-sensitive K+ channels in arterial smooth muscle through protein kinase C. J Gen Physiol 108:315-323. 
Borbouse L, Dick GM, Asano S, Bender SB, Dincer UD, Payne GA, Neeb ZP, Bratz IN, Sturek M and Tune JD (2009) Impaired function of coronary BK(Ca) channels in metabolic syndrome. Am J Physiol Heart Circ Physiol 297:H1629-1637.

Brayden JE, Earley S, Nelson MT and Reading S (2008) Transient receptor potential (TRP) channels, vascular tone and autoregulation of cerebral blood flow. Clin Exp Pharmacol Physiol 35:1116-1120.

Brayden JE, Quayle JM, Standen NB and Nelson MT (1991) Role of potassium channels in the vascular response to endogenous and pharmacological vasodilators. Blood Vessels 28:147-153.

Brenner R, Perez GJ, Bonev AD, Eckman DM, Kosek JC, Wiler SW, Patterson AJ, Nelson MT and Aldrich RW (2000) Vasoregulation by the beta1 subunit of the calcium-activated potassium channel. Nature 407:870-876.

Brown R, Ollerstam A, Johansson B, Skott O, Gebre-Medhin S, Fredholm B and Persson AE (2001) Abolished tubuloglomerular feedback and increased plasma renin in adenosine A1 receptor-deficient mice. Am J Physiol Regul Integr Comp Physiol 281:R1362-1367.

Bryan PT and Marshall JM (1999) Adenosine receptor subtypes and vasodilatation in rat skeletal muscle during systemic hypoxia: a role for A1 receptors. $J$ Physiol $\mathbf{5 1 4}$ ( Pt 1):151-162.

Cabell F, Weiss DS and Price JM (1994) Inhibition of adenosine-induced coronary vasodilation by block of large-conductance $\mathrm{Ca}(2+)$-activated $\mathrm{K}+$ channels. $\mathrm{Am} J$ Physiol 267:H1455-1460. 
Capdevila J, Marnett LJ, Chacos N, Prough RA and Estabrook RW (1982) Cytochrome P-450-dependent oxygenation of arachidonic acid to hydroxyicosatetraenoic acids. Proc Natl Acad Sci U S A 79:767-770.

Carroll MA, Balazy M, Margiotta P, Huang DD, Falck JR and McGiff JC (1996) Cytochrome P-450-dependent HETEs: profile of biological activity and stimulation by vasoactive peptides. Am J Physiol 271:R863-869.

Carroll MA, Doumad AB, Li J, Cheng MK, Falck JR and McGiff JC (2006) Adenosine2A receptor vasodilation of rat preglomerular microvessels is mediated by EETs that activate the cAMP/PKA pathway. Am J Physiol Renal Physiol 291:F155-161.

Carroll MA, Garcia MP, Falck JR and McGiff JC (1992) Cyclooxygenase dependency of the renovascular actions of cytochrome P450-derived arachidonate metabolites. $J$ Pharmacol Exp Ther 260:104-109.

Chacos N, Falck JR, Wixtrom C and Capdevila J (1982) Novel epoxides formed during the liver cytochrome P-450 oxidation of arachidonic acid. Biochem Biophys Res Commun 104:916-922.

Chang K, Xiao D, Huang X, Longo LD and Zhang L (2009) Chronic hypoxia increases pressure-dependent myogenic tone of the uterine artery in pregnant sheep: role of ERK/PKC pathway. Am J Physiol Heart Circ Physiol 296:H1840-1849.

Cheng DY, DeWitt BJ, Suzuki F, Neely CF and Kadowitz PJ (1996) Adenosine A1 and A2 receptors mediate tone-dependent responses in feline pulmonary vascular bed. Am J Physiol 270:H200-207.

Cheng J, Ou JS, Singh H, Falck JR, Narsimhaswamy D, Pritchard KA, Jr. and Schwartzman ML (2008) 20-hydroxyeicosatetraenoic acid causes endothelial 
dysfunction via eNOS uncoupling. Am J Physiol Heart Circ Physiol 294:H10181026.

Cheng MK, Doumad AB, Jiang H, Falck JR, McGiff JC and Carroll MA (2004) Epoxyeicosatrienoic acids mediate adenosine-induced vasodilation in rat preglomerular microvessels (PGMV) via A2A receptors. $\mathrm{Br} J$ Pharmacol 141:441-448.

Cogolludo A, Moreno L, Bosca L, Tamargo J and Perez-Vizcaino F (2003) Thromboxane A2-induced inhibition of voltage-gated $\mathrm{K}+$ channels and pulmonary vasoconstriction: role of protein kinase Czeta. Circ Res 93:656-663.

Croft KD, McGiff JC, Sanchez-Mendoza A and Carroll MA (2000) Angiotensin II releases 20-HETE from rat renal microvessels. Am J Physiol Renal Physiol 279:F544-551.

Danialou G, Vicaut E, Sambe A, Aubier M and Boczkowski J (1997) Predominant role of A1 adenosine receptors in mediating adenosine induced vasodilatation of rat diaphragmatic arterioles: involvement of nitric oxide and the ATP-dependent $\mathrm{K}+$ channels. Br J Pharmacol 121:1355-1363.

Dart C and Standen NB (1993) Adenosine-activated potassium current in smooth muscle cells isolated from the pig coronary artery. J Physiol 471:767-786.

Ding Y, Schwartz D, Posner P and Zhong J (2004) Hypotonic swelling stimulates L-type $\mathrm{Ca} 2+$ channel activity in vascular smooth muscle cells through PKC. Am J Physiol Cell Physiol 287:C413-421.

Dobbelsteyn CJ, Joffres MR, MacLean DR and Flowerdew G (2001) A comparative evaluation of waist circumference, waist-to-hip ratio and body mass index as 
indicators of cardiovascular risk factors. The Canadian Heart Health Surveys. Int J Obes Relat Metab Disord 25:652-661.

Drury AN and Szent-Gyorgyi A (1929) The physiological activity of adenine compounds with especial reference to their action upon the mammalian heart. J Physiol 68:213-237.

El-Awady MS, Ansari HR, Fil D, Tilley SL and Mustafa SJ (2011) NADPH oxidase pathway is involved in aortic contraction induced by A3 adenosine receptor in mice. J Pharmacol Exp Ther 338:711-717.

Fleming I (2001) Cytochrome p450 and vascular homeostasis. Circ Res 89:753-762.

Fleming I (2010) Molecular mechanisms underlying the activation of eNOS. Pflugers Arch 459:793-806.

Ford WR and Broadley KJ (1999) Effects of adenosine receptor agonists on induction of contractions to phenylephrine of guinea-pig aorta mediated via intra- or extracellular calcium. Gen Pharmacol 33:143-150.

Fredholm BB (2007) Adenosine, an endogenous distress signal, modulates tissue damage and repair. Cell Death Differ 14:1315-1323.

Fredholm BB, AP IJ, Jacobson KA, Klotz KN and Linden J (2001) International Union of Pharmacology. XXV. Nomenclature and classification of adenosine receptors. Pharmacol Rev 53:527-552.

Frick GP and Lowenstein JM (1976) Studies of 5'-nucleotidase in the perfused rat heart. Including measurements of the enzyme in perfused skeletal muscle and liver. $J$ Biol Chem 251:6372-6378. 
Frisbee JC, Falck JR and Lombard JH (2000) Contribution of cytochrome P-450 omegahydroxylase to altered arteriolar reactivity with high-salt diet and hypertension. Am J Physiol Heart Circ Physiol 278:H1517-1526.

Fulton D, Balazy M, McGiff JC and Quilley J (1996) Possible contribution of platelet cyclooxygenase to the renal vascular action of 5,6-epoxyeicosatrienoic acid. $J$ Pharmacol Exp Ther 277:1195-1199.

Gebremedhin D, Lange AR, Lowry TF, Taheri MR, Birks EK, Hudetz AG, Narayanan J, Falck JR, Okamoto H, Roman RJ, Nithipatikom K, Campbell WB and Harder DR (2000) Production of 20-HETE and its role in autoregulation of cerebral blood flow. Circ Res 87:60-65.

Hansen PB, Castrop H, Briggs J and Schnermann J (2003) Adenosine induces vasoconstriction through Gi-dependent activation of phospholipase $\mathrm{C}$ in isolated perfused afferent arterioles of mice. J Am Soc Nephrol 14:2457-2465.

Harder DR, Gebremedhin D, Narayanan J, Jefcoat C, Falck JR, Campbell WB and Roman R (1994) Formation and action of a P-450 4A metabolite of arachidonic acid in cat cerebral microvessels. Am J Physiol 266:H2098-2107.

Harder DR, Lange AR, Gebremedhin D, Birks EK and Roman RJ (1997) Cytochrome P450 metabolites of arachidonic acid as intracellular signaling molecules in vascular tissue. J Vasc Res 34:237-243.

Heaps CL and Bowles DK (2002) Gender-specific K(+)-channel contribution to adenosine-induced relaxation in coronary arterioles. J Appl Physiol 92:550-558.

Hein TW and Kuo L (1999) cAMP-independent dilation of coronary arterioles to adenosine : role of nitric oxide, G proteins, and K(ATP) channels. Circ Res 85:634-642. 
Hein TW, Wang W, Zoghi B, Muthuchamy M and Kuo L (2001) Functional and molecular characterization of receptor subtypes mediating coronary microvascular dilation to adenosine. J Mol Cell Cardiol 33:271-282.

Hercule HC and Oyekan AO (2000) Cytochrome P450 omega/omega-1 hydroxylasederived eicosanoids contribute to endothelin(A) and endothelin(B) receptormediated vasoconstriction to endothelin-1 in the rat preglomerular arteriole. $J$ Pharmacol Exp Ther 292:1153-1160.

Hoagland KM, Maier KG, Moreno C, Yu M and Roman RJ (2001) Cytochrome P450 metabolites of arachidonic acid: novel regulators of renal function. Nephrol Dial Transplant 16:2283-2285.

Imig JD (2012) Epoxides and soluble epoxide hydrolase in cardiovascular physiology. Physiol Rev 92:101-130.

Imig JD and Navar LG (1996) Afferent arteriolar response to arachidonic acid: involvement of metabolic pathways. Am J Physiol 271:F87-93.

Imig JD, Pham BT, LeBlanc EA, Reddy KM, Falck JR and Inscho EW (2000) Cytochrome P450 and cyclooxygenase metabolites contribute to the endothelin-1 afferent arteriolar vasoconstrictor and calcium responses. Hypertension 35:307312.

Imig JD, Zou AP, Stec DE, Harder DR, Falck JR and Roman RJ (1996) Formation and actions of 20-hydroxyeicosatetraenoic acid in rat renal arterioles. Am J Physiol 270:R217-227.

Jackson WF (2000) Ion channels and vascular tone. Hypertension 35:173-178.

Jacobson KA and Gao ZG (2006) Adenosine receptors as therapeutic targets. Nat Rev Drug Discov 5:247-264. 
Kitamura K, Xiong Z, Teramoto N and Kuriyama H (1992) Roles of inositol trisphosphate and protein kinase $\mathrm{C}$ in the spontaneous outward current modulated by calcium release in rabbit portal vein. Pflugers Arch 421:539-551.

Kraja AT, Hunt SC, Rao DC, Davila-Roman VG, Arnett DK and Province MA Genetics of hypertension and cardiovascular disease and their interconnected pathways: lessons from large studies. Curr Hypertens Rep 13:46-54.

Krishnamoorthy G, Shi J, Sept D and Cui J (2005) The NH2 terminus of RCK1 domain regulates $\mathrm{Ca} 2+-d e p e n d e n t \mathrm{BK}(\mathrm{Ca})$ channel gating. J Gen Physiol 126:227-241.

Krotz F, Riexinger T, Buerkle MA, Nithipatikom K, Gloe T, Sohn HY, Campbell WB and Pohl U (2004) Membrane-potential-dependent inhibition of platelet adhesion to endothelial cells by epoxyeicosatrienoic acids. Arterioscler Thromb Vasc Biol 24:595-600.

Kunduri S, Mustafa S, Ponnoth D, Dick G and Nayeem M (2013) Adenosine A1 receptors link to smooth muscle contraction via CYP4a, PKC-alpha, and ERK1/2. J Cardiovasc Pharmacol.

Lange A, Gebremedhin D, Narayanan J and Harder D (1997) 20Hydroxyeicosatetraenoic acid-induced vasoconstriction and inhibition of potassium current in cerebral vascular smooth muscle is dependent on activation of protein kinase C. J Biol Chem 272:27345-27352.

Ledoux J, Werner ME, Brayden JE and Nelson MT (2006) Calcium-activated potassium channels and the regulation of vascular tone. Physiology (Bethesda) 21:69-78.

Li G and Cheung DW (2000) Modulation of $\mathrm{Ca}(2+)$-dependent $\mathrm{K}(+)$ currents in mesenteric arterial smooth muscle cells by adenosine. Eur J Pharmacol 394:3540. 
Li PL and Campbell WB (1997) Epoxyeicosatrienoic acids activate K+ channels in coronary smooth muscle through a guanine nucleotide binding protein. Circ Res 80:877-884.

Li PL, Zhang DX, Ge ZD and Campbell WB (2002) Role of ADP-ribose in 11,12-EETinduced activation of $\mathrm{K}(\mathrm{Ca})$ channels in coronary arterial smooth muscle cells. Am J Physiol Heart Circ Physiol 282:H1229-1236.

Livak KJ and Schmittgen TD (2001) Analysis of relative gene expression data using realtime quantitative PCR and the 2(-Delta Delta C(T)) Method. Methods 25:402-408.

Lloyd HG and Fredholm BB (1995) Involvement of adenosine deaminase and adenosine kinase in regulating extracellular adenosine concentration in rat hippocampal slices. Neurochem Int 26:387-395.

Loufrani L, Lehoux S, Tedgui A, Levy BI and Henrion D (1999) Stretch induces mitogen-activated protein kinase activation and myogenic tone through 2 distinct pathways. Arterioscler Thromb Vasc Biol 19:2878-2883.

Ma YH, Gebremedhin D, Schwartzman ML, Falck JR, Clark JE, Masters BS, Harder DR and Roman RJ (1993) 20-Hydroxyeicosatetraenoic acid is an endogenous vasoconstrictor of canine renal arcuate arteries. Circ Res 72:126-136.

Matsumoto T, Tostes RC and Webb RC (2011) Uridine adenosine tetraphosphateinduced contraction is increased in renal but not pulmonary arteries from DOCAsalt hypertensive rats. Am J Physiol Heart Circ Physiol 301:H409-417.

Michaelis UR and Fleming I (2006) From endothelium-derived hyperpolarizing factor (EDHF) to angiogenesis: Epoxyeicosatrienoic acids (EETs) and cell signaling. Pharmacol Ther 111:584-595. 
Miller TM, Donnelly MK, Crago EA, Roman DM, Sherwood PR, Horowitz MB and Poloyac SM (2009) Rapid, simultaneous quantitation of mono and dioxygenated metabolites of arachidonic acid in human CSF and rat brain. $J$ Chromatogr $B$ Analyt Technol Biomed Life Sci 877:3991-4000.

Miyata N and Roman RJ (2005) Role of 20-hydroxyeicosatetraenoic acid (20-HETE) in vascular system. J Smooth Muscle Res 41:175-193.

Moro S, Gao ZG, Jacobson KA and Spalluto G (2006) Progress in the pursuit of therapeutic adenosine receptor antagonists. Med Res Rev 26:131-159.

Nayeem MA, Poloyac SM, Falck JR, Zeldin DC, Ledent C, Ponnoth DS, Ansari HR and Mustafa SJ (2008) Role of CYP epoxygenases in A2A AR-mediated relaxation using A2A AR-null and wild-type mice. Am J Physiol Heart Circ Physiol 295:H2068-2078.

Nayeem MA, Ponnoth DS, Boegehold MA, Zeldin DC, Falck JR and Mustafa SJ (2009) High-salt diet enhances mouse aortic relaxation through adenosine A2A receptor via CYP epoxygenases. Am J Physiol Regul Integr Comp Physiol 296:R567-574.

Nell PG and Albrecht-Kupper B (2009) The adenosine A1 receptor and its ligands. Prog Med Chem 47:163-201.

Nelson MT (1993) Ca(2+)-activated potassium channels and ATP-sensitive potassium channels as modulators of vascular tone. Trends Cardiovasc Med 3:54-60.

Nelson MT, Cheng H, Rubart M, Santana LF, Bonev AD, Knot HJ and Lederer WJ (1995) Relaxation of arterial smooth muscle by calcium sparks. Science 270:633637. 
Nelson MT, Patlak JB, Worley JF and Standen NB (1990) Calcium channels, potassium channels, and voltage dependence of arterial smooth muscle tone. Am J Physiol 259:C3-18.

Nelson MT and Quayle JM (1995) Physiological roles and properties of potassium channels in arterial smooth muscle. Am J Physiol 268:C799-822.

Newby AC, Worku Y and Holmquist CA (1985) Adenosine formation. Evidence for a direct biochemical link with energy metabolism. Adv Myocardiol 6:273-284.

Nowicki S, Chen SL, Aizman O, Cheng XJ, Li D, Nowicki C, Nairn A, Greengard P and Aperia A (1997) 20-Hydroxyeicosa-tetraenoic acid (20 HETE) activates protein kinase C. Role in regulation of rat renal $\mathrm{Na}+\mathrm{K}+-\mathrm{ATPase}$ J Clin Invest 99:12241230.

Obara K, Koide M and Nakayama K (2002) 20-Hydroxyeicosatetraenoic acid potentiates stretch-induced contraction of canine basilar artery via PKC alpha-mediated inhibition of KCa channel. Br J Pharmacol 137:1362-1370.

Oyekan A, Balazy M and McGiff JC (1997) Renal oxygenases: differential contribution to vasoconstriction induced by ET-1 and ANG II. Am J Physiol 273:R293-300.

Paterno R, Faraci FM and Heistad DD (1996) Role of Ca(2+)-dependent K+ channels in cerebral vasodilatation induced by increases in cyclic GMP and cyclic AMP in the rat. Stroke 27:1603-1607; discussion 1607-1608.

Perez GJ, Bonev AD, Patlak JB and Nelson MT (1999) Functional coupling of ryanodine receptors to $\mathrm{KCa}$ channels in smooth muscle cells from rat cerebral arteries. J Gen Physiol 113:229-238. 
Poloyac SM, Zhang Y, Bies RR, Kochanek PM and Graham SH (2006) Protective effect of the 20-HETE inhibitor HET0016 on brain damage after temporary focal ischemia. J Cereb Blood Flow Metab 26:1551-1561.

Ponnoth DS, Nadeem A and Mustafa SJ (2008) Adenosine-mediated alteration of vascular reactivity and inflammation in a murine model of asthma. Am J Physiol Heart Circ Physiol 294:H2158-2165.

Ponnoth DS, Nayeem MA, Kunduri SS, Tilley SL, Zeldin DC, Ledent C and Mustafa SJ (2012a) Role of omega-hydroxylase in adenosine-mediated aortic response through MAP kinase using A2A-receptor knockout mice. Am J Physiol Regul Integr Comp Physiol 302:R400-408.

Ponnoth DS, Nayeem MA, Tilley SL, Ledent C and Jamal Mustafa S (2012b) CYPepoxygenases contribute to $\mathrm{A} 2 \mathrm{~A}$ receptor-mediated aortic relaxation via sarcolemmal KATP channels. Am J Physiol Regul Integr Comp Physiol 303:R1003-1010.

Ponnoth DS, Sanjani MS, Ledent C, Roush K, Krahn T and Mustafa SJ (2009) Absence of adenosine-mediated aortic relaxation in $\mathrm{A}(2 \mathrm{~A})$ adenosine receptor knockout mice. Am J Physiol Heart Circ Physiol 297:H1655-1660.

Prentice DJ, Kelly MD, Ledent C and Hourani SM (2002) Relaxation of the mouse isolated aorta and carotid artery in response to adenosine analogues in geneticallymodified mice lacking the adenosine A(2A) receptor. Naunyn Schmiedebergs Arch Pharmacol 366:127-133.

Preston A, Frydenberg M and Haynes JM (2004) A1 and A2A adenosine receptor modulation of alpha 1-adrenoceptor-mediated contractility in human cultured prostatic stromal cells. Br J Pharmacol 141:302-310. 
Quayle JM, McCarron JG, Brayden JE and Nelson MT (1993) Inward rectifier K+ currents in smooth muscle cells from rat resistance-sized cerebral arteries. Am J Physiol 265:C1363-1370.

Quayle JM, Nelson MT and Standen NB (1997) ATP-sensitive and inwardly rectifying potassium channels in smooth muscle. Physiological reviews 77:1165-1232.

Randriamboavonjy V, Kiss L, Falck JR, Busse R and Fleming I (2005) The synthesis of 20-HETE in small porcine coronary arteries antagonizes EDHF-mediated relaxation. Cardiovasc Res 65:487-494.

Ray CJ and Marshall JM (2006) The cellular mechanisms by which adenosine evokes release of nitric oxide from rat aortic endothelium. J Physiol 570:85-96.

Rogel A, Bromberg Y, Sperling O and Zoref-Shani E (2005) Phospholipase C is involved in the adenosine-activated signal transduction pathway conferring protection against iodoacetic acid-induced injury in primary rat neuronal cultures. Neurosci Lett 373:218-221.

Roman RJ (2002) P-450 metabolites of arachidonic acid in the control of cardiovascular function. Physiol Rev 82:131-185.

Roman RJ, Maier KG, Sun CW, Harder DR and Alonso-Galicia M (2000) Renal and cardiovascular actions of 20-hydroxyeicosatetraenoic acid and epoxyeicosatrienoic acids. Clin Exp Pharmacol Physiol 27:855-865.

Rump LC, Jabbari TJ, von Kugelgen I and Oberhauser V (1999) Adenosine mediates nitric-oxide-independent renal vasodilation by activation of A2A receptors. $J$ Hypertens 17:1987-1993. 
Sakwe AM, Rask L and Gylfe E (2005) Protein kinase C modulates agonist-sensitive release of Ca2+ from internal stores in HEK293 cells overexpressing the calcium sensing receptor. J Biol Chem 280:4436-4441.

Sato A, Terata K, Miura H, Toyama K, Loberiza FR, Jr., Hatoum OA, Saito T, Sakuma I and Gutterman DD (2005) Mechanism of vasodilation to adenosine in coronary arterioles from patients with heart disease. Am J Physiol Heart Circ Physiol 288:H1633-1640.

Schubert R, Noack T and Serebryakov VN (1999) Protein kinase C reduces the KCa current of rat tail artery smooth muscle cells. Am J Physiol 276:C648-658.

Schutz W, Schrader J and Gerlach E (1981) Different sites of adenosine formation in the heart. Am J Physiol 240:H963-970.

Schwartzman ML, Falck JR, Yadagiri P and Escalante B (1989) Metabolism of 20hydroxyeicosatetraenoic acid by cyclooxygenase. Formation and identification of novel endothelium-dependent vasoconstrictor metabolites. $J$ Biol Chem 264:11658-11662.

Schweda F, Segerer F, Castrop H, Schnermann J and Kurtz A (2005) Blood pressuredependent inhibition of Renin secretion requires A1 adenosine receptors. Hypertension 46:780-786.

Sharifi Sanjani M, Zhou X, Asano S, Tilley SL, Ledent C, Teng B, Dick GM and Mustafa SJ (2013) Interactions between A2A adenosine receptors, hydrogen peroxide, and KATP channels in coronary reactive hyperemia. Am J Physiol Heart Circ Physiol. 
Shim JO, Shin CY, Lee TS, Yang SJ, An JY, Song HJ, Kim TH, Huh IH and Sohn UD (2002) Signal transduction mechanism via adenosine A1 receptor in the cat esophageal smooth muscle cells. Cell Signal 14:365-372.

Singh H, Cheng J, Deng H, Kemp R, Ishizuka T, Nasjletti A and Schwartzman ML (2007) Vascular cytochrome P450 4A expression and 20-hydroxyeicosatetraenoic acid synthesis contribute to endothelial dysfunction in androgen-induced hypertension. Hypertension 50:123-129.

Singh TU, Choudhury S, Parida S, Maruti BS and Mishra SK (2012) Arachidonic acid inhibits Na-K-ATPase via cytochrome P-450, lipoxygenase and protein kinase Cdependent pathways in sheep pulmonary artery. Vascul Pharmacol 56:84-90.

Sodhi K, Wu CC, Cheng J, Gotlinger K, Inoue K, Goli M, Falck JR, Abraham NG and Schwartzman ML (2010) CYP4A2-induced hypertension is 20hydroxyeicosatetraenoic acid- and angiotensin II-dependent. Hypertension 56:871-878.

Sudhahar V, Shaw S and Imig JD (2010) Epoxyeicosatrienoic acid analogs and vascular function. Curr Med Chem 17:1181-1190.

Sun CW, Alonso-Galicia M, Taheri MR, Falck JR, Harder DR and Roman RJ (1998) Nitric oxide-20-hydroxyeicosatetraenoic acid interaction in the regulation of $\mathrm{K}+$ channel activity and vascular tone in renal arterioles. Circ Res 83:1069-1079.

Sun CW, Falck JR, Harder DR and Roman RJ (1999) Role of tyrosine kinase and PKC in the vasoconstrictor response to 20-HETE in renal arterioles. Hypertension 33:414418.

Sun D, Samuelson LC, Yang T, Huang Y, Paliege A, Saunders T, Briggs J and Schnermann J (2001) Mediation of tubuloglomerular feedback by adenosine: 
evidence from mice lacking adenosine 1 receptors. Proc Natl Acad Sci U S A 98:9983-9988.

Sundseth SS, Alberta JA and Waxman DJ (1992) Sex-specific, growth hormoneregulated transcription of the cytochrome $\mathrm{P} 4502 \mathrm{C} 11$ and $2 \mathrm{C} 12$ genes. J Biol Chem 267:3907-3914.

Szentmiklosi AJ, Ujfalusi A, Cseppento A, Nosztray K, Kovacs P and Szabo JZ (1995) Adenosine receptors mediate both contractile and relaxant effects of adenosine in main pulmonary artery of guinea pigs. Naunyn Schmiedebergs Arch Pharmacol 351:417-425.

Tabrizchi R and Bedi S (2001) Pharmacology of adenosine receptors in the vasculature. Pharmacol Ther 91:133-147.

Talukder MA, Morrison RR and Mustafa SJ (2002) Comparison of the vascular effects of adenosine in isolated mouse heart and aorta. Am J Physiol Heart Circ Physiol 282:H49-57.

Tawfik HE, Schnermann J, Oldenburg PJ and Mustafa SJ (2005) Role of A1 adenosine receptors in regulation of vascular tone. Am J Physiol Heart Circ Physiol 288:H1411-1416.

Teng B, Tilley S, Ledent C and Mustafa SJ (2011) Functional profile of adenosine receptor subtypes in mouse mesenteric artery. FASEB J 25:816.812.

Toth P, Rozsa B, Springo Z, Doczi T and Koller A (2011) Isolated human and rat cerebral arteries constrict to increases in flow: role of 20-HETE and TP receptors. J Cereb Blood Flow Metab.

Tracey WR, Magee W, Masamune H, Oleynek JJ and Hill RJ (1998) Selective activation of adenosine A3 receptors with N6-(3-chlorobenzyl)-5'-N- 
methylcarboxamidoadenosine (CB-MECA) provides cardioprotection via KATP channel activation. Cardiovasc Res 40:138-145.

Tucker AL, Jia LG, Holeton D, Taylor AJ and Linden J (2000) Dominance of G(s) in doubly $\mathrm{G}(\mathrm{s}) / \mathrm{G}(\mathrm{i})$-coupled chimaeric $\mathrm{A}(1) / \mathrm{A}(2 \mathrm{~A})$ adenosine receptors in HEK-293 cells. Biochem J 352 Pt 1:203-210.

Wang Y, Yang JN, Arner A, Boels PJ and Fredholm BB (2010) Adenosine A(1) receptors and vascular reactivity. Acta Physiol (Oxf) 199:211-220.

Williams JM, Murphy S, Burke M and Roman RJ (2010) 20-hydroxyeicosatetraeonic acid: a new target for the treatment of hypertension. J Cardiovasc Pharmacol 56:336-344.

Wu CC and Schwartzman ML (2011) The role of 20-HETE in androgen-mediated hypertension. Prostaglandins Other Lipid Mediat 96:45-53.

Xia XM, Zeng X and Lingle CJ (2002) Multiple regulatory sites in large-conductance calcium-activated potassium channels. Nature 418:880-884.

Yasuda H, Lindorfer MA, Myung CS and Garrison JC (1998) Phosphorylation of the G protein gamma12 subunit regulates effector specificity. J Biol Chem 273:2195821965.

Yasuda H, Lindorfer MA, Woodfork KA, Fletcher JE and Garrison JC (1996) Role of the prenyl group on the $\mathrm{G}$ protein gamma subunit in coupling trimeric $\mathrm{G}$ proteins to A1 adenosine receptors. J Biol Chem 271:18588-18595.

Zhou XB, Wulfsen I, Utku E, Sausbier U, Sausbier M, Wieland T, Ruth P and Korth M (2009) Dual role of protein kinase C on BK channel regulation. Proc Natl Acad Sci U S A 107:8005-8010. 
Zhou Y, Huang H, Chang HH, Du J, Wu JF, Wang CY and Wang MH (2006) Induction of renal 20-hydroxyeicosatetraenoic acid by clofibrate attenuates high-fat dietinduced hypertension in rats. J Pharmacol Exp Ther 317:11-18.

Zou AP, Fleming JT, Falck JR, Jacobs ER, Gebremedhin D, Harder DR and Roman RJ (1996) 20-HETE is an endogenous inhibitor of the large-conductance $\mathrm{Ca}(2+)$ activated K+ channel in renal arterioles. Am J Physiol 270:R228-237. 


\section{PUBLICATIONS and ABSTRACTS}

\section{Papers:}

- Kunduri SS, Dick GM, Nayeem MA, Mustafa SJ Adenosine $\mathrm{A}_{1}$ receptors regulate BK channels through a PKC $\alpha$-dependent mechanism in mouse aortic smooth muscle ( under review at AJP-Heart and Circulation)

- Kunduri SS, Mustafa SJ, Ponnoth DS, Tilley S, Dick GM, Nayeem MA Adenosine $A_{1}$ receptors link to smooth muscle contraction via CYP4a, PKC- $\alpha$ and ERK1/2 pathway (L Cardiovasc Pharmacol. 2013 Mar 20. [Epub ahead of print])

- Ponnoth DS, Nayeem MA, Kunduri SS, Fil D, Tilley S, Ledent C, Mustafa SJ Role of $\omega$ hydroxylase in adenosine -mediated aortic response through MAP kinase using $A_{2 A}$ receptor knockout mice (Am J Physiol Regul Integr Comp Physiol. 2012 Feb 15;302(4):R400-8. doi: 10.1152/ajpregu.00481.2011. Epub 2011 Dec 7)

Abstracts:

- Kunduri SS, Dick GM, Nayeem MA, Mustafa SJ Adenosine A1 receptor signaling inhbits BK channels. Experimental Biology, 2013

- Kunduri SS, Nayeem MA, Ponnoth DS, Tilley S, Mustafa SJ Role of L-type voltage gated calcium and large conductance potassium channels in $\mathrm{A}_{1} \mathrm{AR}-$ Cyp 450. Experimental Biology 2012

- Ponnoth DS, Nayeem MA, Kunduri SS, Tilley S, Ledent C, Mustafa SJ Cypepoxygenases mediate adenosine $\mathrm{A}_{2 \mathrm{~A}}$ receptor induced vascular relaxation via $\mathrm{K}_{\mathrm{ATP}}$ channels. Experimental Biology 2012

- Kunduri SS, Nayeem MA, Ponnoth DS, Tilley S, Schnermann JS, Mustafa SJ $\omega$-hydroxylase mediates adenosine A1 receptor mediated vasoconstriction. Experimental Biology 2011

- Ponnoth DS, Nayeem MA, Kunduri SS, Fil D, Tilley S, Ledent C, Mustafa SJ Involvement of CYP4A-mediated MAPK pathway in vascular contraction in A2A adenosine receptor knockout mice. Experimental Biology 2011

- Kunduri SS, Falck JR, Schnermann J, Nayeem MA and Mustafa SJ Exaggerated vasoconstriction depends on $\omega$-hydroxyylase through adenosine $A_{1}$ receptor (AR) in $A_{1}$ WT compared to $A_{1}$ KO mouse aorta. Experimental Biology 2010

- Kunduri SS, Nayeem MA, Schnermann J, Mustafa SJ Role of Cyp4a in Adenosine A1 receptor mediated vasoconstriction. Van Liere Research Day,2009 


\section{APPENDIX A}

This section provides preliminary data to determine the effect of adenosine agonists in WT and $\mathrm{A}_{1} \mathrm{KO}$ mice aortae

Fig. A.1.Preliminary experiments were carried out to determine the effect of NECA in WT (C-57/BL6) and $\mathrm{A}_{1} \mathrm{KO}$ mice. NECA induced relaxation in both WT and $\mathrm{A}_{1} \mathrm{KO}$. However, NECA induced relaxation was significantly higher in $\mathrm{A}_{1} \mathrm{KO}$ mice due to ablation of $\mathrm{A}_{1} \mathrm{AR}$ gene $(\mathrm{n}=8-12)$. Data are expressed as Mean $\pm \mathrm{SEM}, * \mathrm{p}<0.05$ as compared to WT; $(\mathrm{n}=8-12)$.

\section{NECA CONCENTRATION RESPONSE CURVE IN WT AND A KO MICE}

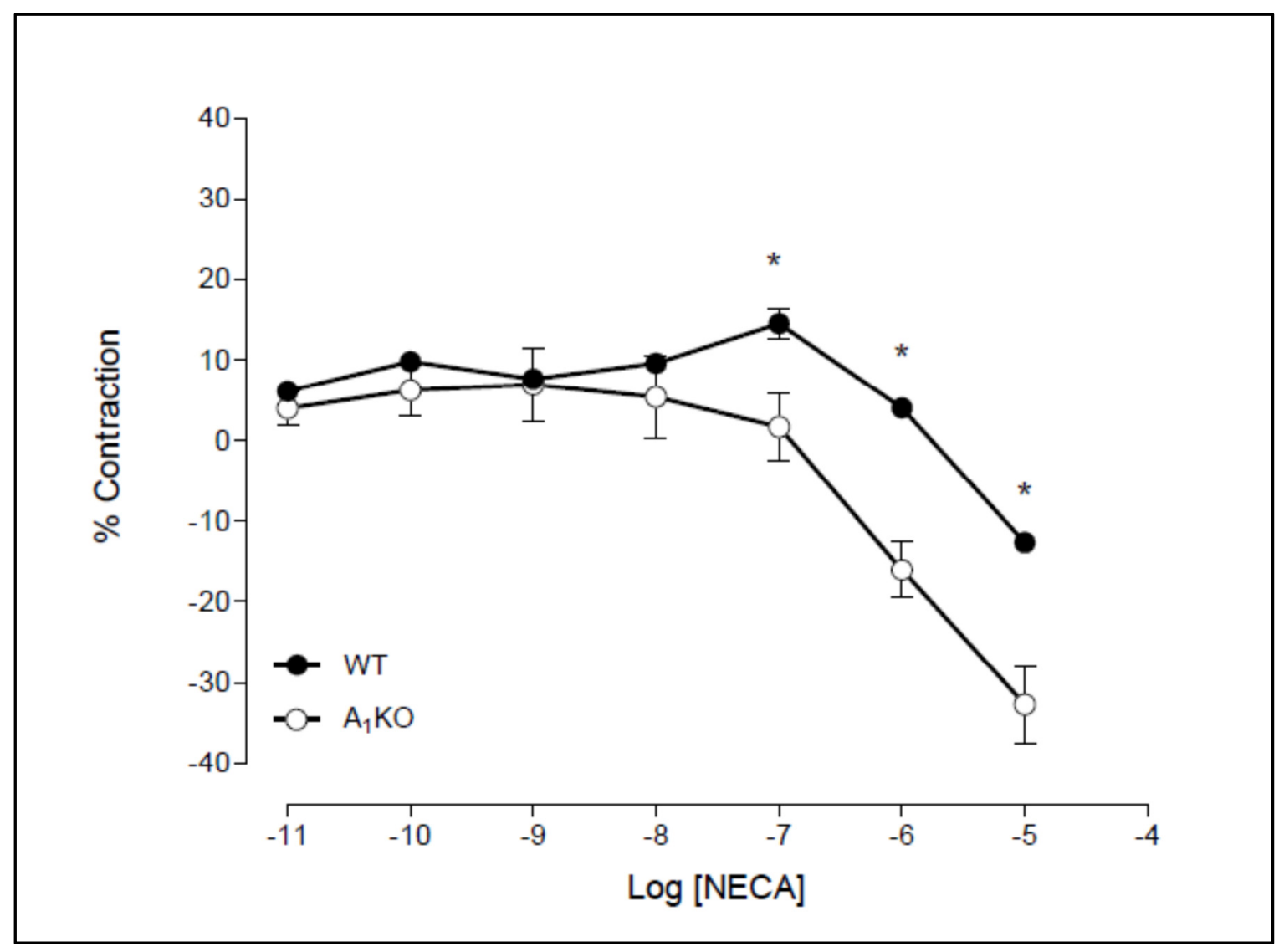


Fig.A.2.Preliminary experiments were carried out to determine the effect of CCPA in WT (C-57/BL6) and $\mathrm{A}_{1} \mathrm{KO}$ mice. CCPA induced contraction in WT and the lack of $\mathrm{A}_{1} \mathrm{AR}$ gene results in relaxation in $\mathrm{A}_{1} \mathrm{KO}$. Data are expressed as Mean $\pm \mathrm{SEM},{ }^{*} \mathrm{p}<0.05$ as compared to WT; $(\mathrm{n}=8-12)$.

\section{CCPA INDUCED CONCENTRATION RESPONSE CURVE}

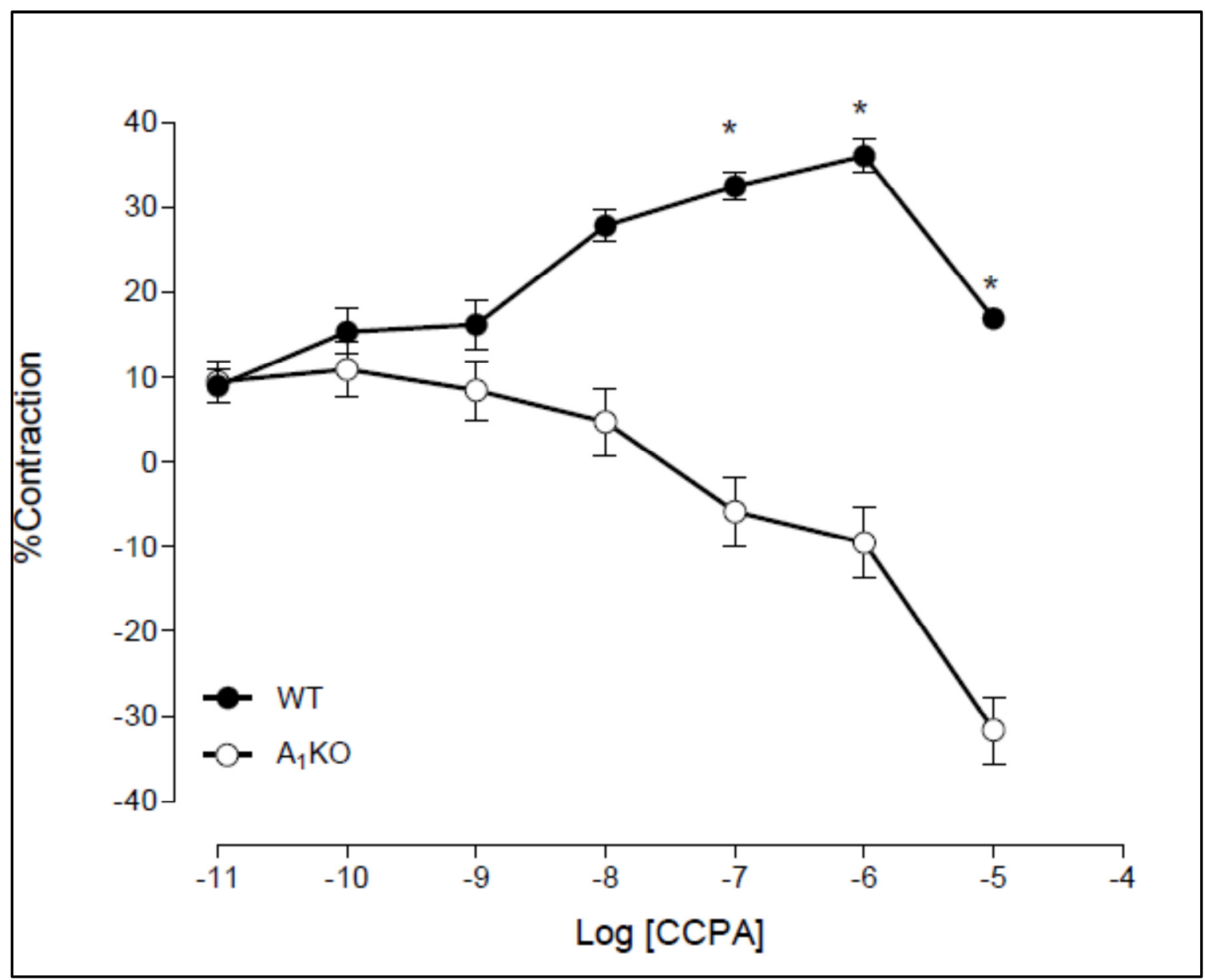


Fig.A.3.Ach induced relaxation in $\mathrm{WT}$ and $\mathrm{A}_{1} \mathrm{KO}$ mice aortae and mesenteric arteries. There was no difference in the acetylcholine induced responses in WT and $\mathrm{A}_{1} \mathrm{KO}$ mice in both aortae and mesenteric arteries. Data are expressed as Mean \pm SEM, * $\mathrm{p}<0.05$ as compared to WT; $(\mathrm{n}=6-12)$.

\section{ACETYLCHOLINE INDUCED RELAXATION}

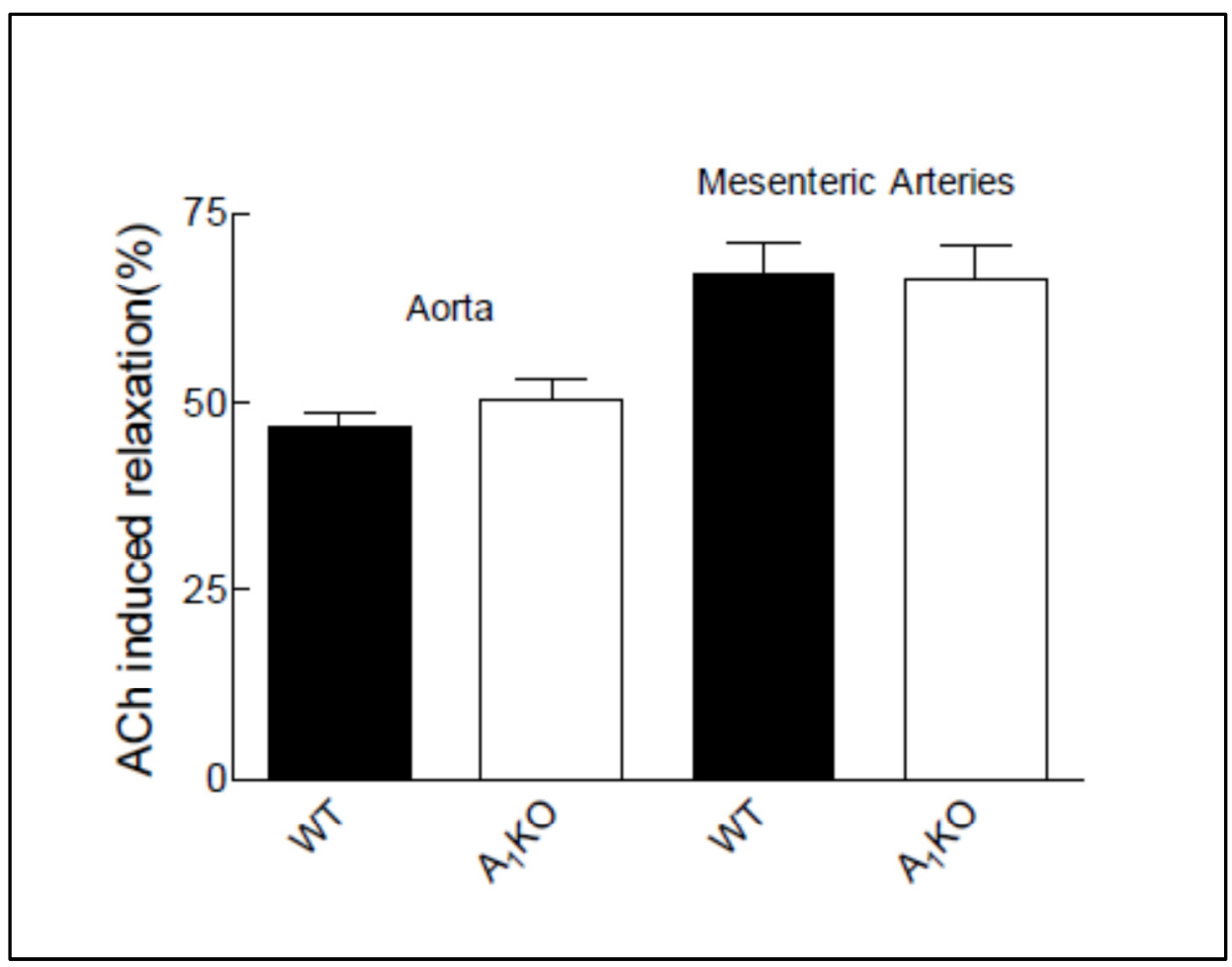




\section{APPENDIX B}

This section provides preliminary data to determine the involvement of L-type $\mathrm{Ca}^{2+}$ channels in the $\mathrm{A}_{1} \mathrm{AR}$ and 20-HETE mediated contraction using WT and $\mathrm{A}_{1} \mathrm{KO}$ mice aortae. Also, the effect of Iberiotoxin on CCPA induced contraction. The results observed were similar to the effect of Penitrem A. 
Fig.B.1.To determine the involvement of $\mathrm{L}-\mathrm{VDCC}$ in $\mathrm{A}_{1} \mathrm{AR}$ mediated contraction, we assessed the effect of Nifedipine on CCPA induced contraction. Nifedipine (Nif) inhibited CCPA-induced contraction and resulted in relaxation similar to control $\mathrm{A}_{1} \mathrm{KO}$. Nif did not effect CCPA induced contraction in $\mathrm{A}_{1} \mathrm{KO}$ mice aortae. Data are expressed as Mean \pm SEM, $* \mathrm{p}<0.05$ as compared to WT; $(\mathrm{n}=8-12)$

\section{EFFECT OF NIFEDIPINE (Nif) ON CCPA- INDUCED CONTRACTION}

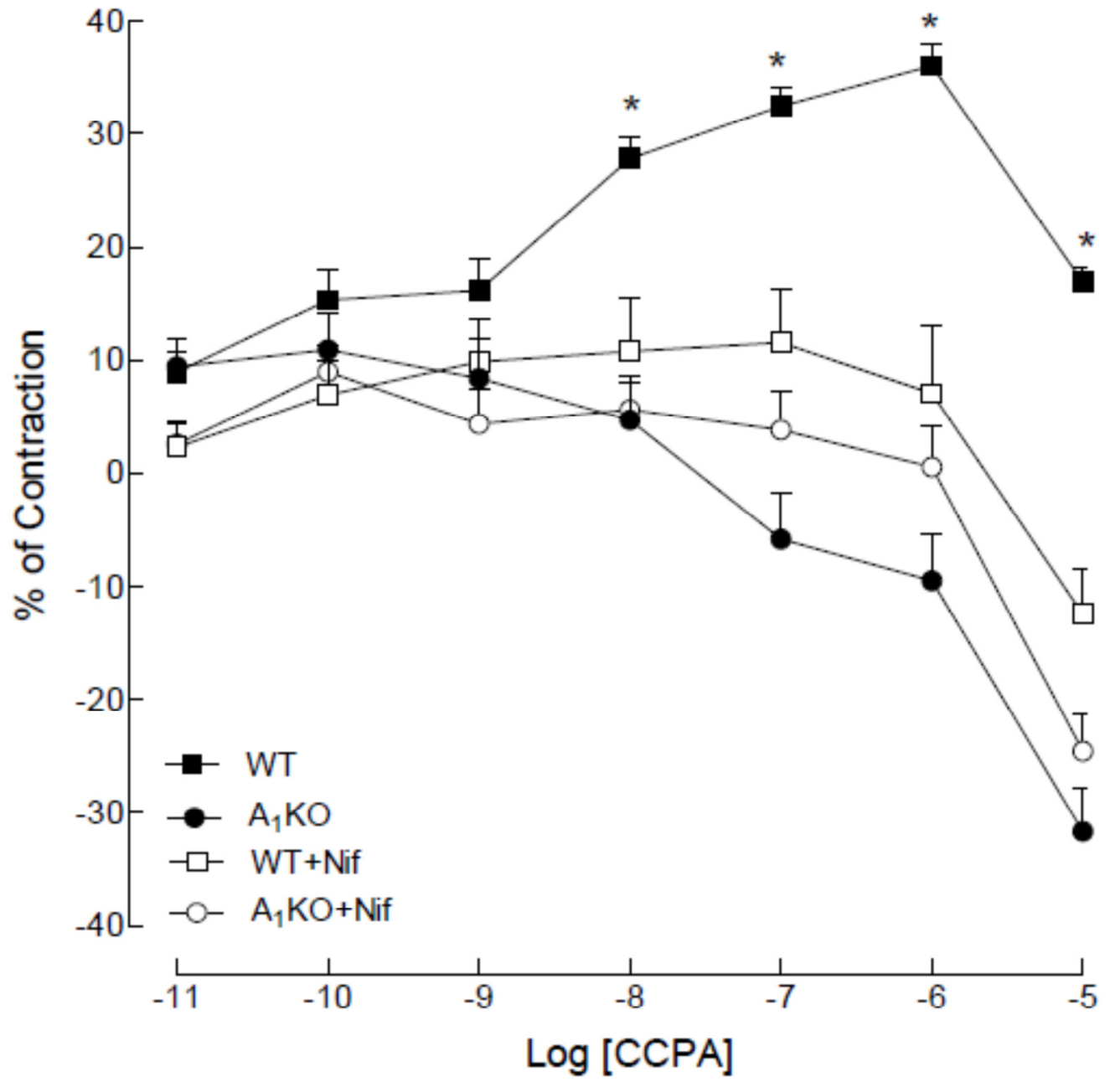


Fig.B.2.To determine the involvement of L-VDCC in 20-HETE mediated contraction, we assessed the effect of Nifedipine on 20-HETE induced contraction. Nifedipine (Nif) attenuated 20-HETE-induced contraction in both WT and $\mathrm{A}_{1} \mathrm{KO}$. However, the decrease in contraction was higher in $\mathrm{A}_{1} \mathrm{KO}$ by Nif. ${ }^{*} \mathrm{p}<0.05$ as compared to WT and ${ }^{*} \mathrm{p}<0.05$ as compared to $\mathrm{A}_{1} \mathrm{KO}$.

EFFECT OF NIFEDIPINE ON 20-HETE INDUCED CONTRACTION

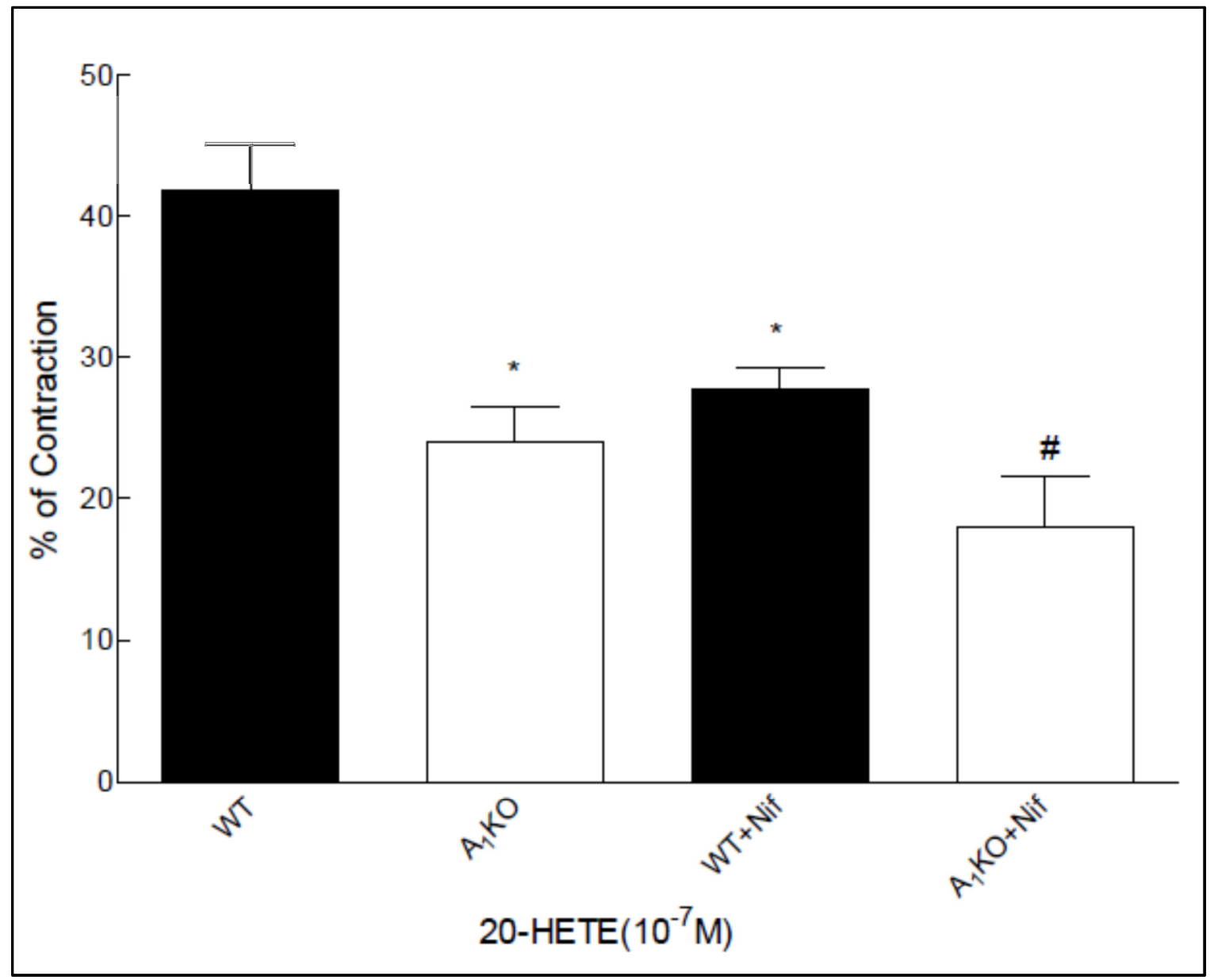


Fig.B.3.Iberiotoxin (Ibtx; BK channel inhibitor) had no effect on CCPA induced contraction in WT. Data are expressed as Mean \pm SEM; $n=6$

\section{EFFECT OF IBERIOTOXIN ON CCPA INDUCED CONTRACTION}

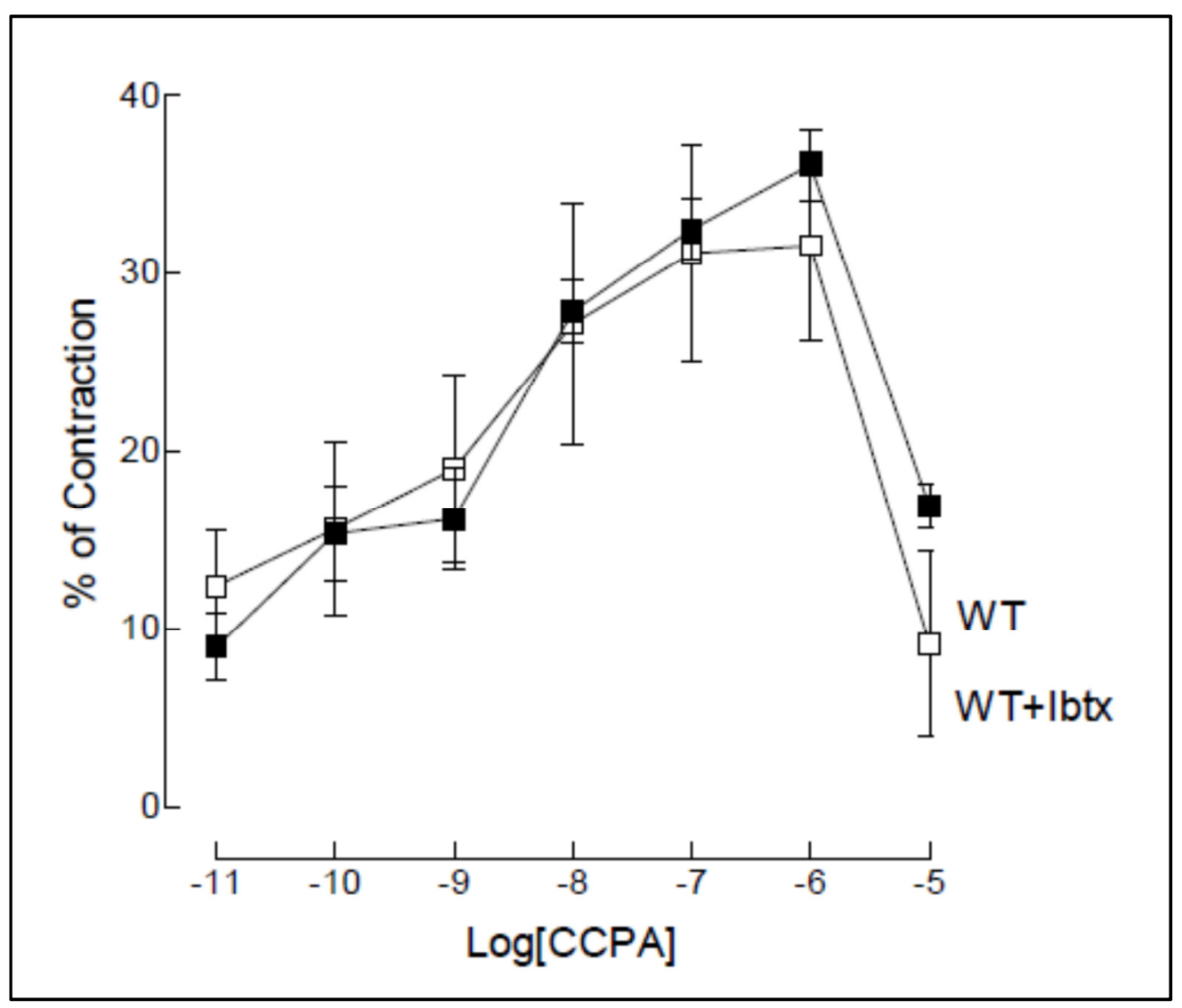




\section{APPENDIX C}

This section provides preliminary data to determine the effect of adenosine agonists in WT and Cyp2c29KO mice aortae. It also shows ACh response of WT and Cyp2c29KO mice aortae and mesenteric arteries. These mice were obtained from NIEHS to further explore the role of adenosine receptors and CYP metabolites. However, the results weren't promising. 
Fig.C.1.NECA induced concentration response in WT and Cyp2c29KO. Data are expressed as Mean \pm SEM, $\mathrm{n}=6$

NECA CONCENTRACTION RESPONSE IN Cyp2c29KO MICE

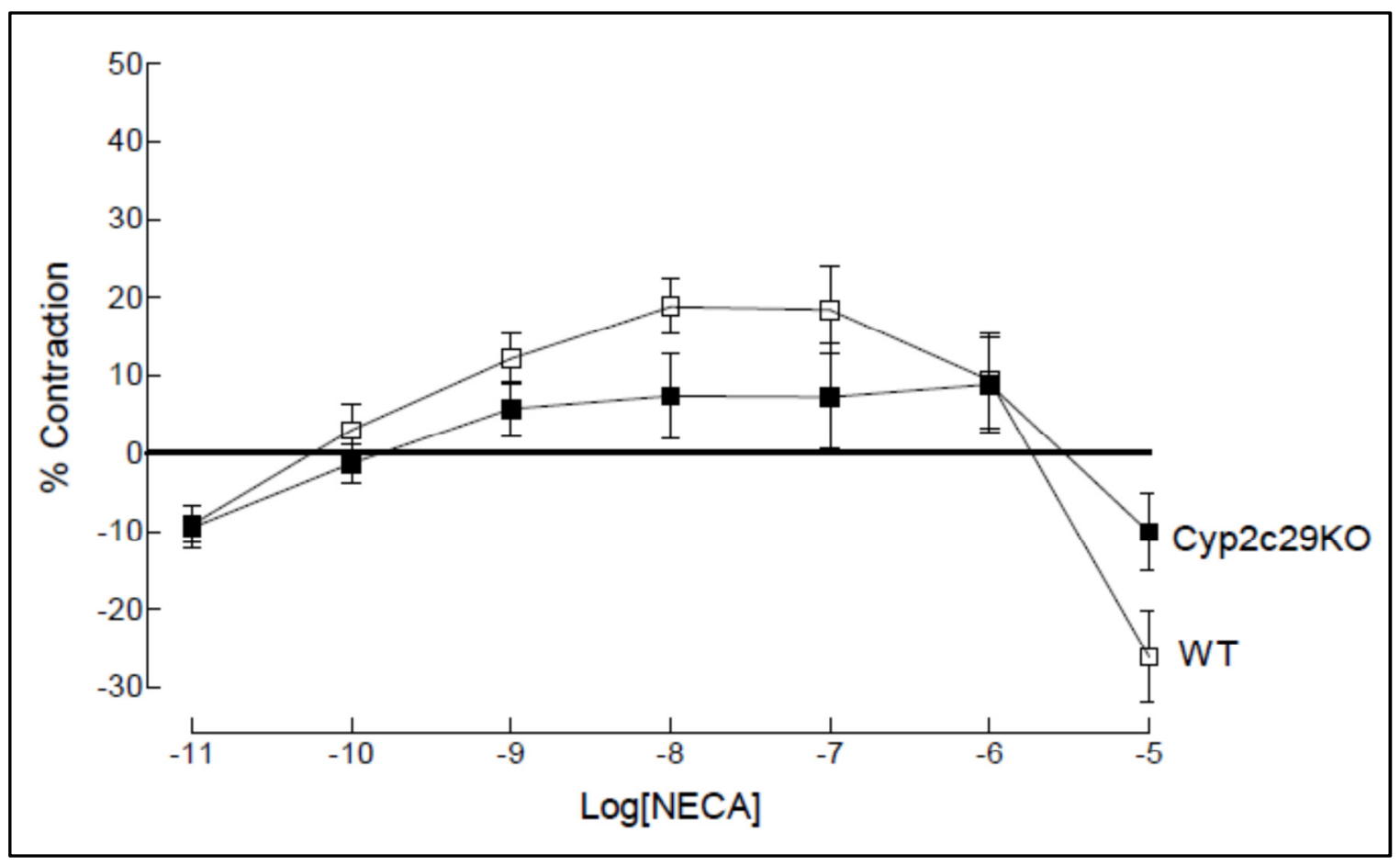


Fig.C.2.CCPA induced concentration response in WT and Cyp2c29KO. Data are expressed as Mean \pm SEM, $\mathrm{n}=6$.

\section{CCPA CONCENTRATION RESPONSE CURVE IN Cyp2c29KO MICE}

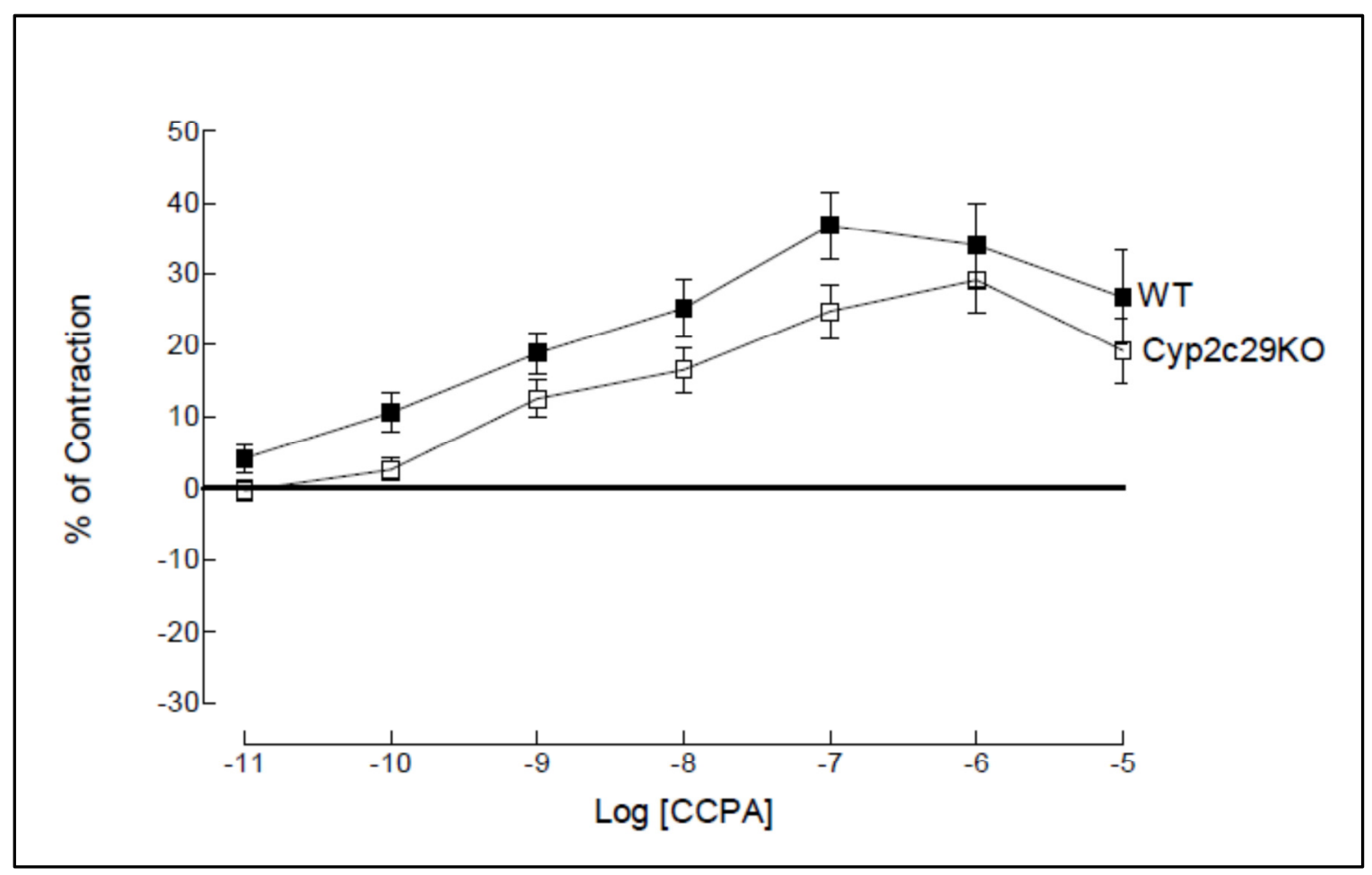


Fig.C.3.CGS induced concentration response in WT and Cyp2c29KO. Data are expressed as Mean \pm SEM, $\mathrm{n}=6$.

\section{CGS CONCENTRATION CURVE IN Cyp2c29KO MICE}

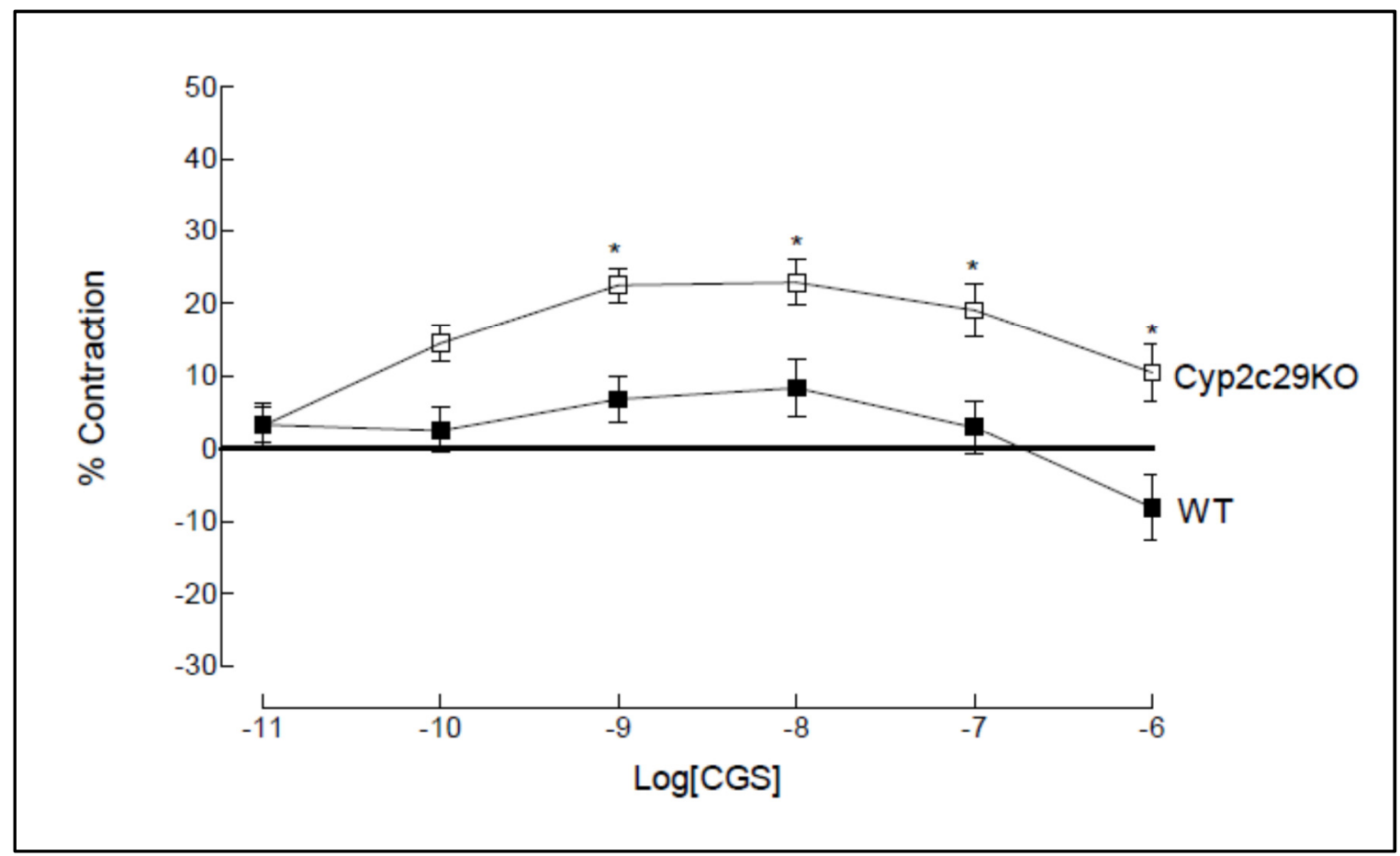


Fig.C.4.ACh induced relaxation was no different in WT and Cyp2c29Ko mice. Data are expressed as mean \pm SEM; $n=8-10$

ACETYLCHOLINE INDUCED RELAXATION IN Cyp2c29KO MICE

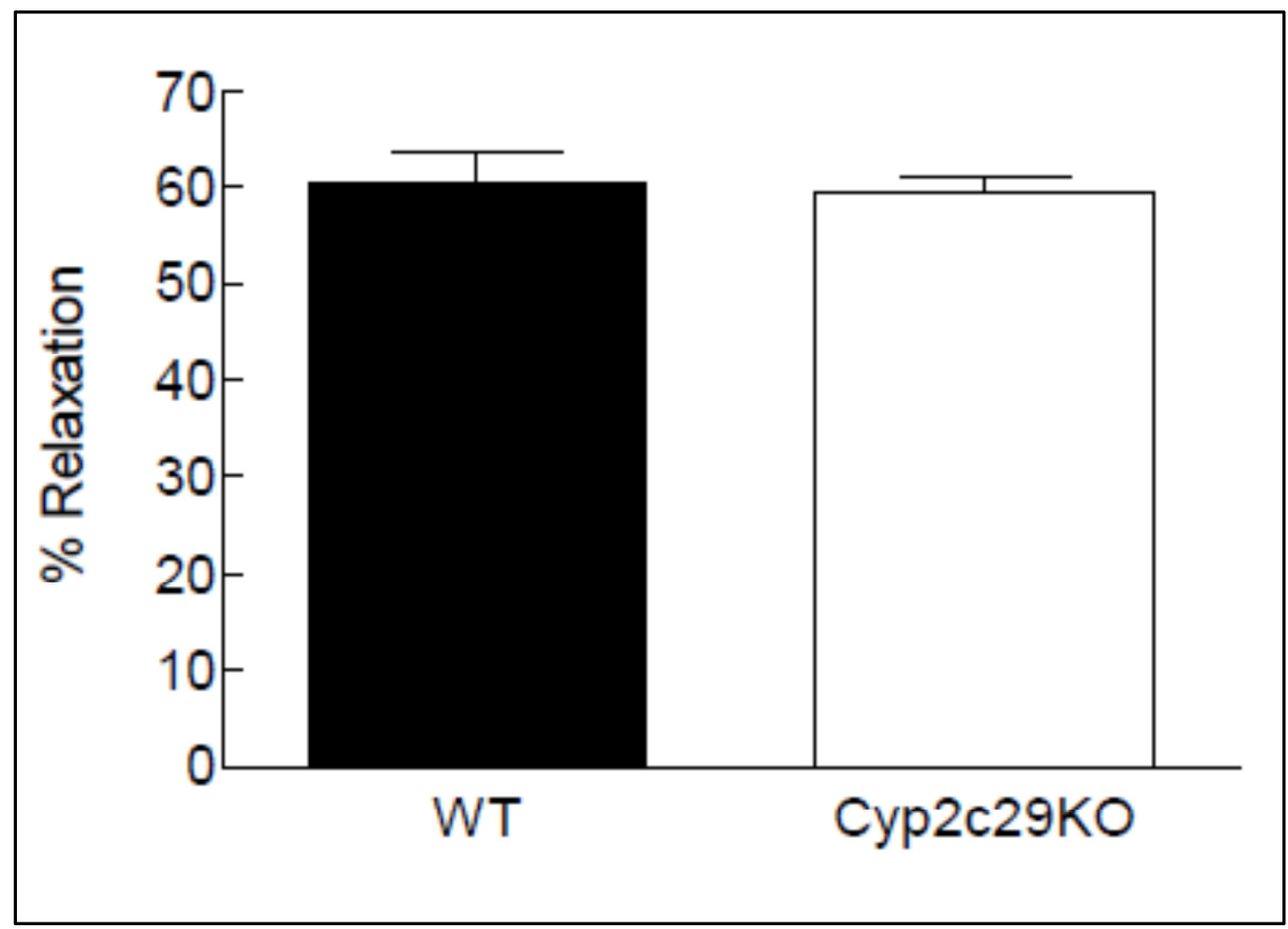




\section{CURRICULUM VITAE}

\section{EDUCATION}

2013 (August) PhD in Physiology and Pharmacology, West Virginia University, Morgantown

2006

M.S in Biomedical Sciences, University of Delhi, Delhi, India

2004

B.S in Zoology (Honors), University of Delhi, Delhi, India

\section{TECHNICAL SKILLS}

Animal Work(breeding, weaning and maintaining mice colonies), Organ bath, Patch Clamp, Cell Culture, Genotyping, Electroporation, Immunoprecipitation, Protein Extraction and Purification, Protein Labeling, Western Blots, DNA Extraction and Purification, DNA Labeling, PCR, RT-PCR, Bacterial Work (Transformation, Competent Cells)

\section{RESEARCH EXPERIENCE}

08/08-Present Doctoral Candidate, Center for Cardiovascular and Respiratory Sciences,

05/06-05/07 Graduate Research Assistant, Mary Babb Randolph Cancer Center, West Virginia University, Morgantown, West Virginia

05/05-05/07 Summer Research Internship, Dr.B.R.Ambedkar Center for Biomedical Sciences, Delhi, India

01/06-06/06 Research Internship, Dr.B.R.Ambedkar Center for Biomedical Sciences, Delhi, India

\section{AWARDS and HONORS}

2013

2012

2012

2011

2010

2010

2010

2004

2005

1998 $2^{\text {nd }}$ place, Basic Science group poster competition, E.J.Van Lier Research Day,, WVU

School of Pharmacy Doctoral Student Travel Award, WVU

$3^{\text {rd }}$ place, Basic Science poster presentation, 20 $0^{\text {th }}$ American Heart Association Fellows Meeting

$2^{\text {nd }}$ place, Basic Science group poster competition, , E.J.Van Liere Research Day,WVU

American Radiolabeled Chemicals Junior Scientist Award in Pharmacology, Experimental Biology Meeting, 2010

Graduate Research and Education Doctoral Student Travel Award, WVU

School of Pharmacy Doctoral Student Travel Award, WVU

Council of Scientific \& Industrial Research - Catch them young scholarship

for academic brilliance in post-graduation, Delhi, India

Council of Scientific \& Industrial Research - Catch them young scholarship

for academic brilliance in post-graduation, Delhi, India

Top 0.1\% in Mathematics, Central Board of Secondary Education

\section{WORKSHOPS:}


Professional Skills development: poster and oral presentations workshop

\section{TEACHING EXPERIENCE:}

$6 / 12-12 / 12$

Instructor, Cell Methods Course

$9 / 11-4 / 12$

Facilitator, Medical Pharmacology

\section{PUBLICATIONS:}

Papers:

- Kunduri SS, Dick GM, Nayeem MA, Mustafa SJ Adenosine $A_{1}$ receptors regulate BK channels through a PKC $\alpha$-dependent mechanism in mouse aortic smooth muscle (in Press at Physiological Reports)

- Kunduri SS, Mustafa SJ, Ponnoth DS, Tilley S, Dick GM, Nayeem MA Adenosine $A_{1}$ receptors link to smooth muscle contraction via CYP4a, PKC- $\alpha$ and ERK1/2 pathway (L Cardiovasc Pharmacol. 2013 Mar 20. [Epub ahead of print])

- Ponnoth DS, Nayeem MA, Kunduri SS, Fil D, Tilley S, Ledent C, Mustafa SJ Role of $\omega$ hydroxylase in adenosine -mediated aortic response through MAP kinase using $\mathrm{A}_{2 \mathrm{~A}}$ receptor knockout mice (Am J Physiol Regul Integr Comp Physiol. 2012 Feb 15;302(4):R400-8. doi: 10.1152/ajpregu.00481.2011. Epub 2011 Dec 7)

\section{Abstracts:}

- Kunduri SS, Dick GM, Nayeem MA, Mustafa SJ Adenosine A1 receptor signaling inhbits BK channels. Experimental Biology, 2013

- Kunduri SS, Nayeem MA, Ponnoth DS, Tilley S, Mustafa SJ Role of L-type voltage gated calcium and large conductance potassium channels in A AR-Cyp450. Experimental Biology 2012

- Ponnoth DS, Nayeem MA, Kunduri SS, Tilley S, Ledent C, Mustafa SJ Cypepoxygenases mediate adenosine $A_{2 A}$ receptor induced vascular relaxation via $K_{A T P}$ channels. Experimental Biology 2012

- Kunduri SS, Nayeem MA, Ponnoth DS, Tilley S, Schnermann JS, Mustafa SJ $\omega$-hydroxylase mediates adenosine A1 receptor mediated vasoconstriction. Experimental Biology 2011

- Ponnoth DS, Nayeem MA, Kunduri SS, Fil D, Tilley S, Ledent C, Mustafa SJ Involvement of CYP4A-mediated MAPK pathway in vascular contraction in A2A adenosine receptor knockout mice. Experimental Biology 2011

- Kunduri SS, Falck JR, Schnermann J, Nayeem MA and Mustafa SJ Exaggerated vasoconstriction depends on $\omega$-hydroxyylase through adenosine $A_{1}$ receptor (AR) in $A_{1}$ WT compared to $\mathrm{A}_{1} \mathrm{KO}$ mouse aorta. Experimental Biology 2010

- Kunduri SS, Nayeem MA, Schnermann J, Mustafa SJ Role of Cyp4a in Adenosine A1 receptor mediated vasoconstriction. Van Liere Research Day,2009

\section{CONFERENCES}

2012 American Heart Association Fellows Meeting, Pittsburgh

2012 Experimental Biology Meeting, San Diego

2011 Experimental Biology Meeting, Washington D.C

2010 Experimental Biology Meeting, Anaheim 